$13 / 1^{2} 3^{9^{9}}+5(1)$

GA-A20493

UC-224

\title{
TFE VERIFICATION PROGRAM
}

\section{SEMIANNUAL REPORT \\ FOR THE PERIOD ENDING MARCH 31, 1991}

\author{
Prepared under \\ CONTRACT DE-AC03-86SF16298 \\ FOR THE SAN FRANCISCO OPERATIONS OFFICE \\ DEPARTMENT OF ENERGY
}

$$
\begin{gathered}
\text { DO NOT MICROFILM } \\
\text { COVER }
\end{gathered}
$$

DATE PUBLISHED: APRIL 1991

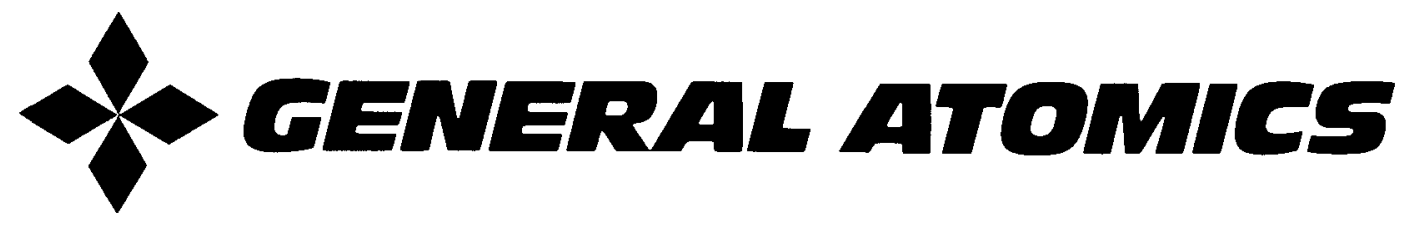




\section{DISCLAIMER}

This report was prepared as an account of work sponsored by an agency of the United States Government. Neither the United States Government nor any agency Thereof, nor any of their employees, makes any warranty, express or implied, or assumes any legal liability or responsibility for the accuracy, completeness, or usefulness of any information, apparatus, product, or process disclosed, or represents that its use would not infringe privately owned rights. Reference herein to any specific commercial product, process, or service by trade name, trademark, manufacturer, or otherwise does not necessarily constitute or imply its endorsement, recommendation, or favoring by the United States Government or any agency thereof. The views and opinions of authors expressed herein do not necessarily state or reflect those of the United States Government or any agency thereof. 


\section{DISCLAIMER}

Portions of this document may be illegible in electronic image products. Images are produced from the best available original document. 
This report was prepared as an account of work sponsored by the United States Government. Neither the United States nor the United States Department of Energy, nor any of their employees, makes any warranty, express or implied, or assumes any legal liability or responsibility for the accuracy, completeness, or usefulness of any information, apparatus, product, or process disclosed, or represents that its use would not infringe privately owned rights. Reference herein to any specific commercial product, process, or service by trade name, mark, manufacturer, or otherwise, does not necessarily constitute or imply its endorsement, recommendation, or favoring by the United States Government or any agency thereof. The views and opinions of authors expressed herein do not necessarily state or reflect those of the United States Government or any agency thereof.

\section{CO NOT MICPREX
COVER}

This report has been reproduced directly from the best available copy.

Available to DOE and DOE contractors from the Office of Scientific and Technical Information, P.0. Box 62, Oak Ridge, TN 37831; prices available from (615) 576-8401, FTS 626.8401.

Available to the public from the National Technical Information Service, U.S. Department of Commerce, 5285 Port Royal Rd., Springfield, VA 22161. 
GA-A--20493

DE91 015224

\title{
TFE VERIFICATION PROGRAM
}

\section{SEMIANNUAL REPORT \\ FOR THE PERIOD ENDING MARCH 31, 1991}

\author{
Prepared under \\ CONTRACT DE-AC03-86SF16298 \\ FOR THE SAN FRANCISCO OPERATIONS OFFICE \\ DEPARTMENT OF ENERGY
}

GENERAL ATOMICS PROJECT NO. 3450

DATE PUBLISHED: APRIL 1991

\% general atomics 
1. INTRODUCTION . . . . . . . . . . . . . . . . . . . . . 1

1.1 Objective of Progress Report . . . . . . . . . . . . . . 1

1.2 TFE Verification Program Goal . . . . . . . . . . . . . . . 1

1.3 Technical Approach . . . . . . . . . . . . . . . . 1

2. CONCEPT DESIGN TASK . . . . . . . . . . . . . . . . . . . . 5

2.1 Objective....................... . 5

2.2 Technical Approach .................... 5

2.3 System Definition Update . . . . . . . . . . . . . . 6

3. CONVERTER PERFORMANCE TASK . . . . . . . . . . . . . . . . . . . . 7

3.1 Objective . . . . . . . . . . . . . . . . . . . . . 7

3.2 Task Description . . . . . . . . . . . . . . . . 7

4. INSULATOR SEAL TASK . . . . . . . . . . . . . . . . . . . . 9

4.1 Objective . . . . . . . . . . . . . . . . . 9

4.2 Task Description .. . . . . . . . . . . . . . . . 11

4.3 Design and Materials Downselection . . . . . . . . . . . . . 11

4.3.1 Fabrication Development . . . . . . . . . . . 12

4.4 Ex-Reactor Testing . . . . . . . . . . . . . . . . 12

4.5 In-Reactor Testing . . . . . . . . . . . . . . . . 13

4.5.1 UCA-3 Irradiation . . . . . . . . . . . . . . 13

4.5.2 UCA-2 PIE . . . . . . . . . . . . . . . . 13

4.5 .3 UFAC-3..................... 15

4.6 Status Summary . . . . . . . . . . . . . . . 15

References .. . . . . . . . . . . . . . . 19

5. SHEATH INSULATOR TASK . . . . . . . . . . . . . . . . . . . . 21

5.1 Objective and Technical Approach . . . . . . . . . . . 21

5.2 Task Description . . . . . . . . . . . . . . . . . . 23

5.3 Design and Materials Downselection . . . . . . . . . . 24

5.4 Ex-reactor Testing . . . . . . . . . . . . . . . . . 24

5.5 In-Reactor Testing . . . . . . . . . . . . . . 25

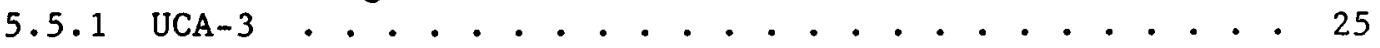

5.5 .2 IFAC-SI . . . . . . . . . . . . . . 27

5.6 Postirradiation Examination (PIE) . . . . . . . . . . . 27

5.6.1 UCA-2 PIE . . . . . . . . . . . . . . . . . . 27

5.6.2 Thermal Conductivity of Sheath Insulators . . . . . 34

5.7 Status Summary . . . . . . . . . . . . . . . . . . 34

6. FUELED EMITTER TASK . . . . . . . . . . . . . . . . . . . . . . . 36

6.1 Objective and Technical Approach . . . . . . . . . . . . 36

6.2 Ex-Reactor Testing . . . . . . . . . . . . . . . . 42

6.3 In-Reactor Testing . . . . . . . . . . . . . . . . . . 42

6.3.1 Reevaluation of Neutron Radiographs . . . . . . . 42

6.3.2 UFAC-1 FE Test Specimens ... . . . . . . . 42

6.3.3 UFAC-2 Status . . . . . . . . . . . . 52

6.3.4 UFAC-3 Status . . . . . . . . . . . . . 52

6.3.5 PIE Data Evaluation . . . . . . . . . . . 53

References ..................... 56 
CONTENTS (Continued)

Page

7. CESIUM RESERVOIR AND INTERCONNECTIVE TFE COMPONENTS . . . . . . . 57

7.1 Objective . . . . . . . . . . . . . . . . . . . . . . . 57

7.2 Task Description .. . . . . . . . . . . . . . . . . 57

7.3 Progress During Present Reporting Period. . . . . . . . . . 58

7.3.1 Cs-Graphite Reservoir Model Development . . . . . . 58

7.3.2 UCA-3 Irradiations... . . . . . . . . . . 66

References ..................... 73

8. THERMIONIC FUEL ELEMENT . . . . . . . . . . . . . . . . 74

8.1 objective . . . . . . . . . . . . . . . . . . . . . 74

8.2 Task Description . . . . . . . . . . . . . . . . . 74

8.2.1 Testing Logic . . . . . . . . . . . . . . . . . 74

8.2.2 TFE Design . . . . . . . . . . . . . . . . . 77

8.2.3 TRIGA Facility . . . . . . . . . . . . . . . . 81

8.3 Engineering and Hardware Design . . . . . . . . . . . . 81

8.3.1 Test Article Design for TFE-3H1 and $3 \mathrm{H} 5$. . . . . . . 81

8.3.2 Test Vehicle Design for TFE-6H1/6H2 . . . . . . . 81

8.3.3 Test Vehicle Design . . . . . . . . . . . . 82

8.4 TFE Fabrication . . . . . . . . . . . . . . . . . . 83

8.4.1 Summary of Past Work . . . . . . . . . . . . 85

8.4.2 H-Series Fabrication . . . . . . . . . . . . 86

8.5 TFE Operating Experience . . . . . . . . . . . . . . . . 93

8.5.1 TFE $1 \mathrm{H} 1$. . . . . . . . . . . . . . . . . . . 94

8.5.2 TFE $1 \mathrm{H} 2$ and $\mathrm{TFE}-1 \mathrm{H} 3$. . . . . . . . . . . . 97

References . . . . . . . . . . . . . . . . 99 
1-1 Logic to demonstrate technology readiness of megawatt class TFE . . . 2

4-1 Thermionic cell showing insulator locations . . . . . . . . . . . . . 10

4-2 Single crystal alumina taper seal resistance vs time . . . . . . . . 13

4-3 Longitudinal surface of UCA-2 single crystal alumina taper seal insulator

$\left(\mathrm{S} / \mathrm{N} 003\right.$, peak fast fluence $4.4 \times 10^{22} \mathrm{n} / \mathrm{cm}^{2}$, operating temperature

$1115 \mathrm{~K})$. . . . . . . . . . . . . . . . . . . . . . 16

4-4 Longitudinal surface of UCA-2 single crystal YAG taper seal insulator

$\left(\mathrm{S} / \mathrm{N} 001\right.$, peak fast fluence $5.5 \times 10^{22} \mathrm{n} / \mathrm{cm}^{2}$, operating temperature

$1120 \mathrm{~K})$. . . . . . . . . . . . . . . . . . . . . .

4-5 Longitudinal surface of UCA-2 yttria trilayer seal insulator seals

( $\mathrm{S} / \mathrm{N} 280 \mathrm{~B}$, peak fast fluence $4.0 \times 10^{22} \mathrm{n} / \mathrm{cm}^{2}$, operating temperature

$1135 \mathrm{~K})$

5-1 Thermionic cell showing insulator locations . . . . . . . . . . . . . 22

5-2 Electrical resistance vs time for GA graded yttria . . . . . . . . . 25

5-3 Electrical resistance vs time for GA graded alumina . . . . . . . . . 26

5-4 Electrical resistance vs time for TTC alumina cermet with $5 \% \mathrm{Nb}$. . . 26

5-5 Longitudinal surface of UCA-2 graded alumina step end sheath insulator

(S/N 336 , peak fast fluence $5.8 \times 10^{22} \mathrm{n} / \mathrm{cm}^{2}$, operating temperature

$1128 \mathrm{~K})$. . . . . . . . . . . . . . . . . . . . . . . . . . .

5-6 Transverse surface of UCA-2 graded alumina step end sheath insulator

( $\mathrm{S} / \mathrm{N} 317$, peak fast fluence $3.7 \times 10^{22} \mathrm{n} / \mathrm{cm}^{2}$, operating temperature

$1114 \mathrm{~K})$. . . . . . . . . . . . . . . . . . . . . . . . .

5-7 Longitudinal surface of UCA-2 graded yttria step end sheath insulator

( $\mathrm{S} / \mathrm{N} 346$, peak fast fluence $5.9 \times 10^{22} \mathrm{n} / \mathrm{cm}^{2}$, operating temperature

$1128 \mathrm{~K}) \cdot$. . . . . . . . . . . . . . . . . . . . . . . . . 31

5-8 Longitudinal surface of UCA-2 alumina cermet square end sheath insulator

(S/N TA9, peak fast fluence $6.0 \times 10^{22} \mathrm{n} / \mathrm{cm}^{2}$, operating temperature

$1121 \mathrm{~K})$. . . . . . . . . . . . . . . . . . . . 32

5-9 Transverse surface of UCA-2 alumina cermet square end sheath insulator

(S/N TA8, peak fast fluence $3.7 \times 10^{22} \mathrm{n} / \mathrm{cm}^{2}$, operating temperature

$1109 \mathrm{~K})$. . . . . . . . . . . . . . . . . . 33

6-1 Fuel element irradiation strategy road map . . . . . . . . . . . . . 38

6-2 UFAC irradiation schedule.... . . . . . . . . . . . . . . 40

6-3 UFAC-1B fueled emitter SU1-4 . . . . . . . . . . . . . . . . . . . 48

6-4 UFAC-1B fueled emitter SU1-5 . . . . . . . . . . . . . . . . . . . 49

6-5 UFAC-1B fueled emitter SU1-8 . . . . . . . . . . . . . . . . . . . . 50

6-6 UFAC-1B fueled emitter SU1-9 . . . . . . . . . . . . . . . . . . 51

7-1 Pleated layer model for 2 nd, $3 \mathrm{rd}$ and 4 th stage Cs-graphite intercalation compounds . . . . . . . . . . . . . . . . . . . . . . . 60

7-2 Experimental Cs pressure vs graphite temperature . . . . . . . . . . 63

7-3 Coordinate system for calculating dimensional changes in an isotropic material composed of a collection of anisotropic crystallies . . . 63

7-4 Converter performance for reference case, with reservoir at the collector temperature ..................... 67

7-5 Emitter temperature and current density dependence on input power at constant load resistance................... 68 
7-6 Converter performance for reference case with reservoir temperature determined by radiative coupling to both emitter and collector and also conductive coupling to the collector . . . . . . . . . . . . 69

7-7 X-ray radiographs of the four UCA-3 POCO reservoir samples . . . . . 70

8-1 H-series thermionic converter (typical of 3H1) . . . . . . . . . 79

8-2 TFEs for TRIGA test . . . . . . . . . . . . . . . . . . . . . 80

8-3 Interference due to weld distortion . . . . . . . . . . . . . 82

8-4 Capsule piping schematic . . . . . . . . . . . . . . . . . 84

8-5 View of lower end of $3 \mathrm{H} 1$ primary containment assembly . . . . . . . . 88

8-6 Upper end of $3 \mathrm{H} 1$ primary containment assembly . . . . . . . . . . . . 89

8-7 Components for emitter fuel loading. . . . . . . . . . . . . . . 89

8-8a, b, c Converters and dummy cell for TFE-3H5 . . . . . . . . . . . . . 90

8-9 Four of six converters for TFE 6H1 . . . . . . . . . . . . . . . . . 92

8-10 1H1 radial deformation . . . . . . . . . . . . . . . . . . . . . . 96

8-11 1H3 radial deformation . . . . . . . . . . . . . . . . . . . . . 98 
2-1 TFE design definition . . . . . . . . . . . . . . . 6

3-1 Ex-reactor planar converter test program . . . . . . . . . . . . . . 8

3-2 Ex-reactor cylindrical converter test program . . . . . . . . . . . 8

4-1 UCA-3 insulator seals test matrix . . . . . . . . . . . . . 14

4-2 UCA-2 insulator seals . . . . . . . . . . . . . . . . . . . . 15

4-3 UFAC-3 Batch 2 insulator seals test matrix . . . . . . . . . . . . . 15

4-4 Insulator seal technology status . . . . . . . . . . . . . . 20

5-1 UCA-3 Batch B sheath insulators test matrix . . . . . . . . . . . 25

5-2 UCA-2 sheath insulators . . . . . . . . . . . . . . . . 28

5-3 Sheath insulator technology status . . . . . . . . . . . . 35

6-1 Fueled emitter design requirements . . . . . . . . . . . . . 36

6-2 Summary status of UFAC test series in EBR-II as of January 1, 1991 . 39

6-3 UFAC emitter identification scheme . . . . . . . . . . . . . . 41

6-4 UFAC neutron radiography history . . . . . . . . . . . . . . . 43

6-5 Final test conditions in UFAC-1... . . . . . . . . . . . . . . . . 44

6-6 Helium-to-argon ratios from UFAC batch-1 fueled emitters . . . . . . 44

6-7 Gas volume captured in plenums from UFAC batch-1 fueled emitters . . 45

6-8 Gas composition in plenum, mole \% . . . . . . . . . . . . . . . . 46

6-9 Gamma scan results from capsule 2: relative count rate . . . . . . . 54

6-10 Emitter temperatures . . . . . . . . . . . . . . . . . . . . . . . 55

6-11 Unguarded specimen resistance measurements . . . . . . . . . . . . . 56

6-12 Guarded specimen resistance measurements . . . . . . . . . . . . . . 56

7-1 C-axis swelling of oriented graphite due to Cs intercalation . . . 61

7-2 Comparison of thermodynamic values . . . . . . . . . . . . . . 62

7-3 Expansion of graphite upon Cs intercalation . . . . . . . . . . . . . 64

7-4 Dimensional changes . . . . . . . . . . . . . . . . . 72

8-1 Comparison of TFE test requirements with system baseline design

requirements . . . . . . . . . . . . . . . . 75

8-2 TFE in-reactor test summary matrix . . . . . . . . . . . . . . . . 76

8-3 TFE test matrix... . . . . . . . . . . . . . . . . 78

8-4 Cell and TFE fabrication status summary through March 31, 1991 . . 87

8-5 Irradiation testing events - October 1990 through March 1991 . . . . 93

8-6 Irradiation status of H-series TFEs as of 3-1-91 . . . . . . . . . . 94

References . . . . . . . . . . . . . . . . . . . . 99 


\section{INTRODUCTION}

\subsection{OBJECTIVE OF PROGRESS REPORT}

The objective of the semiannual progress report is to summarize the technical results obtained during the latest reporting period. The information presented herein will include evaluated test data, design evaluations, the results of analyses and the significance of results.

\subsection{TFE VERIFICATION PROGRAM GOAL}

The program objective is to demonstrate the technology readiness of a TFE suitable for use as the basic element in a thermionic reactor with electric power output in the 0.5 to $5.0 \mathrm{MW}(\mathrm{e})$ range, and a full-power life of 7 years.

\subsection{TECHNICAL APPROACH}

The TFE Verification Program builds directly on the technology and data base developed in the 1960s and early 1970s in an AEC/NASA program, and in the SP-100 program conducted in 1983, 1984 and 1985. In the SP-100 program, the attractive features of thermionic power conversion technology were recognized but concern was expressed over the lack of fast reactor irradiation data. The TFE Verification Program addresses this concern.

The general logic and strategy of the program to achieve its objectives is shown on Fig. 1-1. Five prior programs form the basis for the TFE Verification Program:

1) AEC/NASA program of the 1960 s and early 1970s.

2) SP-100 concept development program.

3) SP-100 thermionic technology program.

4) Thermionic irradiations program in TRIGA in FY-86.

5) Thermionic Technology Program in 1986 and 1987.

These programs provide both the systems and technology expertise necessary to design and demonstrate a megawat class TFE. 


\section{LOGIC TO DEMONSTRATE TECHNOLOGY READINESS OF MEGAWATT CLASS TFE}

PAIOR AEC/NASA THERMIONIC DATA BASE SP-100 CONCEPT DEV. PROGRAM

SP-100 THERMIONIC TECHNOLOGY PROGAAM THERMIONICS IRRADIATIONS PROGRAM THERMIONIC TECHNOLOGY PROGRAM

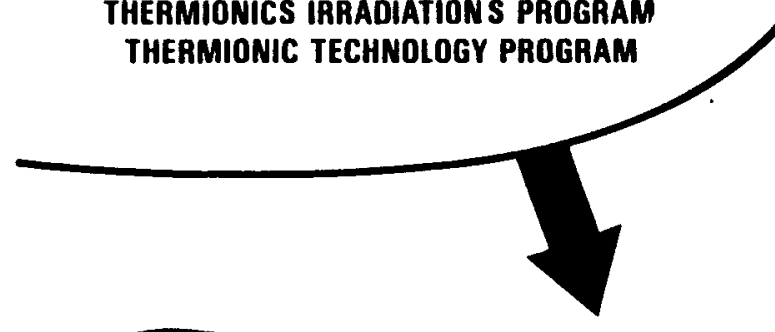

DEFINE TFE FOR 2 MW(e) REACTOR 
The approach to be followed is to design a TFE that will meet the reliability and lifetime requirements for the 2 MW(e) conceptual reactor design, and initiate component testing in a fast reactor. The demonstration of a 7-year component lifetime capability will be through the combined use of analytical models and accelerated, confirmatory tests. Iterative testing will be performed where the results of one test series will lead to evolutionary improvements in the next test specimens.

The TFE components will undergo screening and initial development testing in ex-reactor tests. Several design and materials options will be considered for each component. As screening tests permit, down selection will occur. It is necessary to rapidly make baseline design and materials selections to make optimum use of irradiation testing.

In parallel with ex-reactor testing, and fast reactor component testing, components will be integrated into a TFE and tested in the TRIGA. Realtime testing of partial length TFEs will be used to test support, alignment and interconnective TFE components, and to verffy TFE performance in-reactor with integral cesium reservoirs. Realtime testing will also be used to verify the relation between TFE performance and fueled emitter swelling, to test the durability of intercell insulation, to check temperature distributions, and to verify the adequacy over time of the fission gas venting channels.

Predictions of TFE lifetime will rest primarily on the accelerated component testing results, as correlated and extended to realtime by the analytical models developed.

The fast reactor testing of fueled emitters will be calibrated by verifying the accuracy of emitter temperature predictions through complementary analysis and ex-reactor and in-reactor diagnostic tests. Instrumented sheath insulators will be tested in a fast reactor with an applied voltage.

A test of prototypic TFEs will be run in a fast reactor as a verification of the basic TFE design. This design may be upgraded based on the final component testing results. 
The deliverables of the program are:

1) Conceptual design of a megawatt class power system including component specifications and a system description.

2) Thermionic components with verified performance.

3) TFE demonstration in a fast reactor.

4) Fabrication process specifications.

5) Verified performance models. 


\section{CONCEPT DESIGN TASK}

\subsection{OBJECTIVE}

Task 2 provides the design guidance for the TFE Verification Program. The primary goals of this task are:

1) Establish the conceptual design of an in-core thermionic reactor for a $2 \mathrm{MW}(\mathrm{e})$ space nuclear power system with a 7-year operating lifetime.

2) Demonstrate scalability of the above concept over the output power range of $500 \mathrm{KW}(\mathrm{e})$ to $5 \mathrm{MW}(\mathrm{e})$.

3) Define the TFE which is the basis for the $2 \mathrm{MW}(\mathrm{e})$ reactor design. This TFE specification will then be the basis for the test program.

\subsection{TECHNICAL APPROACH}

The technical approach being taken in the concept design effort can be characterized as follows:

1) Perform system-level tradeoffs to determine initial TFE features and reactor scalability trends;

2) Refine these results and identify the $2 \mathrm{MW}(\mathrm{e})$ reactor general arrangement with primary emphasis on characterizing the features and performance of the TFE;

3) Enter this information into the program data base via two separate design description documents:

- Two MW(e) reactor-converter system description.

- TFE component specification. 


\subsection{SYSTEM DEFINITION UPDATE}

The current description of the $2 \mathrm{MW}(e)$ thermionic power system used to define the reference TFE for the program was reported in Ref. $2-1$ and is shown on Table 2.1. This has not changed during the current reporting period.

\section{$\underline{\text { References }}$}

2-1 GA-A20335, TFE Verification Program Semiannual Report for the Period Ending September 30, 1990 (Published March 1991).

TABLE 2-1

\section{PERFORMANCE}

\section{TFE DESIGN DEFINITION}

Overa11 TFE:

Output electrical power (We) 662

Efficiency 9.3

Maximum voltage

U-235 burnup (a/o)

Fluence (nvt)

Converter:

Converter power (Wt/We)

Emitter power flux $\left(\mathrm{We} / \mathrm{cm}^{2}\right)$

Diode current density $\left(\mathrm{a} / \mathrm{cm}^{2}\right)$

Thermionic work function $(\mathrm{eV})$

5.9 (15)

4.1 avg, 5.3 peak

$2.7 \times 10^{22} \mathrm{avg}, 3.5 \times 10^{22}$ peak

Emitter temperature (K)

Collector temperature (K)

Cesium pd (mil-torr)

$594 / 55.2$

2.72

7.0

4.9

1800

1000

30

Converter output voltage

0.49

Converter current (amp) 140

CONFIGURATION

Overa11 TFE:

TFE length (active core)(in) $\quad 39.6$

TFE length (overall) TBD

Sheath tube o.d. (in) 0.694

Lead o.d. (in) 0.875

Lead length (in) 4

Converters per TFE 12

Converter:

$\begin{array}{ll}\text { Emitter o.d. } \times \mathrm{L} \times \mathrm{t} \text { (in) } & 0.5 \times 2.0 \times 0.040 \\ \text { Emitter stem } \mathrm{L} \times \mathrm{t} \text { (in) } & 0.45 \times 0.020 \\ \text { Diode gap (in) } & 0.010 \\ \text { Trilayer t: collector } & 0.028 \\ \quad \text { insulator (in) } & 0.016 \\ \text { outer cylinder } & 0.028 \\ \text { Fuel specification } & 93 \% \text { enriched } \mathrm{UO}_{2} \text {; variable } \\ \text { Intercell axial space (in) } & 0.74\end{array}$




\section{CONVERTER PERFORMANCE TASK}

\subsection{OBJECTIVE}

The objective of the converter performance task is to establish accurate converter performance models which have been correlated to observe test data. The data base will be developed from near prototypic converters using emitter and collector materials of interest over the full range of anticipated operating parameters. Part of the data base will include off-design and nonideal operation of the converters. The resulting models will be used to determine the optimum converter configuration (materials, additives, spacing, etc.) for use in the prototypic $\mathrm{TFE}$ and reactor design.

A thermionic reactor is composed of a large array of thermionic cells, each of which has a unique input power, emitter temperature, and operating current density. In addition, individual cells will vary in performance over the system lifetime due to changing operating conditions caused by fuel burnup and variations in operating power requirement, or losses of some of the cells. Thus, the design and performance prediction of a thermionic reactor require an extensive data base on prototypical cell performance over a wide range of operating conditions.

The data and models will also be used in the startup of the TFEs in TRIGA and the FFTF and also in the startup of thermionic reactors. The observed current-voltage data during startup can be related to system temperatures through the ex-reactor correlations.

\subsection{TASK DESCRIPTION}

The current test matrix is shown on Tables $3-1$ and $3-2$.

Planar Converter $-1(\mathrm{PC}-1)$ is a planar (variable spacing) converter with a tungsten $\langle 110\rangle$ emitter, a niobium collector and a graphite cesium reservoir external to the converter. The emitter has a small cavity for accepting a fuel pellet of depleted uranium oxide. The test strategy is to first obtain comparative maps without uranium oxide present. 
TABLE $3-1$

EX-REACTOR PLANAR CONVERTER TEST PROGRAM

Cs

Emitter Collector Reservoir Rationale for Test

\begin{tabular}{|c|c|c|c|c|}
\hline PC-1 & Duplex W & $\mathrm{Nb}$ & Graphite & $\begin{array}{l}\text { Performance map with graphite-cesium } \\
\text { reservoir. }\end{array}$ \\
\hline$P C-2$ & Duplex W & $\begin{array}{l}\mathrm{Nb} \\
\text { Tilted }\end{array}$ & Pool & $\begin{array}{l}\text { A verification of the model which } \\
\text { relates converter output to emitter } \\
\text { distortion. }\end{array}$ \\
\hline$P C-3$ & $\begin{array}{l}\text { High } \\
\text { Strength } \\
\text { Emitter }\end{array}$ & $\mathrm{Nb}$ & Pool & $\begin{array}{l}\text { Establish data base on performance } \\
\text { with high strength emitter }\end{array}$ \\
\hline $\begin{array}{l}\text { PC-1 } \\
\text { (Mod) }\end{array}$ & Duplex W & $\mathrm{Nb}$ & Graphite & $\begin{array}{l}\mathrm{UO}_{2} \text { in contact with the emitter. } \\
\text { When compared to PC-1, differential } \\
\text { data on the } \mathrm{UO}_{2} \text { effect will be } \\
\text { available. Conduct a life test. }\end{array}$ \\
\hline
\end{tabular}

TABLE 3-2

EX-REACTOR CYLINDICAL CONVERTER TEST PROGRAM

Emitter Collector Reservoir $\begin{array}{lll}\text { Life } & \text { Test }\end{array}$

$\mathrm{CC}-1 \quad$ Duplex $\mathrm{Nb} \quad$ Graphite $\quad$ No $\quad \begin{aligned} & \text { Performance map with } \\ & \text { reference electrodes and } \\ & \text { reservolr. }\end{aligned}$

The converter with the $\mathrm{UO}_{2}$ installed is designated PC-1 (Mod). The uranium oxide is separated from the interelectrode space by a relatively thin layer of tungsten. At the operating temperature of the emitter, $1800 \mathrm{~K}$ to $2000 \mathrm{~K}$, the oxygen from the uranium oxide will migrate into the interelectrode space and change the performance of the converter.

PC-1 (mod) will be used to measure the long term performance of the converter with the combined effects of oxygen and cesium from a cesiumgraphite reservoir. Both $\mathrm{PC}-1$ and $\mathrm{PC}-1$ (Mod) will be built in FY-91 with testing of PC-1 (Mod) to be carried into later years. 


\subsection{OBJECTIVE}

The overall objective of the insulator seal task is to develop and validate the performance of an insulator seal for use in the thermionic fuel element reference design. In particular, the objectives are:

1. Produce designs for the insulator seal.

2. Develop required fabrication processes for insulator seals and document the process specifications.

3. Fabricate insulator seals for ex-reactor and in-reactor testing.

4. Verify the performance characteristics and lifetimes associated with insulator seals by means of ex-reactor and in-reactor testing. Perform postirradiation examination of the seal spectmens and use the test results to improve the seal design.

5. Develop an analytical model of the performance and lifetime of the insulator seal and validate the model with test data.

The insulator seal, shown schematically in Fig. 4-1, must provide electrical isolation between adjacent collectors while maintaining a leak-tight seal separating the cesium vapor of the interelectrode space from the fission products. The current design requirements are listed below:

1. Insulator temperature

2. Nominal fast fluence, E>0.1 Mev

3. Nominal applied voltage Maximum applied voltage

4. Operating environment

5. Leak tightness (unirradiated)

6. Electrical resistance

7. Lifetime $1070^{\circ} \mathrm{K}$ to $1150^{\circ} \mathrm{K}$

$2.3 \times 10^{22} \mathrm{n} / \mathrm{cm}^{2}$

0.49 volts

0.63 volts

1-3 torr $C s$ and fission gases

$\leq 2 \times 10^{-11} \mathrm{Std} \mathrm{cc} / \mathrm{s}$ (fabricated)

$<5 \times 10^{-5} \mathrm{Std} \mathrm{cc} / \mathrm{s}$ (end lifetime)

$>10$ ohms $\left(1150^{\circ} \mathrm{K}\right)$

$\geq 7$ years. 


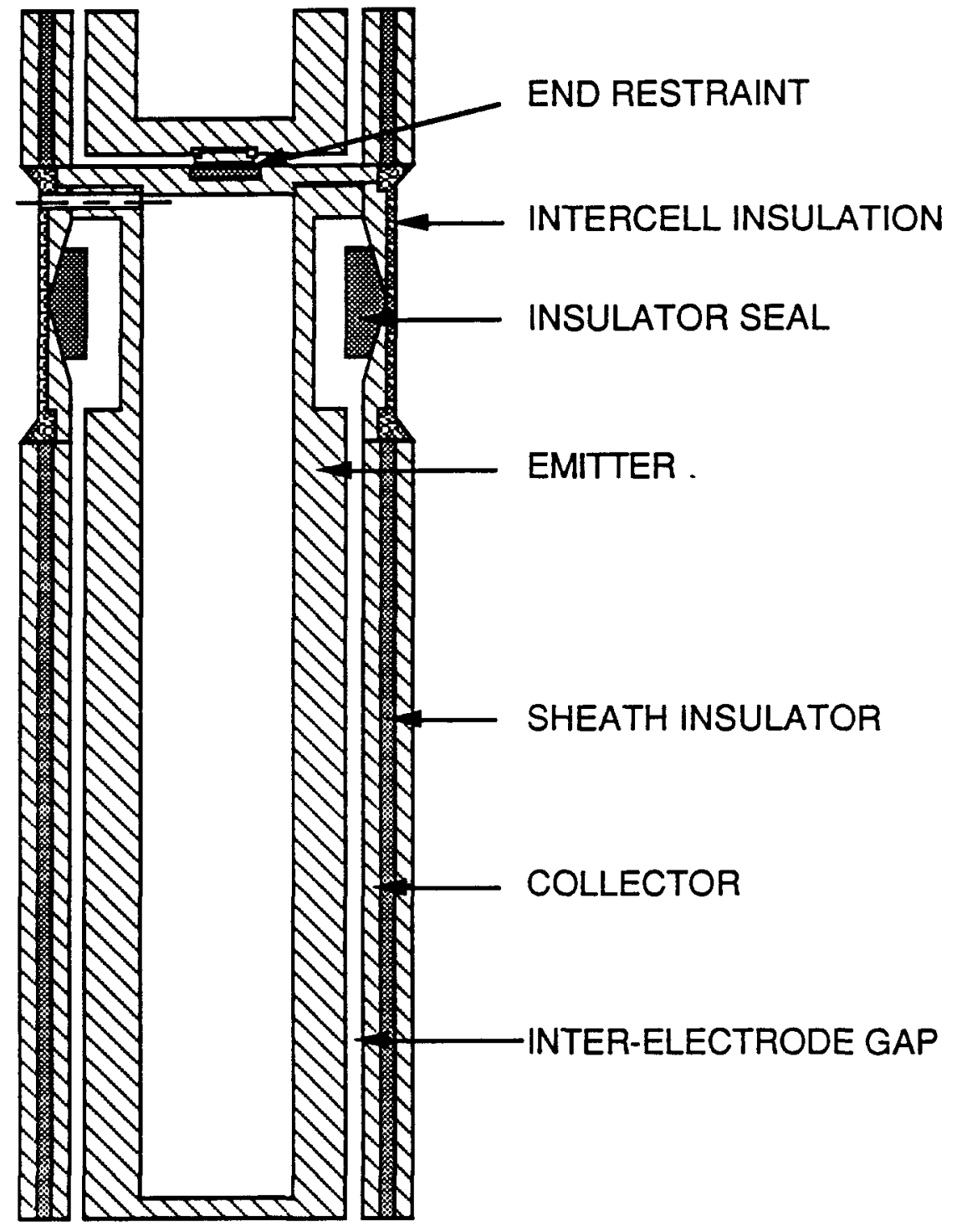

Figure 4-1. Thermionic cell showing insulator locations 


\subsection{TASK DESCRIPTION}

The insulator seal task consists of five subtasks:

1. Seal design. Seal designs consistent with the TFE requirements are to be developed. Designs to be considered are the taper seal, the butt seal and trilayer seal.

2. Fabrication development. Select appropriate insulator materials. Develop appropriate bonding techniques for each insulator material selected. Fabricate sufficient insulator seal specimens to support the ex-reactor and in-reactor test effort. Prepare and issue process specifications. Insulator materials considered are alumina $\left(\mathrm{Al}_{2} \mathrm{O}_{3}\right)$, yttria $\left(\mathrm{Y}_{2} \mathrm{O}_{3}\right)$ and $\mathrm{YAG}\left(\mathrm{Y}_{3} \mathrm{Al}_{5} \mathrm{O}_{12}\right)$.

3. Ex-reactor testing. Perform ex-reactor tests to evaluate the effects of thermal cycling, cesium compatibility, applied voltage and material interdiffusion on insulator seal performance and lifetime.

4. In-reactor testing. Perform in-reactor tests and the related postirradiation examinations to determine seal mechanical stability, electrical resistance and hermeticity after exposure to fast neutron fluences.

5. Modeling. Develop and validate analytical models to predict seal lifetime and performance.

\subsection{DESIGN AND MATERIALS DOWNSELECTION}

The seal design has been downselected to the taper seal configuration. The trilayer seal design is still a viable alternative, and its development will be part of the sheath insulator task (Task 5). While the trilayer design is different from the sheath insulator design, the technology is identical for the two insulators. 
The insulator materials being developed for the taper seal are single crystal alumina, the reference material, polycrystalline alumina and polycrystalline YAG. PIE results of the UCA-1 single crystal YAG taper seal shows that YAG has good neutron damage resistance and requires additional testing. YAG exhibits considerably less swelling than alumina but is not as strong, and will therefore be developed as a backup to alumina.

\subsubsection{Fabrication Development}

Two new braze alloys, niobium-zirconium and titanium-vanadium, were tested for wetting, bond strength and compatibility with alumina, YAG and niobium. Taper seals were fabricated using these two alloys. The niobiumzirconium alloy is compatible with niobium, alumina and YAG. The wetting behavior of this alloy is very sensitive to heating above the melting point. A single crystal alumina taper seal fabricated using the niobium-zirconium alloy will be included in the UCA-3 irradiation test.

The tantalum-vanadium alloy is not compatible with alumina. The alloy peels the metallizer away from the alumina. Single crystal alumina taper seals made with this alloy are not leak tight. Titanium-vanadium is compatible with YAG and leak tight seals can easily be fabricated. YAG has the problem that is not as strong as the single crystal alumina and many taper seals fabricated with this alloy have not been leak tight after the final machining of the seal. Final machining requires that the ID of the insulator be ground.

\subsection{EX-REACTOR TESTING}

The ex-reactor electrical testing of a single crystal alumina taper seal under accelerated conditions was terminated in December 1990. The seal accumulated a total of 200 days of testing at the accelerated temperature of $1275 \mathrm{~K}$ and three applied potentials, 1,10 and 30 volts. The resistance as a function of time for the seal is shown in Fig. 4-2. The data show no indications of deterioration of the resistance of the seal with applied potential and temperature. 
SINGLE CRYSTAL TAPER SEAL

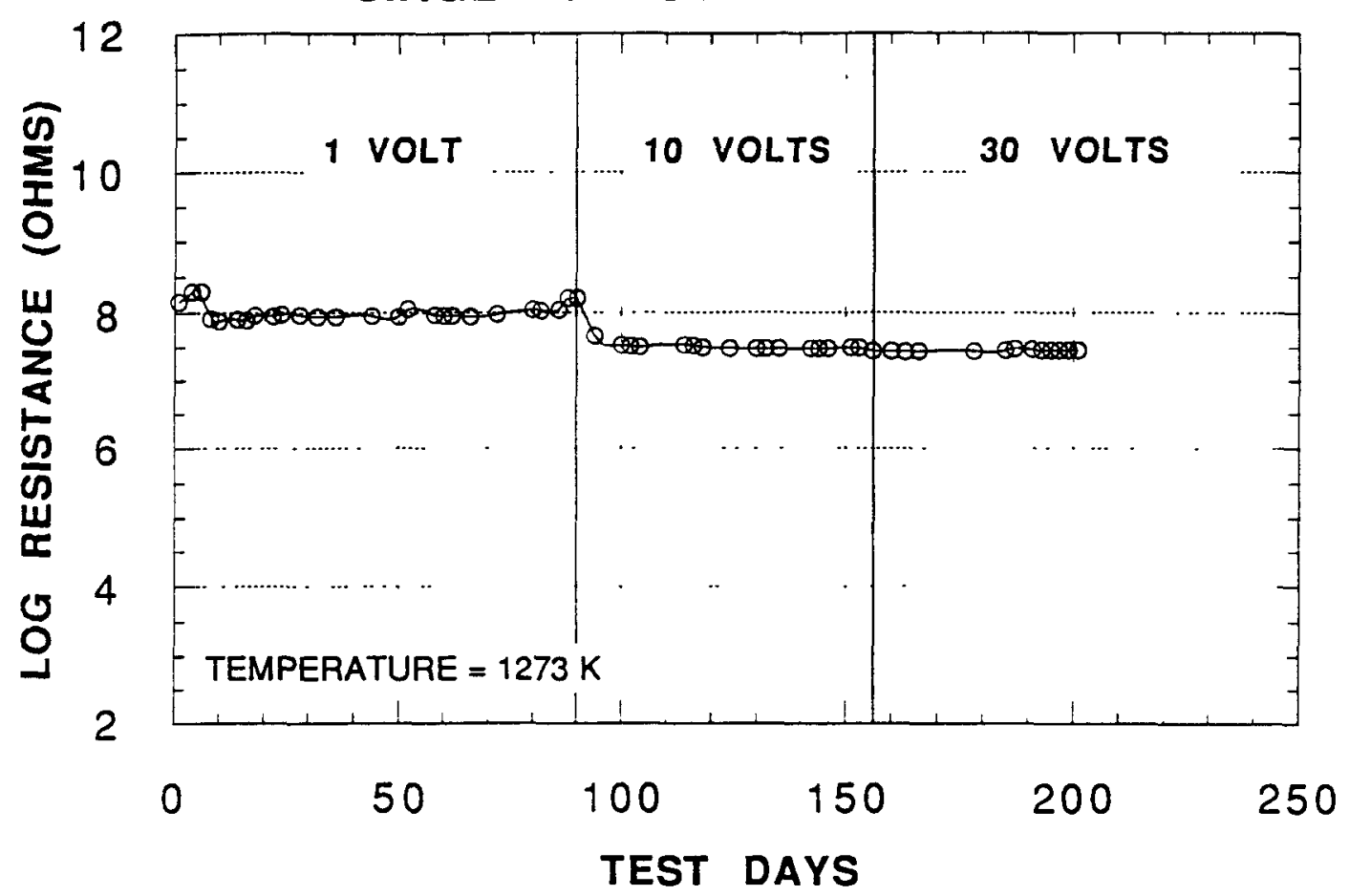

Figure 4-2. Single crystal alumina taper seal resistance vs time

\subsection{IN-REACTOR TESTING}

\subsubsection{UCA-3 Irradiation}

UCA-3 is the last in the series of in-reactor component testing. It incorporates results from ex-reactor testing as well as results from the postirradiation examination of UCA-1 and UCA-2 insulator seals. UCA-3 was divided into two batches. Irradiation of Batch-A started in cycle 156 of EBR-II on December 20, 1990 and will end in the middle of March 1991 with an estimated exposure of approximately $1.5 \times 10^{22} \mathrm{n} / \mathrm{cm}^{2}$. Batch-B will start irradiation in Cycle 157 of EBR-II at the end of May 1991 and is going to be exposed to a fast fluence of about $3 \times 10^{22} \mathrm{n} / \mathrm{cm}^{2}$. The sample test matrix for UCA-3 is shown in Table 4-1.

\subsubsection{UCA-2 PIE}

The postirradiation examination of UCA-2 samples has been completed. UCA-2 is the second in the series of in-reactor component testing. 
TABLE $4-1$

UCA-3 INSULATOR SEALS TEST MATRIX

\begin{tabular}{lccc} 
Materials & Batch & Configuration & Number \\
\hline Alumina (SC) & A & Taper & 2 \\
Alumina (SC) & B & Taper & 2 \\
YAG (PC) & B & Taper & 1 \\
Alumina (PC) & B & Trilayer Graded & 2 \\
Alumina (PC) & B & Trilayer Cermet 5\% Nb & 2 \\
Alumina (PC) & B & Trilayer Cermet 10\% Nb & 2 \\
& & & \\
SC = single crystal & & \\
PC = polycrystalline & &
\end{tabular}

Irradiation testing in FFTF was completed on Janaury 8, 1989. The insulators were irradiated for approximately 335 effective full power days (EFPD) and received fluences between 3.8 and $5.5 \times 10^{22}$ nvt at $1130 \mathrm{~K}$. The test matrix, high temperature resistance and He leak tightness results for the insulator seals in UCA-2 are given in Table 4-2. Three seals (S/N 003, S/N 001, and $S / N$ 280B) were selected for metallographic examination. The single crystal alumina taper seal ( $\mathrm{S} / \mathrm{N}$ 003) metallography looks the same as the UCA-1 single crystal alumina taper seal. The niobium skirt peeled away from the single crystal with the fracture occurring through the single crystal as shown in Fig. 4-3.

The metallography of the YAG taper seal (S/N 001) is similar to that of the single crystal alumina, but the peeling is not as pronounced, as shown in Fig. 4-4. Improvements in seal performance, He leak tightness and strength, are expected in the UCA-3 irradiation tests in which new fabrication procedures are implemented, lapping of the insulating gap and use of new braze a1loy.

The metallography of the yttria trilayer seal showed circumferential cracks at each of the ends but did not extend all the way through as shown in Fig. 4-5. Yttria is no longer being considered as a candidate insulator material because of its poor ex-reactor electrical performance. 
TABLE 4-2

UCA-2 INSULATOR SEALS

\begin{tabular}{lccccc} 
Configuration & S/N & $\begin{array}{l}\text { Irradiation } \\
\text { Temperature }\end{array}$ & $\begin{array}{c}\text { F1uence } \\
10^{22} \text { nvt }\end{array}$ & $\begin{array}{c}1070 \mathrm{~K} \\
\text { Resistance }\end{array}$ & $\begin{array}{l}\text { He Leak Rate } \\
\text { Std. cc/sec }\end{array}$ \\
\hline Taper alumina & 003 & $1115 \mathrm{~K}$ & 4.4 & $1.02 \times 10^{8}$ & .5 \\
Taper YAG & 001 & $1162 \mathrm{~K}$ & 5.5 & $4.62 \times 10^{4}$ & 1 \\
Yttria trilayer & $297 \mathrm{~B}$ & $1138 \mathrm{~K}$ & 3.8 & 1595 & $1 \times 10^{-2}$ \\
Yttria trilayer & 280B & $1135 \mathrm{~K}$ & 4.0 & 2257 & $1 \times 10^{-2}$
\end{tabular}

\subsubsection{UFAC-3}

To gain additional fast reactor experience with insulator seals, a set of specimens was fabricated for irradiation testing in EBR-II as part of the UFAC program. The specimens include individual taper seal components as well as complete taper seals. The UFAC-3 test matrix is shown in Table 4-3. Irradiation began in January 1990 and ended in September 1990. The samples were exposed for a total of 170 EFPD at a fast fluence of $3 \times 10^{22}$ nvt at $1140 \mathrm{~K}$. The seals are at the Westinghouse Hanford Company undergoing postirradiation examination.

TABLE $4-3$

UFAC-3 Batch 2 INSULATOR SEALS TEST MATRIX

Materials Seals Ceramic Rings Skirts

\begin{tabular}{|c|c|c|c|}
\hline $\begin{array}{l}\text { Alumina (SC) } \\
\text { YAG (PC) } \\
\text { Niobium }\end{array}$ & $\begin{array}{l}1 \\
2\end{array}$ & $\begin{array}{l}2(1) \\
2(1)\end{array}$ & $2(2)$ \\
\hline $\begin{array}{l}S C=\text { Single } \\
P C=\text { Polycry } \\
\text { (1) One ring } \\
\text { (2) Top and }\end{array}$ & $\begin{array}{l}\text { ystal } \\
\text { alline } \\
\text { etallized } \\
\text { ttom }\end{array}$ & & \\
\hline
\end{tabular}

\subsection{STATUS SUMMARY}

The current reference seal insulator specifications are summarized below:

$\begin{array}{ll}\text { Reference material: } & \text { Single crystal alumina } \\ \text { Design: } & \text { Taper seal } \\ \text { Fabrication: } & \text { Braze to niobium. }\end{array}$



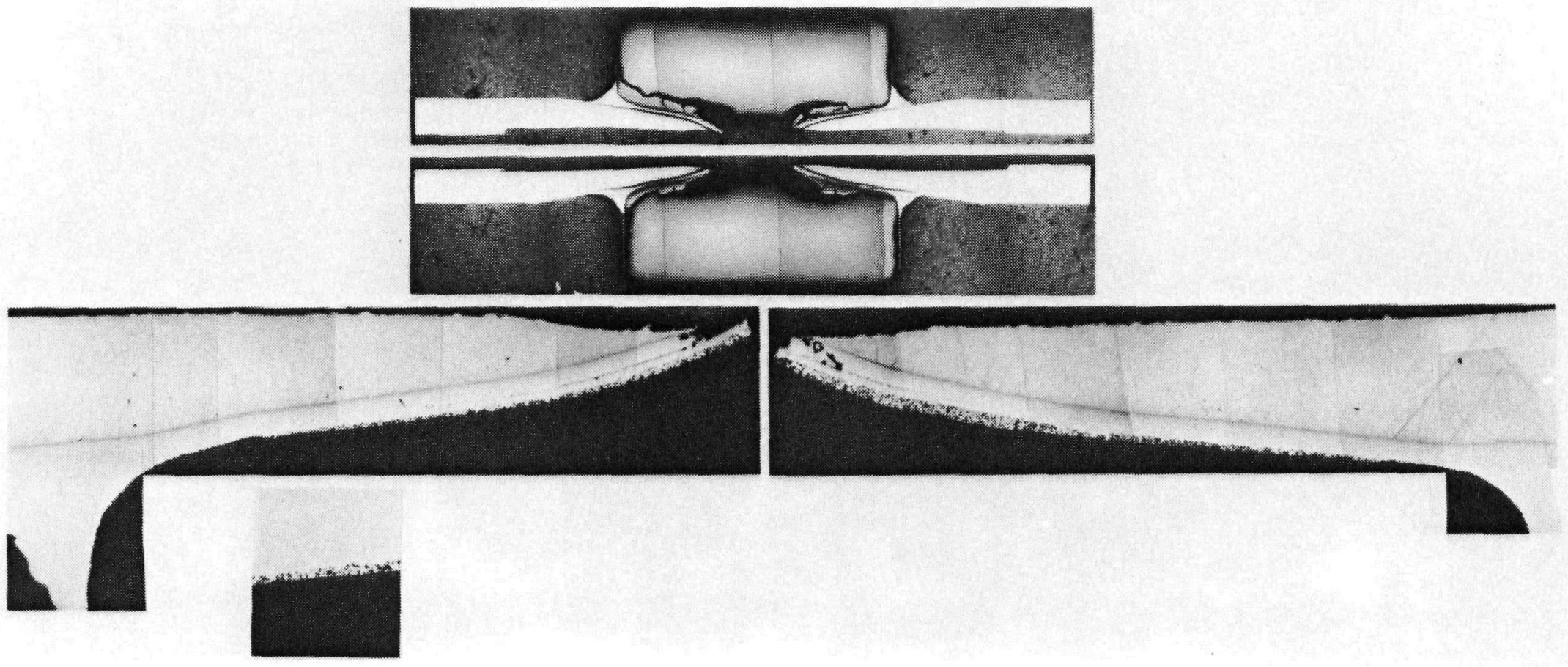

Figure 4-3. Longitudinal surface of UCA-2 single crystal alumina taper seal insulator ( $\mathrm{S} / \mathrm{N} 003$, peak fast fluence $4.4 \times 10^{22} \mathrm{n} / \mathrm{cm}^{2}$, operating temperature $1115 \mathrm{~K})$. 

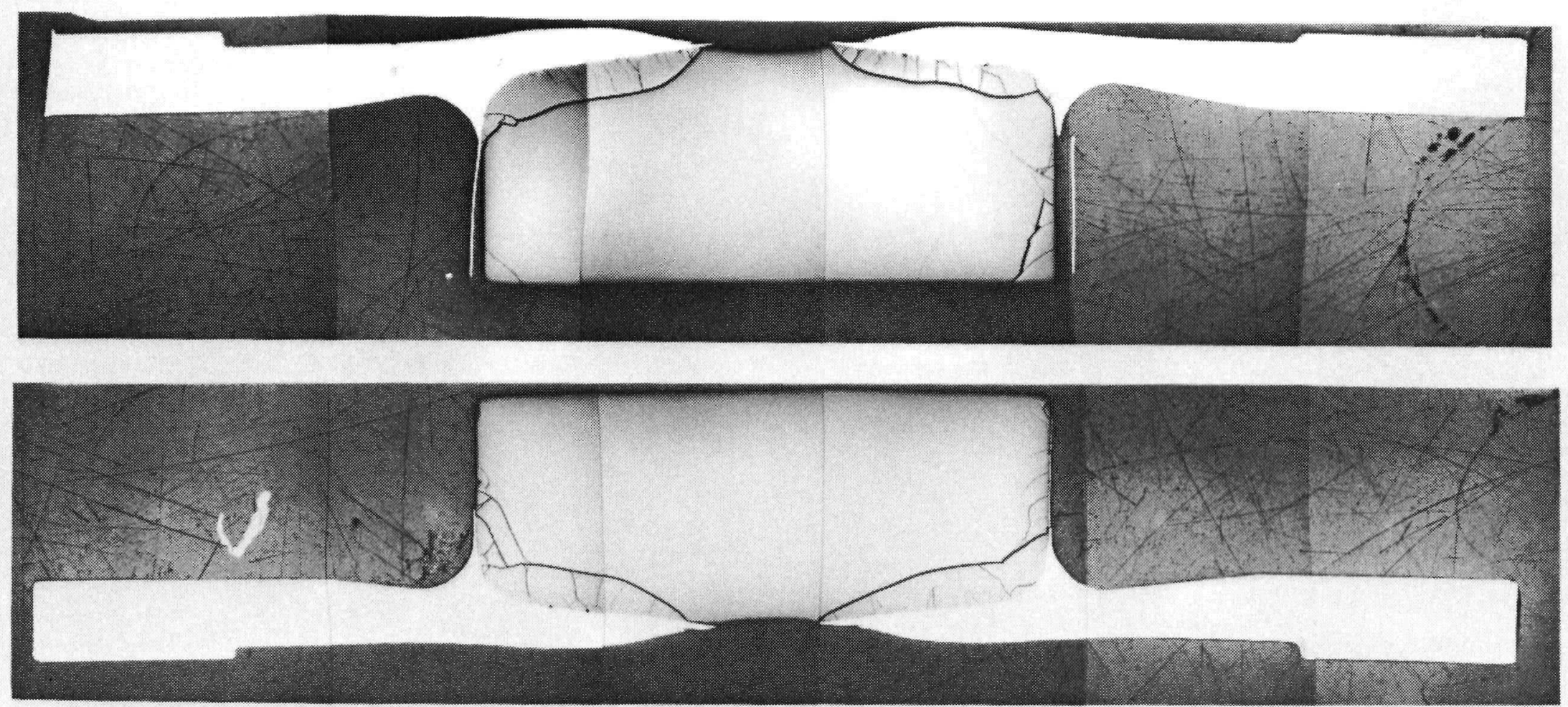

Figure 4-4. Longitudinal surface of UCA-2 single crystal YAG taper seal insulator $\left(\mathrm{S} / \mathrm{N} 001\right.$, peak fast fluence $5.5 \times 10^{22} \mathrm{n} / \mathrm{cm}^{2}$, operating temperature (1) 120 K). 

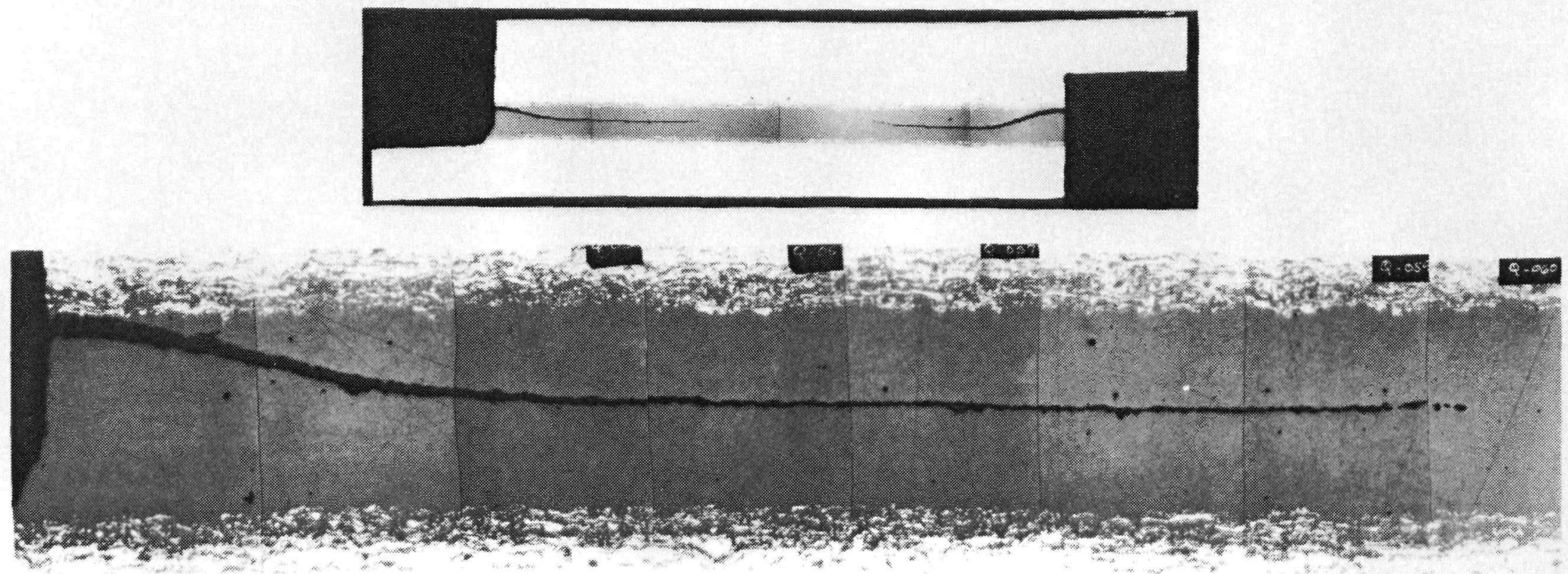

Figure 4-5. Longitudinal surface of UCA-2 yttria trilayer seal insulator $\left(\mathrm{S} / \mathrm{N} 280 \mathrm{~B}\right.$, peak fast fluence $4.0 \times 10^{22} \mathrm{n} / \mathrm{cm}^{2}$, operating temperature $1135 \mathrm{~K})$. 
The taper insulator seal material backups are:

Polycrystaline YAG

Polycrystalline alumina.

The insulator seal design backup is:

Alumina trilayer.

The polycrystalline alumina taper seal has experienced over 30,000 real time test hours in the TRIGA reactor, good evidence that its lifetime is at least several years. YAG is also being carried as a backup because of its low irradiation induced swelling and good electrical properties. More fabrication development and testing, both in-reactor and ex-reactor, are needed for YAG.

The alumina trilayer design used in the sheath insulator task, (Task 5) has remained hermetic after irradiation to three times the nominal fluence expected for the insulator seals and is being carried as an alternate design in case the tape seal cannot be made to be leak tight.

A summary of the seal insulator development effort is shown on Table 4-4.

\section{$\underline{\text { References }}$}

4-1 TFE Verification Program Semiannual Report for the Period Ending September 30, 1990, GA-20335. 
TABLE 4-4

INSULATOR SEAL TECHNOLOGY STATUS

Test Matrix (No. of Specimens)

Electrical Neutron Fabric- UCA UCA UFAC UCA TFEs Emitter

Material Design Properties Stability ability $\begin{array}{llllll}-1 & -2 & -3 & -3 & \text { (TRIGA) (TRIGA) }\end{array}$

\begin{tabular}{|c|c|c|c|c|c|c|c|c|c|c|}
\hline Alumina & Taper SC & Good & Acceptable & Good & 3 & 1 & 1 & 4 & & \\
\hline YAG & Taper SC & Acceptable & Good & Good & & 1 & & & & \\
\hline Alumina & Taper PC & Good & Acceptable & Good & & & & & 6 & 9 \\
\hline YAG & Taper PC & TBD & Good & Good & & & 3 & 1 & & \\
\hline Alumina & $\begin{array}{l}\text { Trilayer } \\
\text { Graded }\end{array}$ & Good & Acceptable & Good & 6 & 2 & & 2 & & \\
\hline Alumina & $\begin{array}{l}\text { Trilayer } \\
\text { Cermet }\end{array}$ & Good & Good & Good & 3 & 2 & & 4 & & \\
\hline
\end{tabular}

PC - Polycrystalline

SC - Single crystal 


\section{SHEATH INSULATOR TASK}

\subsection{OBJECTIVE AND TECHNICAL APPROACH}

The overall objective of the sheath insulator task is to develop and validate the performance of a sheath insulator for use in the thermionic fuel element reference design. In particular, the objectives are:

1. Produce designs for the sheath insulator.

2. Develop fabrication processes for the sheath insulators design and document the process spectifications.

3. Fabricate sheath insulators for ex-reactor and in-reactor (uninstrumented and instrumented) testing.

4. Verify the performance characteristics and lifetimes associated with sheath insulators by means of ex-reactor and in-reactor testing.

5. Develop an analytical model of the performance and lifetime of the sheath insulator and validate the model with test data.

The sheath insulator, shown schematically in Fig. 5-1, must provide electrical isolation between the collector of each converter and the outer sheath tube which is in contact with the reactor liquid metal coolant. The sheath insulator must also provide good thermal conduction between the collector and the sheath tube. The current design requirements are listed below:

1. Insulator temperature

2. Nominal fast fluence, E $>0.1 \mathrm{MeV}$

3. Nominal applied voltage Maximum applied voltage

4. Operating environment

5. Electrical resistance

6. Thermal conductivity

7. Lifetime
$1070 \mathrm{~K}$

$2.3 \times 10^{22} \mathrm{n} / \mathrm{cm}^{2}$

5.9 volts

7.5 volts

Fission gases

$>1000$ ohms $(1070 \mathrm{~K})$

$>0.03 \mathrm{~W} /(\mathrm{cm}-\mathrm{K})$

$\geq 7$ years 


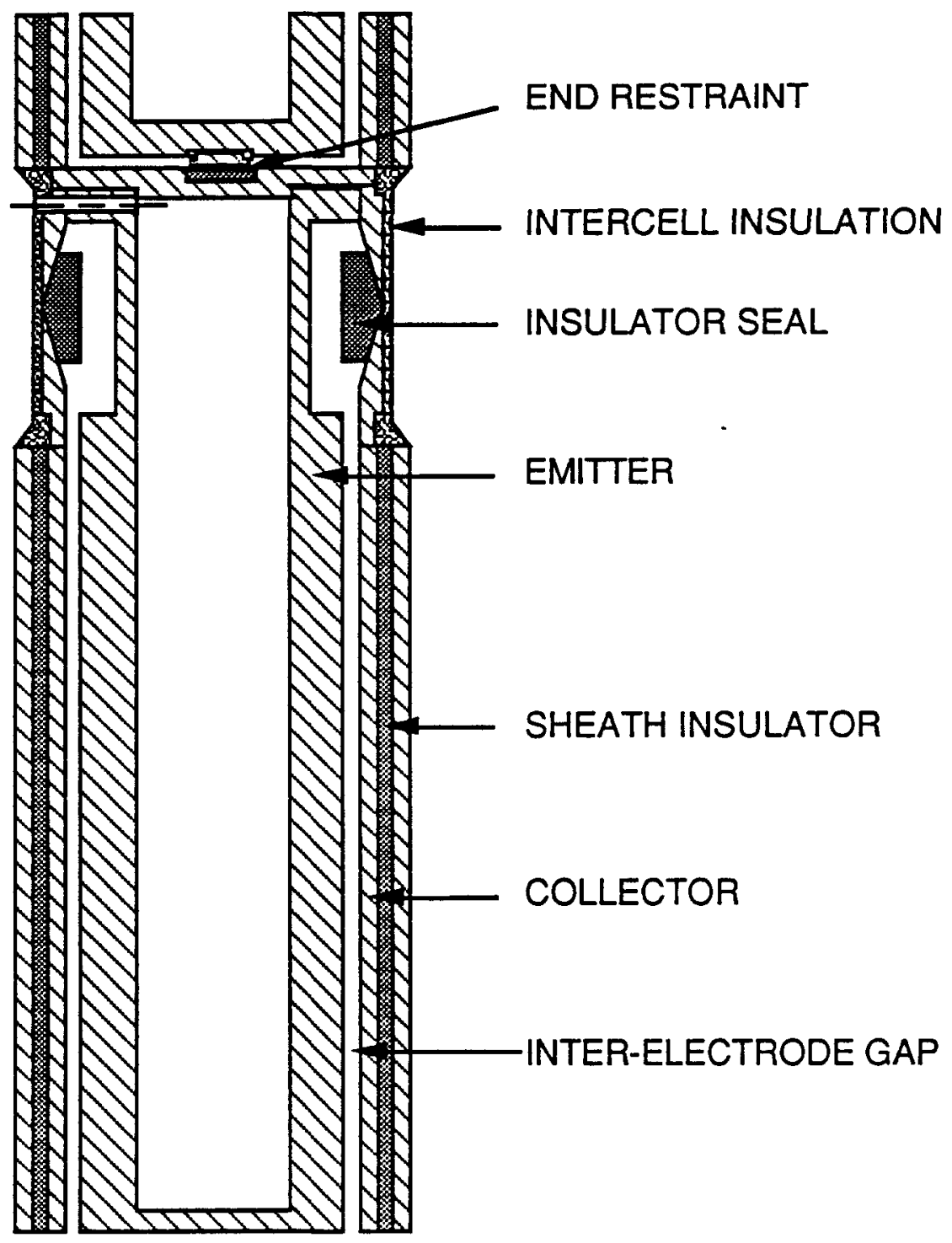

Figure 5-1. Thermionic cell showing insulator locations 
The technical concerns are the unbonding of the sheath insulator structure due to fast neutron induced damage, and electrolysis which could lead to low electrical resistance, and electrical breakdown. The objective of the sheath insulator task is to resolve these concerns and to develop and validate the performance of a sheath insulator for use in a prototypic TFE.

\subsection{TASK DESCRIPTION}

The sheath insulator task consists of five subtasks:

1. Sheath design. Sheath designs consistent with the TFE requirements are to be developed. The current design is the trilayer, consisting of an insulator layer between the niobium collector and the outer niobium sheath tube.

2. Fabrication development. Select appropriate insulator materials. Develop appropriate fabrication techniques for each insulator materfal selected. Fabricate sufficient sheath insulator specimens to support the ex-reactor and in-reactor test efforts. Prepare and issue process specifications. Insulator materials being considered are alumina $\left(\mathrm{Al}_{2} \mathrm{O}_{3}\right)$, yttria $\left(\mathrm{Y}_{2} \mathrm{O}_{3}\right)$ and $\mathrm{YAG}\left(\mathrm{Y}_{3} \mathrm{Al}_{5} \mathrm{O}_{12}\right)$. The fabrication techniques include plasma spraying the insulator onto the niobium collector, and thermal bonding of free standing ceramic tubes to the collector.

3. Ex-reactor testing. Perform ex-reactor tests to evaluate the effects of thermal cycling, applied voltage and material interdiffusion on the sheath insulators performance and lifetime.

4. In-reactor testing. Perform uninstrumented and instrumented inreactor tests and the related postirradiation examinations to determine the sheath insulator mechanical stability, electrical resistance and thermal conductivity after exposure to fast neutron fluences with and without an applied voltage.

5. Modeling. Develop and validate analytical models to predict sheath insulator lifetime and performance. 


\subsection{DESIGN AND MATERIALS DOWNSELECTION}

Two manufacturing processes and one insulator material are currently being evaluated. The manufacturing processes are the plasma sprayed graded trilayer being developed at $G A$ and the cermet trilayer being developed at TTC. The insulator material under investigation is alumina. Yttria, an insulator material that was under investigation, has been dropped from the program because of its poor electric performance in ex-reactor tests.

During the current reporting period, graded alumina and alumina cermets with 5 and $10 \%$ niobium were manufactured to make samples for ex-reactor and in-reactor tests, in particular test specimens for UCA-3.

\subsection{EX-REACTOR TESTING}

The ex-reactor testing of the sheath insulators is done by Rasor Associates Inc. (RAI). Testing includes long term tests at the nominal operating temperature $(1070 \mathrm{~K})$ and applied potential (7.5 volts) as well as accelerated tests at higher temperatures ( $1170 \mathrm{~K}$ and $1270 \mathrm{~K}$ ) and higher applied potentials ( 30,50 and 100 volts).

A total of fifteen samples, six alumina cermets with $5 \%$ niobium, six graded alumina and three graded yttria are currently being tested both under realtime and accelerated conditions. After a total of 100 days of testing all of the yttria samples shorted out; the resistance as a function of time is shown in Fig. 5-2. Yttria sheath insulators do not survive the ex-reactor testing at accelerated temperatures and voltages. Yttria is now considered to be an inadequate insulator material for the sheath insulators.

The alumina samples show a stable performance as a function of time, temperature and applied potential. The applied potential has increased in stages from the nominal 7.5 volts to 30 volts then to 50 volts and finally after 200 days of testing to 100 volts. Testing under the current conditions will continue until all the samples have accumulated 250 days of testing. Current results are shown in Figs. 5-3 and 5-4 for the graded alumina and alumina cermet specimens respectively. 


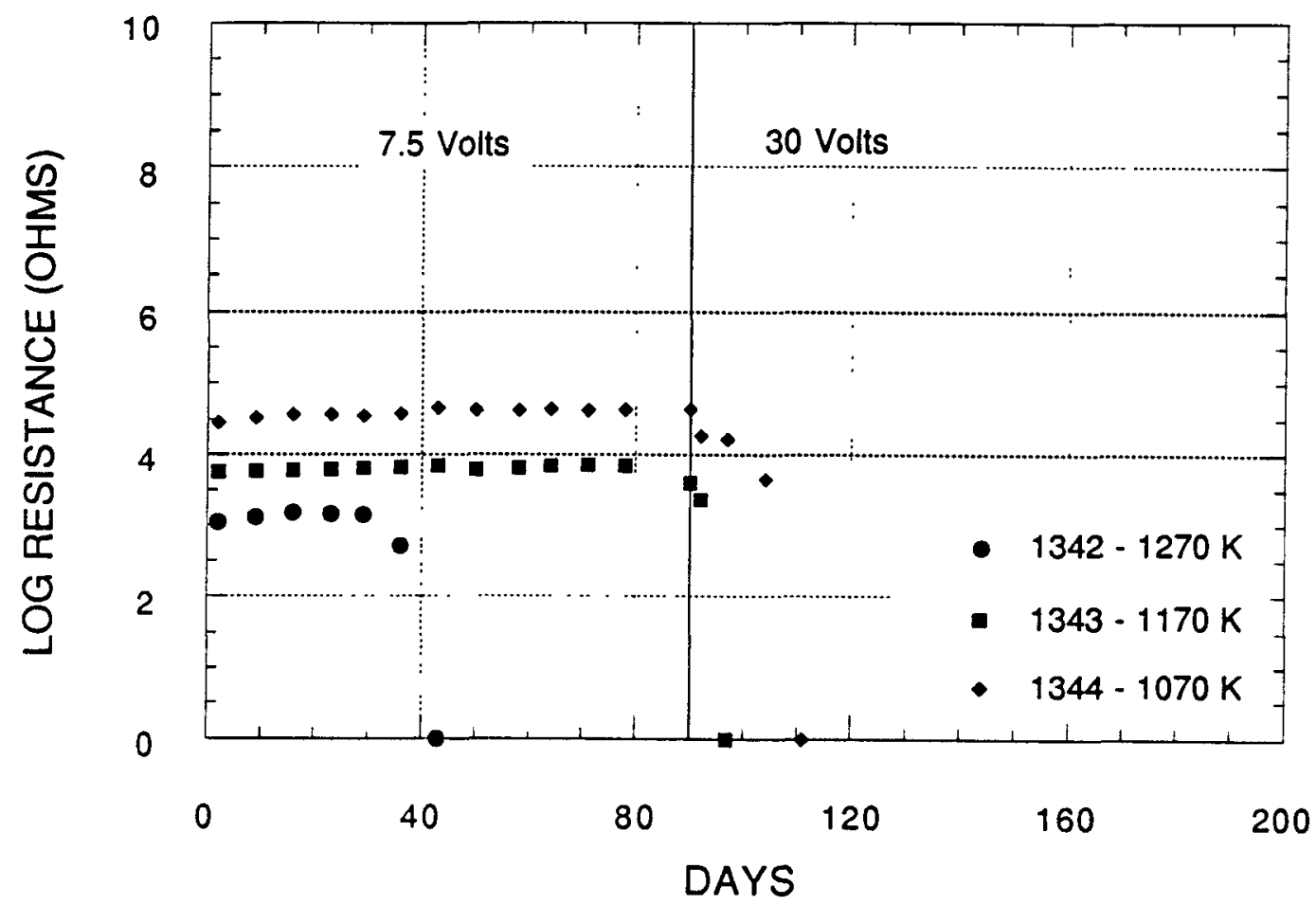

Figure 5-2, Electrical resistance vs time for GA graded yttria

\subsection{IN-REACTOR TESTING}

\section{5 .1 UCA-3}

UCA-3 is the last in the series of in-reactor component testing. It incorporates results from ex-reactor testing as well as results from the postirradiation examination of UCA-1 and UCA-2 sheath insulators. UCA-3 was divided into two batches, Batch-A and Batch-B. Sheath insulators will be tested in Batch-B. Batch-B will start irradiation in cycle 157 of EBR-II at the end of May, 1991, and will be exposed for 180 EFPDs to a fast fluence of about $3 \times 10^{22} \mathrm{n} / \mathrm{cm}^{2}$. The sample test matrix for UCA-3 is shown in Table $5-1$.

TABLE 5-1

UCA-3 BATCH-B SHEATH INSULATORS TEST MATRIX

End

Material Form Number Configuration

$\begin{array}{llll}\text { Alumina } & \text { Graded } / \mathrm{Nb} & 2 & \text { Step end } \\ \text { Alumina } & \text { Cermet } 5 \% / \mathrm{Nb} & \mathrm{S} & \text { Step end } \\ \text { Alumina } & \text { Cermet } 10 \% / \mathrm{Nb} & 2 & \text { Step end }\end{array}$




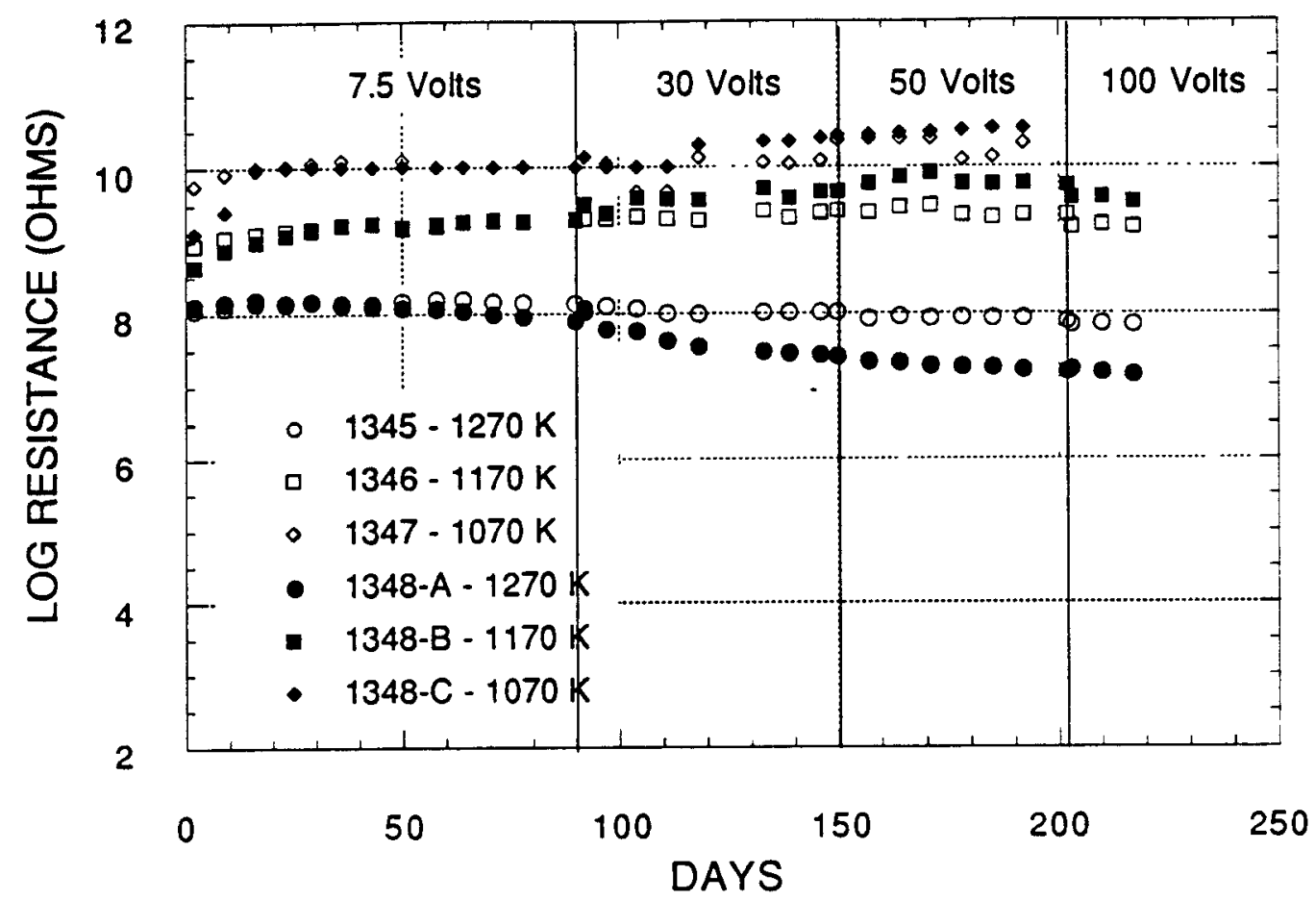

Figure 5-3. Electrical resistance vs time for GA graded alumina

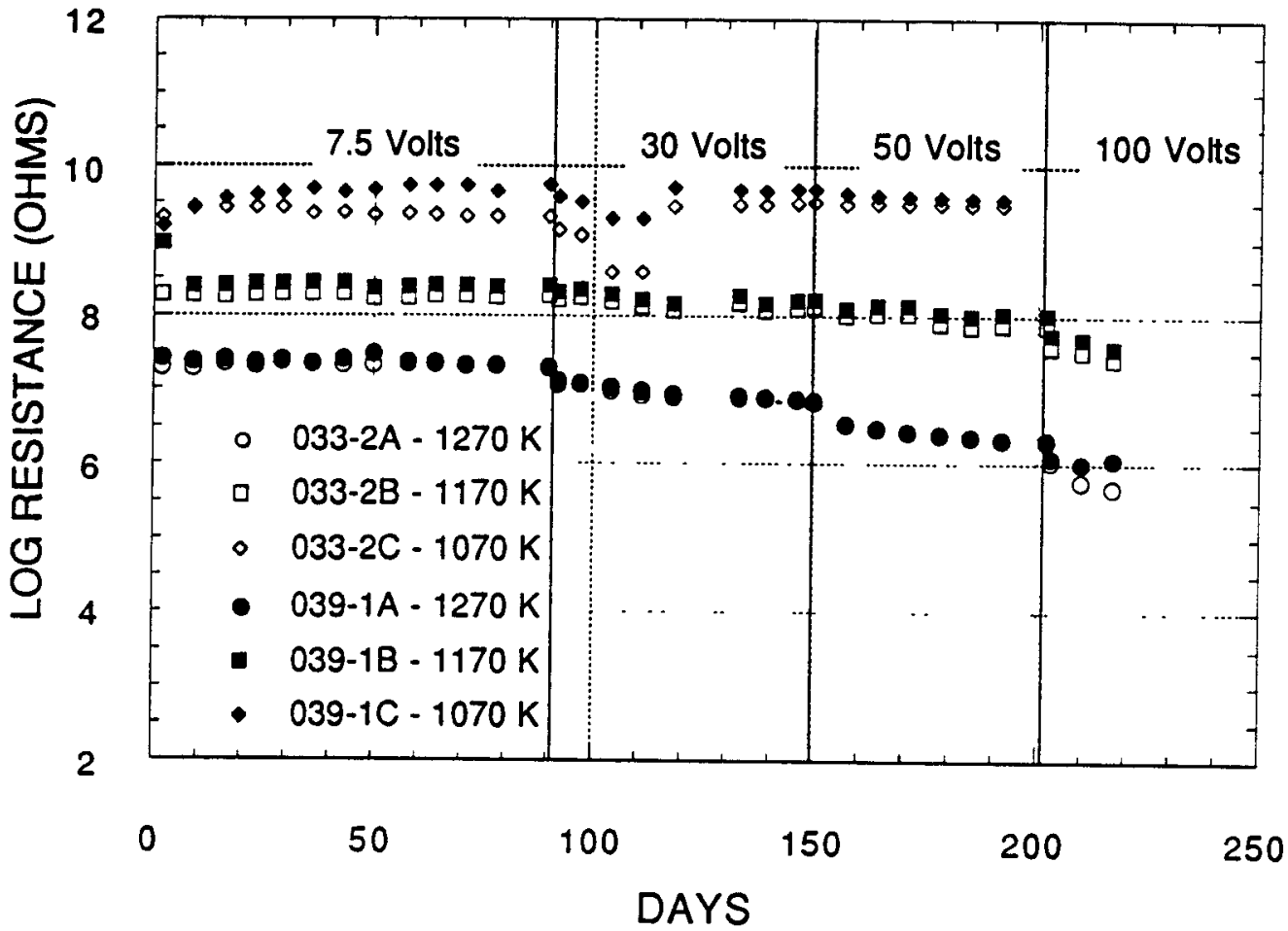

Figure 5-4 - Electrical resistance vs time for TTC alumina cermet with $5 \% \mathrm{Nb}$. 


\section{5 .2 IFAC-SI}

Fabrication of the sol-gel graded alumina sheath insulator samples is complete, while the fabrication of the cermet samples with 5 and $10 \%$ niobium is still in progress.

A11 required instrumentation for the IFAC-SI test has been procured and installed in an instrument rack. Preliminary wiring of the instrument console is in progress. The initial objective is to apply power and communication links to the instruments in order to develop and test the computer software. The software development plan is beign prepared. Programming for the I\&C system will begin following approval of the software development plan.

The current schedule for the test is as follows:

$\begin{array}{lll}\text { - GA/TTC deliver heat pipes to WHC } & \text { February } 1992 \\ \text { - WHC encapsulate, deliver to EBR-II } & \text { November } 1992 \\ \text { - EBR-II start irradiation } & \text { March } 1993 .\end{array}$

\subsection{POSTIRRADIATION EXAMINATION (PIE)}

\section{$5.6 .1 \quad \underline{U C A-2}$ PIE}

The PIE of UCA-2 samples was completed. The test matrix, high temperature resistance and He leak tightness results for the sheath insulators in UCA-2 are given in Table 5-2.

Five sheath insulators ( $\mathrm{S} / \mathrm{N} 317, \mathrm{~S} / \mathrm{N} 336, \mathrm{~S} / \mathrm{N} 346, \mathrm{~S} / \mathrm{N}$ TA8, and S/N TA9) were selected for metallographic examination. The two graded alumina samples examined, Fig. 5.5 (longitudinal) and Fig. 5-6 (transverse) showed excellent bonding of the ceramic to the metal with no cracking in the guarded transition region. There were no axial cracks from either end of the ceramic, as was the case for the UCA-1 graded alumina. The step end configuration relieves the stress concentration at the ends. 
TABLE 5-2

UCA-2 SHEATH INSULATORS

\begin{tabular}{|c|c|c|c|c|c|}
\hline onfiguration & $\mathrm{S} / \mathrm{N}$ & $\begin{array}{l}\text { Irradiation } \\
\text { Temperature }\end{array}$ & $\begin{array}{l}\text { Fluence } \\
\times 10^{22} \text { nvt }\end{array}$ & $\begin{array}{c}1070 \mathrm{~K} \\
\text { Resistance }\end{array}$ & $\begin{array}{l}\text { He Leak Rate } \\
\text { Std. cc/sec }\end{array}$ \\
\hline
\end{tabular}

\begin{tabular}{llllrl}
\hline Graded Alumina & 317 & $1114 \mathrm{~K}$ & 3.7 & $8.25 \times 10^{7}$ ohms & $6.8 \times 10^{-5}$ \\
Graded Alumina & 336 & $1128 \mathrm{~K}$ & 5.8 & $5.13 \times 10^{7}$ ohms & $5.4 \times 10^{-7}$ \\
Graded Yttria & 345 & $1117 \mathrm{~K}$ & 3.4 & $4.62 \times 10^{5}$ ohms* & Not tested \\
Graded Yttria & 346 & $1128 \mathrm{~K}$ & 5.9 & 401 ohms & $<10^{-8}$ \\
Graded YAG & 333 & $1113 \mathrm{~K}$ & 3.8 & 133 ohms & $1.7 \times 10^{-4}$ \\
Graded YAG & 334 & $1130 \mathrm{~K}$ & 5.6 & 296 ohms & $1.6 \times 10^{-4}$ \\
Alumina Cermet & TA8 & $1109 \mathrm{~K}$ & 3.7 & $7.83 \times 10^{6}$ ohms & $2.8 \times 10^{-4}$ \\
Alumina Cermet & TA9 & $1121 \mathrm{~K}$ & 6.0 & $4.40 \times 10^{7}$ ohms & $2.9 \times 10^{-4}$ \\
Yttria Cermet & TY2 & $1112 \mathrm{~K}$ & 3.4 & 248 ohms & $2.7 \times 10^{-6}$ \\
Yttria Cermet & TY5 & $1122 \mathrm{~K}$ & 6.2 & 225 ohms & $1.2 \times 10^{-4}$ \\
\hline
\end{tabular}

*Tested only to $873 \mathrm{~K}$.

The postirradiation microstructure of the samples was essentially the same as the preirradiation microstructure. The graded alumina sheath insulators examined in UCA-1 after irradiation showed significantly different microstructures than those from UCA-2. The UCA-1 microstructure was characterized by micro cracking at the grain boundaries with laminar porosity oriented along the axis of the sample. The differences between UCA-1 and UCA-2 in this regard are not fully understood. Both UCA-1 and UCA-2 samples were fabricated in the same way and both were exposed to similar neutron fluences. In the UCA-1 samples the outer sheath was made of $\mathrm{Nb}-1 \% \mathrm{Zr}$ and in the UCA-2 samples the outer sheath was made of pure nobium. However, this difference is probably not responsible for the difference in microstructure.

The yttria sheath insulator (S/N 346) with the step end configuration showed cracks through the insulator, with the cracks starting at each end and extending about $1 / 8$ inch into the ceramic, as shown in Fig. 5-7. In the graded transition region there is excellent bonding of the ceramic to the metal. The microstructure of the sample is very similar to the microstructure of the UCA-1 graded yttria.

Two alumina cermet samples with square ends were examined as shown in Fig. 5-8 (longitudina1) and Fig. 5-9 (transverse). The samples show excellent 

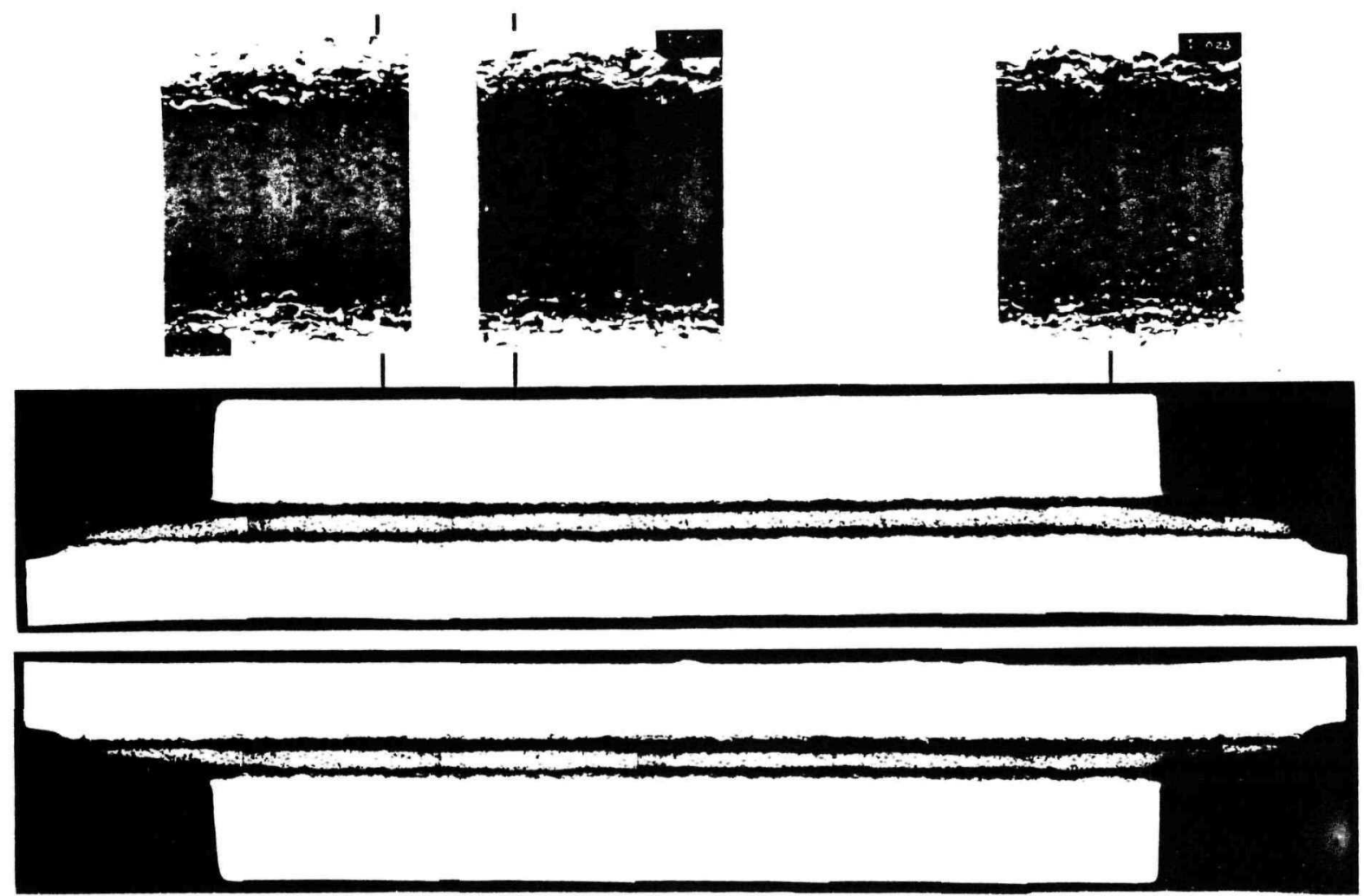

Figure 5-5. Longitudinal surface of UCA-2 graded alumina step end sheath insulator $\left(\mathrm{S} / \mathrm{N} 336\right.$, peak fast fluence $5.8 \times 10^{22} \mathrm{n} / \mathrm{cm}^{2}$, operating temperature $1128 \mathrm{~K}$ ). 

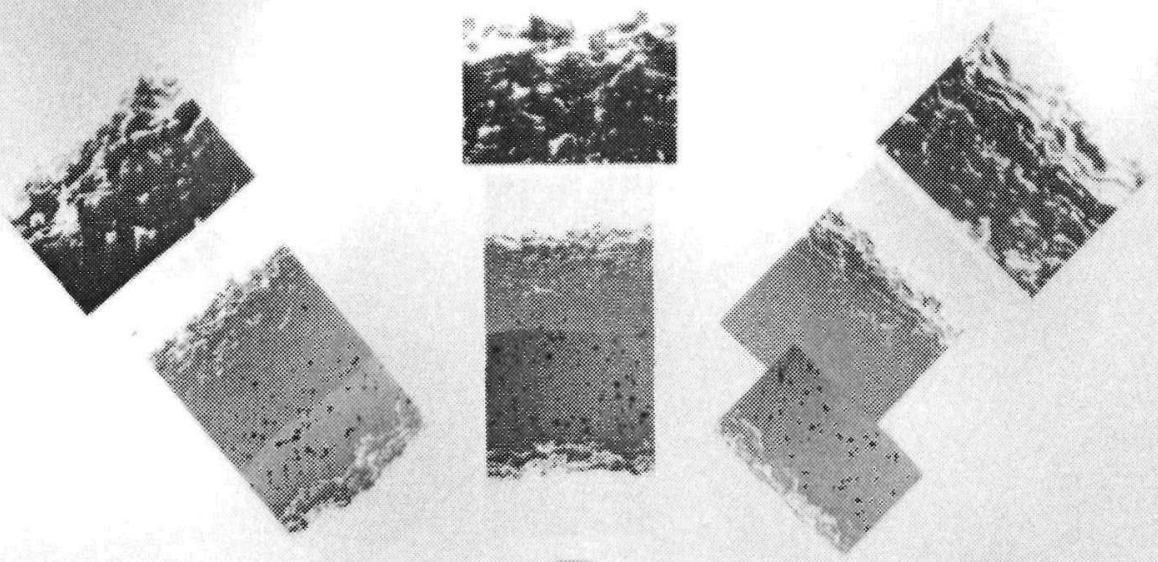

m
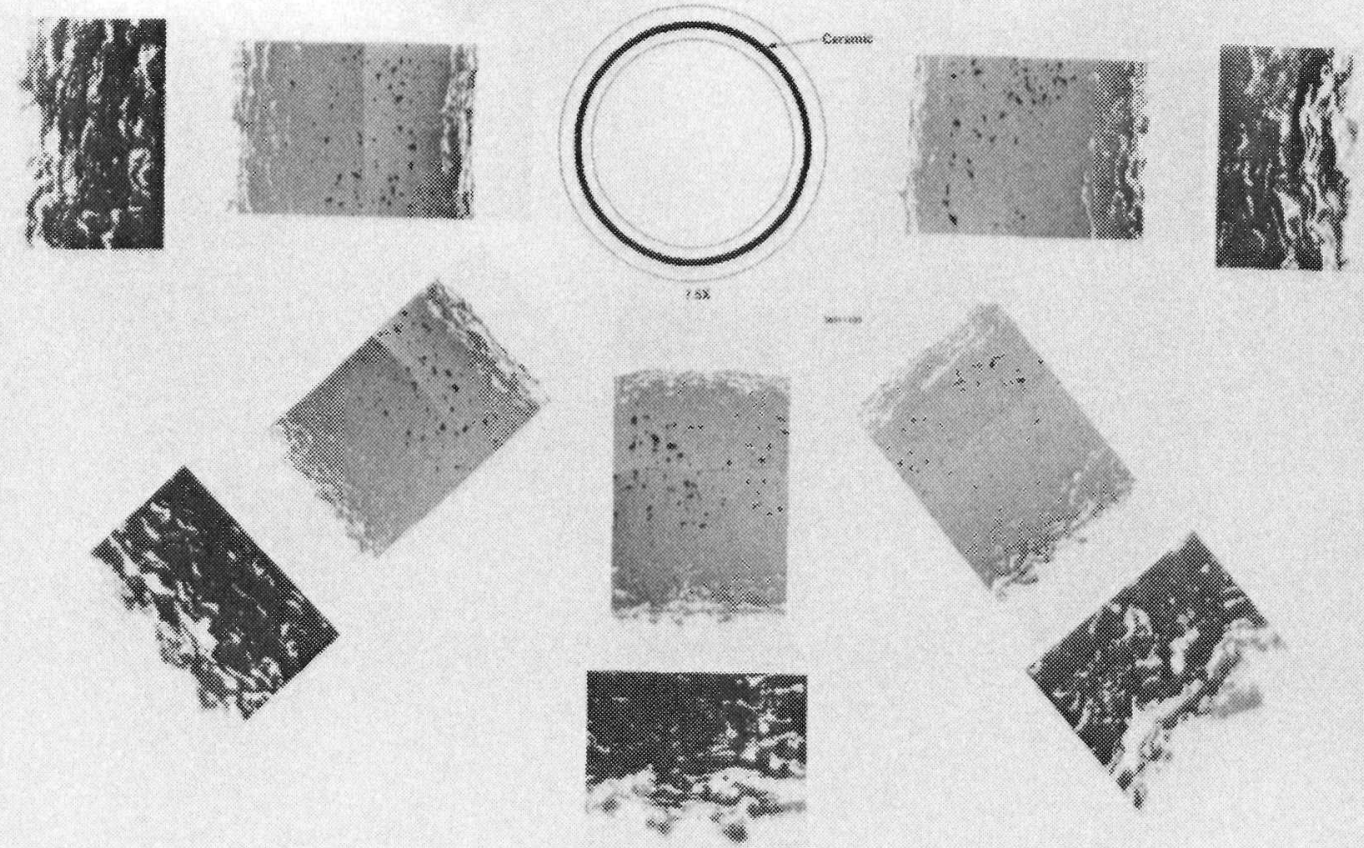

Figure 5-6

Transverse surface of UCA-2 graded alumina step end sheath insulator ( $\mathrm{S} / \mathrm{N}$ 317, peak fast fluence $3.7 \times 10^{22}$ $\mathrm{n} / \mathrm{cm}^{2}$, operating temperature $1114 \mathrm{~K}$ ) 

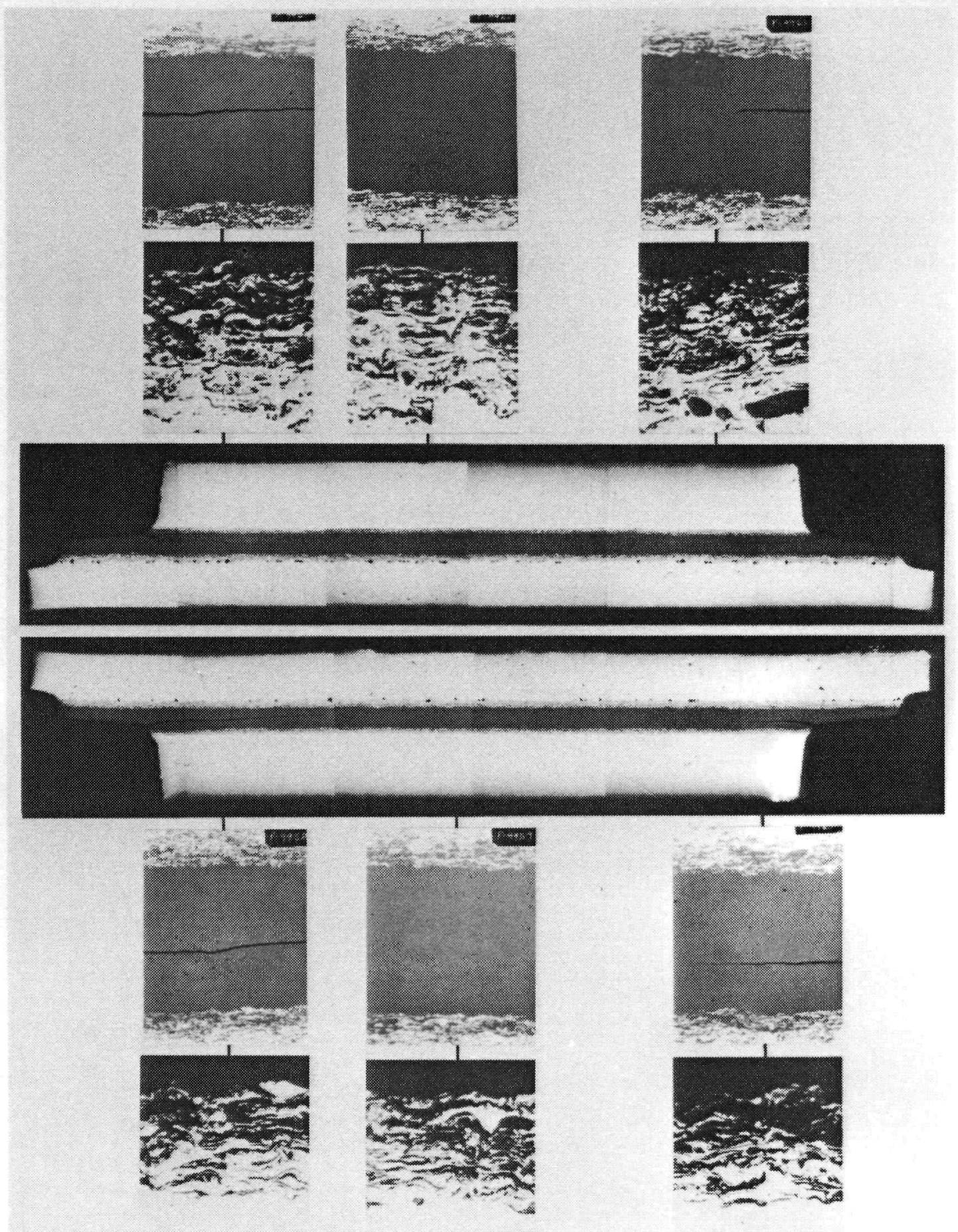

insulator ( $\mathrm{S} / \mathrm{N} 346$, peak fast fluence $5.9 \times 10^{L L} \mathrm{n} / \mathrm{cm}^{L}$, operating temperature $1128 \mathrm{~K}$ ). 

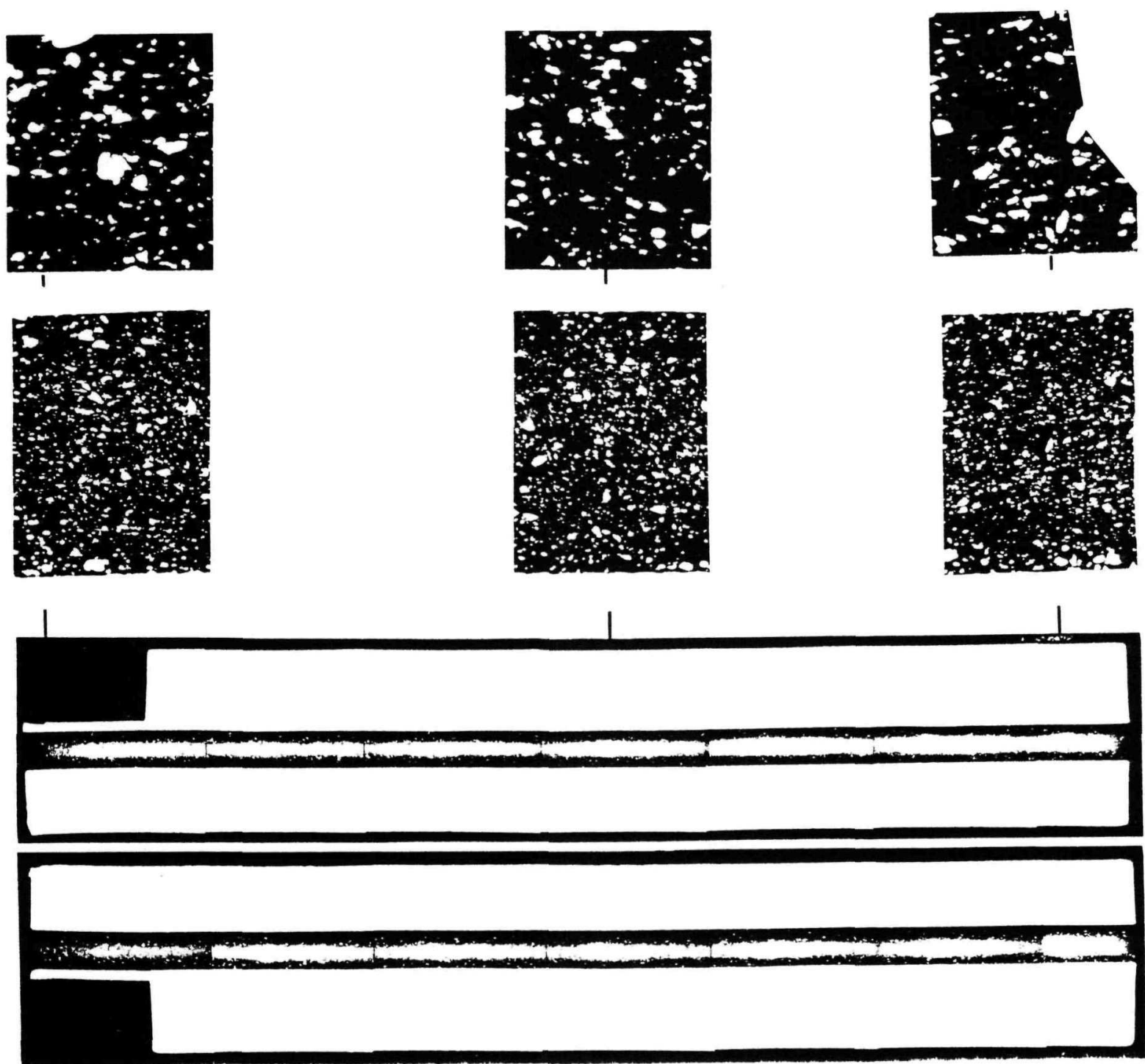

Figure 5-8. Longitudinal surface of UCA-2 alumina cermet square end sheath insulator (S/N TA9, peak fast fluence $6.0 \times 10^{22} \mathrm{n} / \mathrm{cm}^{2}$, operating temperature $1121 \mathrm{~K}$ ). 


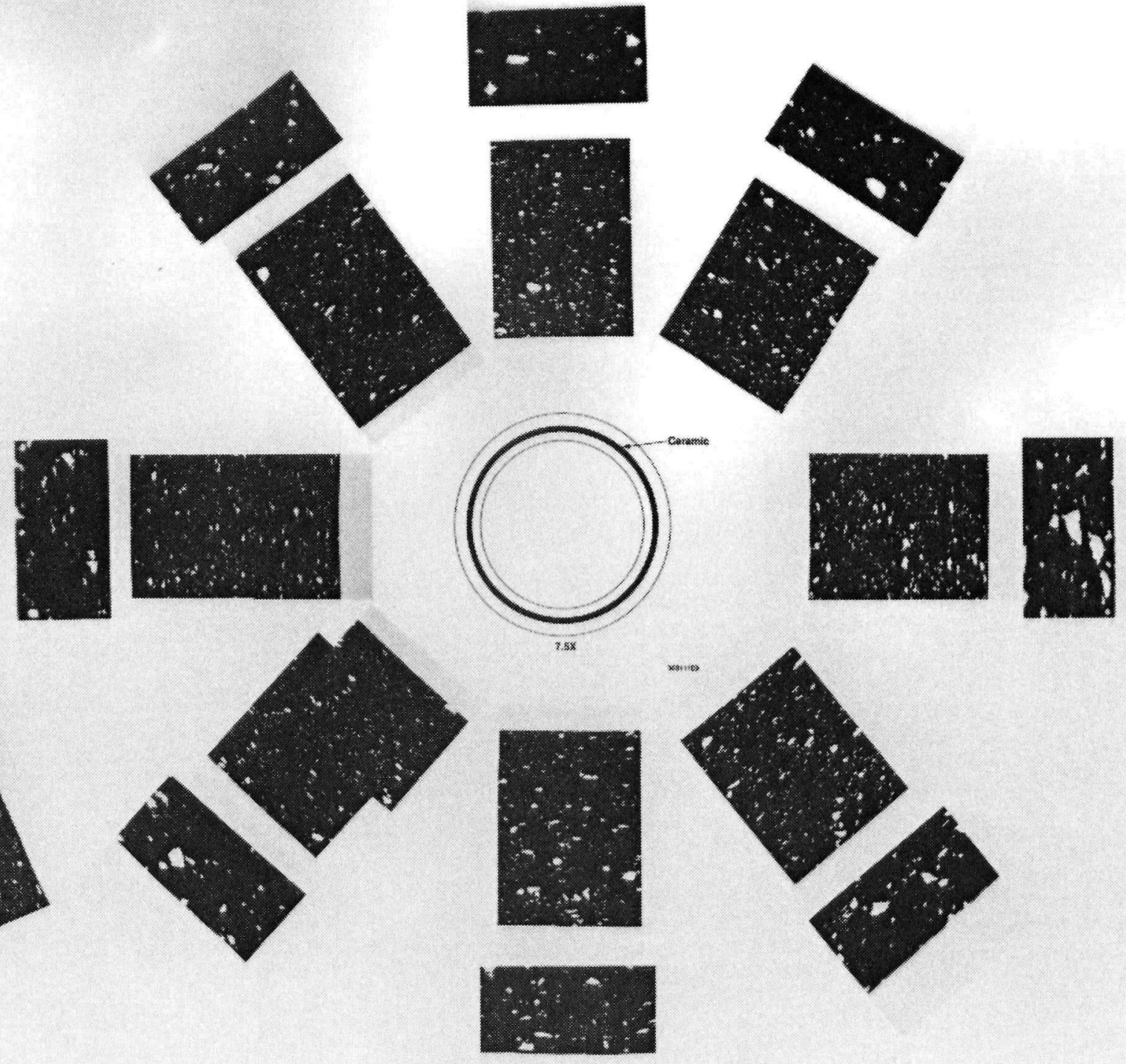

Figure 5-9. Transverse surface of UCA-2 alumina cermet square end sheath insulator (S/N TA8, peak fast fluence $3.7 \times 10^{2} 2 \mathrm{n} / \mathrm{cm}^{2}$, operating temperature $1109 \mathrm{~K}$ ) 
bonding of the cermet to the metal with no cracking at the interface. There was no cracking of the cermet and no interaction between the matrix oxide and the metal particles that make the cermet. The alumina cermets show similar microstructures to the cermets examined in UCA-1 with the only difference being the shape of the metal particles and their volume percent.

\subsubsection{Thermal Conductivity of Sheath Insulators}

Sheath insulators in addition to having good electrical resistance must have good thermal conductivity at the TFE operating conditions. The objective of this task is to measure the thermal conductivity of irradiated sheath insulator samples.

Varfous techniques to measure thermal conductivity up to $1173 \mathrm{~K}$ were evaluated at WHC. The initial selected method involves measuring thermal diffusivity using induction heating for both controlling the specimen temperature, and pulsing the specimen. A laboratory demonstration of the induction heating system operating in the pulse mode showed that for a sheath insualtor type sample the temperature increase from the energy pulse is very small, i.e., approximately $0.5^{\circ} \mathrm{C}$. This small temperature increase will be difficult to measure with accuracy. Consequently, an alternate heating system was evaluated. The new system also uses a pulse technique with the pulse generated by flash lamp which can deliver up to 3000 watts of energy. This energy deposition is more than sufficient to raise the temperature of the sheath insulator and get an accurate temperature measurement. The decision was made to proceed with procurement of a custom flash lamp and associated power supply and power leads.

\subsection{STATUS SUMMARY}

A summary of the sheath insulator development effort is shown in Table 5-3. The development priority at the moment is as follows:

$\begin{array}{ll}\text { Reference material: } & \text { Alumina oxide } \\ \text { Design: } & \text { Trilayer } \\ \text { Fabrication: } & \text { Plasma sprayed graded or slip cast cermet. }\end{array}$


Polycrystailine aluminum oxide both graded and cermet have shown good ex-reactor and in-reactor electrical properties and have survived fast neutron fluences $2-1 / 2$ times higher than what is expected in a seven year lifetime. Polycrystalline aluminum oxide plasma sprayed graded trilayer has experienced over 30,000 realtime test hours in the TRIGA reactor.

TABLE 5-3

\section{SHEATH INSULATOR TECHNOLOGY STATUS}

\begin{tabular}{|c|c|c|c|c|c|c|c|c|c|c|}
\hline \multirow[b]{3}{*}{ Material } & \multirow[b]{3}{*}{ Priority } & \multirow{3}{*}{$\begin{array}{r}\text { Elec- } \\
\text { trical } \\
\text { Prop- } \\
\text { erties }\end{array}$} & \multirow[b]{3}{*}{$\begin{array}{c}\text { Neutron } \\
\text { Stability }\end{array}$} & \multirow[b]{3}{*}{$\begin{array}{l}\text { Fabric- } \\
\text { ability }\end{array}$} & \multicolumn{6}{|c|}{ Test Matrix (Number of Specimens) } \\
\hline & & & & & \multirow[b]{2}{*}{ UCA-1 } & \multirow[b]{2}{*}{$\mathrm{UCA}-2$} & \multirow[b]{2}{*}{ UCA-3 } & \multicolumn{2}{|c|}{ (TRIGA) } & \multirow[b]{2}{*}{$\begin{array}{c}\text { Ex- } \\
\text { Reactor }\end{array}$} \\
\hline & & & & & & & & TFE & $\begin{array}{l}\text { Fueled } \\
\text { Emitter }\end{array}$ & \\
\hline $\mathrm{Y}_{2} \mathrm{O}_{3}(\mathrm{PC})$ & Low & Poor & Good & Good & 3 & 4 & & 1 & & 23 \\
\hline YAG $(P C)$ & Low & Good & Good & Difficult & $* 3$ & 2 & & & & 7 \\
\hline $\mathrm{Al}_{2} \mathrm{O}_{3}(\mathrm{PC})$ & High & Good & Good & Good & 10 & 4 & 6 & 5 & 9 & 34 \\
\hline $\mathrm{Al}_{2} \mathrm{O}_{3}(\mathrm{SC})$ & Low & Good & $\begin{array}{l}\text { Accept- } \\
\text { able }\end{array}$ & Difficult & & & & & & 2 \\
\hline
\end{tabular}

$\mathrm{PC}=$ Polycrystalline

$\mathrm{SC}=$ Single crystal

*Not crack free. 


\section{FUELED EMITTER TASK}

\subsection{OBJECTIVE AND TECHNICAL APPROACH}

The function of the fueled emitter is to generate the heat necessary to drive the thermionic conversion process with the geometry, power densi- ties and temperatures required by the reference TFE design, using materials compatible with both the thermionic process and reactor requirements. Specific requirements for the emitter are given in Table 6-1.

TABLE $6-1$

\section{FUELED EMITTER DESIGN REQUIREMENTS}

\section{Emitter}

\section{Materia1}

Outside diameter, $\mathrm{cm}$

Thickness, cm

Emitter/collector gap, cm

Nominal temperature, $\mathrm{K}$
Duplex Tungsten

1.27

0.10

0.025

1800

Fue1

Outside diameter, $\mathrm{cm}$

1.0

Inside diameter, $\mathrm{cm}$

Enrichment, \% U-235

Variable

93

Fuel length, cm

4.65

Nominal fuel burnup, atom percent

4.1

Peak fuel burnup, atom percent

5.3

The key technical concern is the emitter distortion as a result of fuel swelling over the 7-year lifetime. It is the objective of the fueled emitter task to develop and demonstrate by appropriate ex-reactor testing, in-reactor testing and analytical verification a fueled emitter capable of meeting the above design requirements.

The strategy to demonstrate the performance and lifetime of the fueled emitter is based on extensive in-reactor testing. While duplex tungsten will be the focus of most of the testing, alternate materials, particularly 
the HfC strengthened materlals, look very promising and will be considered. Additionally, alternate fuel forms will be evaluated which either weaken the fuel or change its swelling characteristics, thereby minimizing emitter distortion. These forms include insulated fuel, and wafered fuel.

The uninstrumented fast reactor accelerated component (UFAC) test program in EBR-II consists of three batches of fueled emitters (FE's). The accelerated testing of several specimens in Batch 1 has been completed. The real time specimens of Batch 1 and all of Batch 2 are currently under irradiation. Batch 3 is planned for FY-92.

A road map showing the irradiation strategy for the FE's in EBR-II is shown on Fig. 6-1. More detail is shown on Table 6-2 which also shows the current irradiation status of the test specimens. The recent irradiation history and the FY-91 projection are shown on Fig. 6-2 for both the UFAC subassemblies and EBR-II. Periodically, an interim non-destructive examination is performed during which a neutron radiograph (NR) is taken, and at that time the letter designation of the subassembly is changed, e.g., UFAC-1 to UFAC-1A, etc.

A summary of activity in the current reporting period is presented below. The FE identification scheme is show on Table 6-3 for Batches 1 and 2 .

Subassemb1y UFAC-1. The 4 accelerated FE specimens in this subassembly reached the goal burnup in April, 1990, of about 4 atom-percent (a/0) and were removed for postirradiation examination (PIE). The PIE is in progress.

Subassembly UFAC-2. The irradiation of this subassembly continued with 2 Batch 1 and 3 Batch 2 prototype FEs undergoing real time testing.

Subassembly UFAC-3. The irradiation of 3 Batch-1 accelerated FE's continued.

Fueled emitter modeling. The re-evaluation of all NR's taken continued. The evaluation of actual irradiation temperatures also continued. 
Figure 6-1

\section{ROAD MAP: FUELED EMITTER TESTING IN EBR-II}

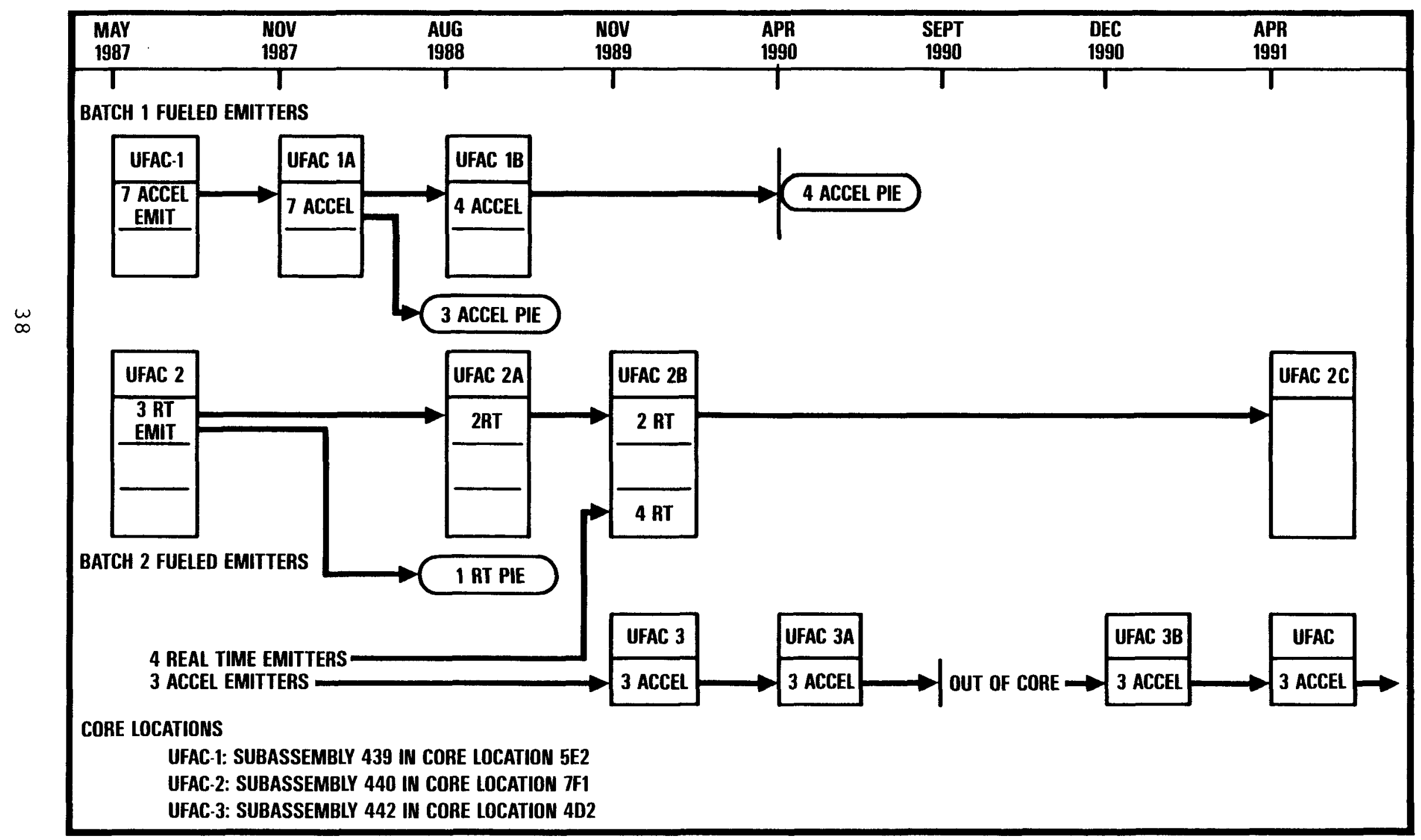


TABLE 6-2

SUMMARY STATUS OF UFAC TEST SERIES IN EBR-II AS OF JANUARY 1, 1991

\begin{tabular}{|c|c|c|c|}
\hline \multicolumn{2}{|c|}{ Irradiation } & \multirow[b]{2}{*}{$\begin{array}{l}\text { Peak } \\
\text { Burnup } \\
\text { (at.\%) }\end{array}$} & \multirow[b]{2}{*}{$\begin{array}{c}\text { Postirradiation } \\
\text { Examination } \\
\text { Status }\end{array}$} \\
\hline EFPD* & $\begin{array}{c}\text { Fast } \\
\text { Fluence } \\
\times 10^{22} \mathrm{n} / \mathrm{cm}^{2}\end{array}$ & & \\
\hline
\end{tabular}

Test Designation Test Content Status EF

\begin{tabular}{|c|c|c|c|c|c|c|}
\hline UFAC- 1 & $\begin{array}{l}7 \text { Batch-1 fueled } \\
\text { emitters }\end{array}$ & $\begin{array}{l}\text { Complete } \\
8-87\end{array}$ & 94.5 & 1.5 & 1.0 & $\begin{array}{l}\text { NDE } 7 \text { capsules } \\
\text { complete } 11-87\end{array}$ \\
\hline UFAC-1A & $\begin{array}{l}7 \text { Batch-1 fueled } \\
\text { emitters }\end{array}$ & $\begin{array}{l}\text { Complete } \\
4-88\end{array}$ & 221.5 & 3.6 & 2.1 & $\begin{array}{l}\text { NDE } 7 \text { capsules } \\
\text { complete } 7-88 \\
\text { DE } 3 \text { capsules } \\
\text { complete } 6-89\end{array}$ \\
\hline UFAC-1B & $\begin{array}{l}4 \text { Batch-1 fueled } \\
\text { emitters } \\
3 \text { dummy capsules }\end{array}$ & $\begin{array}{l}\text { Complete } \\
4-90\end{array}$ & 518 & 7.6 & 4.3 & $\begin{array}{l}\text { NDE } 4 \text { capsules } \\
\text { complete } 6-90\end{array}$ \\
\hline UFAC - 2 & $\begin{array}{l}3 \text { Batch-1 fueled } \\
\text { emitters } \\
4 \text { dummy capsules }\end{array}$ & $\begin{array}{l}\text { Complete } \\
4-88\end{array}$ & 285 & 2.8 & 0.5 & $\begin{array}{l}\text { NDE } 3 \text { capsules } \\
\text { complete } 6-88 \\
\text { DE } 1 \text { capsules } \\
\text { complete } 6-89\end{array}$ \\
\hline UFAC $-2 A$ & $\begin{array}{l}2 \text { Batch-1 fueled } \\
\text { emitters } \\
5 \text { dummy capsules }\end{array}$ & $\begin{array}{l}\text { Complete } \\
3-89\end{array}$ & 467 & 4.2 & 1.1 & $\begin{array}{l}\text { NDE } 2 \text { capsules } \\
\text { complete } 6-89\end{array}$ \\
\hline UFAC-2B & $\begin{array}{l}2 \text { Batch-1 fueled } \\
\text { emitters } \\
4 \text { Batch-2 fueled } \\
\text { emitters } \\
1 \text { dummy capsule }\end{array}$ & In-reactor & $\begin{array}{l}700 \\
234\end{array}$ & $\begin{array}{l}6.52 \\
2.06\end{array}$ & $\begin{array}{l}1.67 \\
0.55\end{array}$ & \\
\hline UFAC - 3 & $\begin{array}{l}3 \text { Batch-2 fueled } \\
\text { emitters } \\
2 \text { dummy capsules }\end{array}$ & $\begin{array}{l}\text { Complete } \\
4-90\end{array}$ & 63 & 0.9 & 0.6 & $\begin{array}{l}\text { NDE } 3 \text { capsules } \\
\text { complete } 5-89\end{array}$ \\
\hline$U F A C-3 A$ & $\begin{array}{l}3 \text { Batch-2 fueled } \\
\text { emitters } \\
3 \text { dummy capsules }\end{array}$ & $\begin{array}{l}\text { Complete } \\
9-90\end{array}$ & 170 & 3.0 & 1.55 & $\begin{array}{l}\text { NDE } 3 \text { capsules } \\
\text { complete } 11-90\end{array}$ \\
\hline UFAC $-3 B$ & $\begin{array}{l}3 \text { Batch-2 fueled } \\
\text { emitters } \\
3 \text { dummy capsules }\end{array}$ & In-reactor & 177 & 3.1 & 1.61 & \\
\hline
\end{tabular}

*NOTES: - Equivalent full power days.

- NDE, nondestructive examinations: visual, dimensional, gamma-scan, neutron radiography.

- DE, destructive examinations: gas sampling, radiochemical burnup, metallography. 
Figure 6-2

\section{UFAC IRRADIATION SCHEDULE}

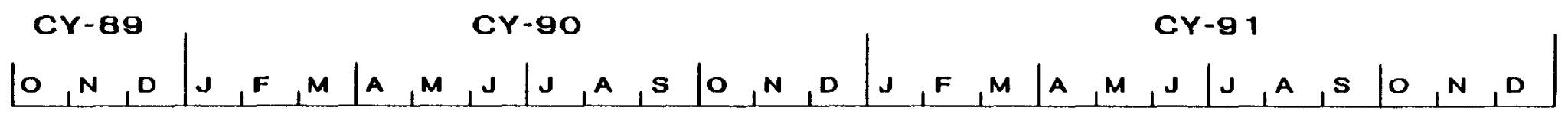

EBR-II

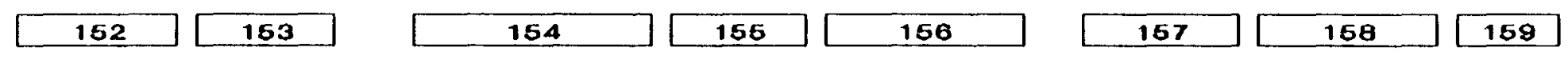

$\therefore \quad$ UFAC- 1

TERMINAL

UFAC-2

(X440)

UFAC- 3

(X442)
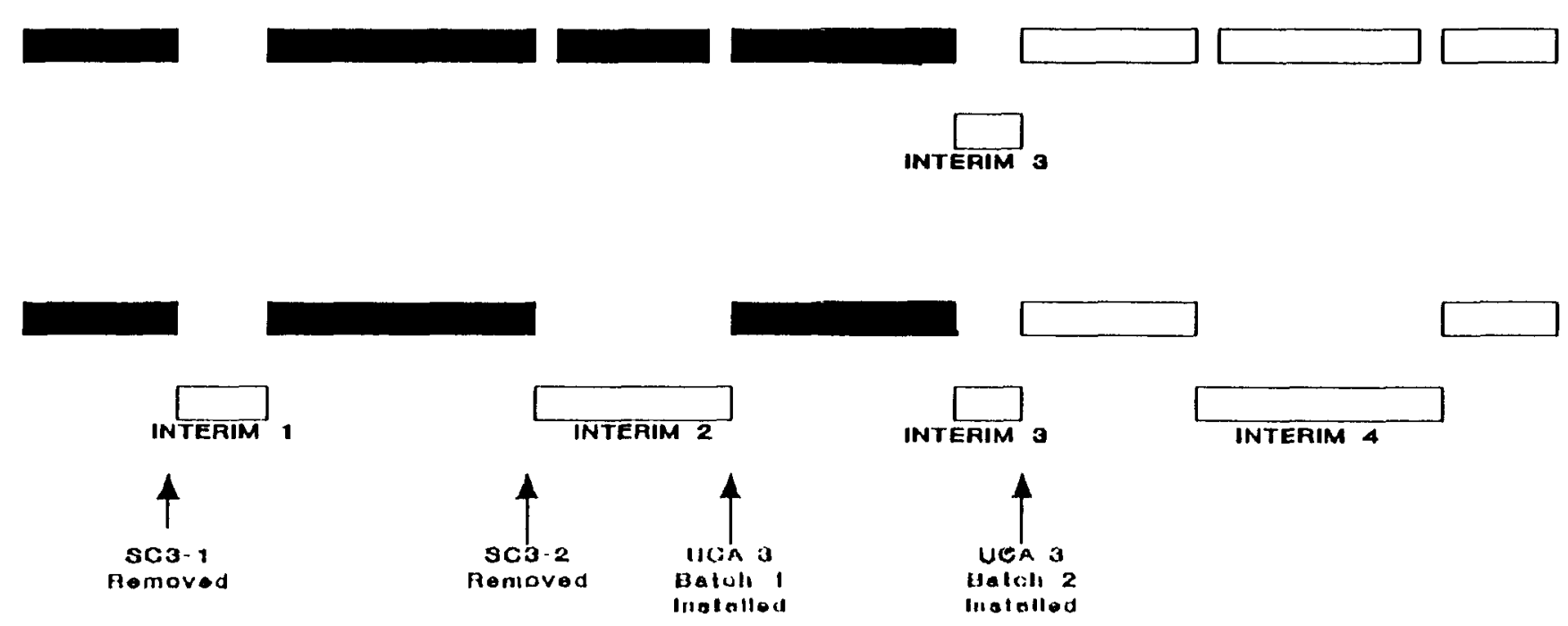
TABLE $6-3$

\section{UFAC EMITTER IDENTIFICATION SCHEME}

\begin{tabular}{|c|c|c|c|c|c|c|}
\hline Real Time & $\begin{array}{l}\text { Number } \\
\text { Accelerated }\end{array}$ & Diameter & Thickness & Temperature & Fuel Design & Comme \\
\hline & & \multicolumn{5}{|c|}{ UFAC BATCH - 1} \\
\hline SU2-1 & & 0.5 & 0.040 & 1800 & $15 \%$ void & Reference Desi \\
\hline $\mathrm{SU} 2-2$ & & 0.5 & 0.050 & 1800 & $15 \%$ void & Thick Emitter \\
\hline \multirow[t]{9}{*}{$\star \mathrm{SU} 2-3$} & & 0.5 & 0.040 & 1800 & Solid & Solid Fuel \\
\hline & SU1-4 & 0.25 & 0.020 & 1700 & $15 \%$ void & Reference Desigr \\
\hline & SUl-5 & 0.25 & 0.020 & 1800 & $15 \%$ void & Reference Desig. \\
\hline & $* S U 1-6$ & 0.25 & 0.020 & 1900 & $15 \%$ void & Reference Desigr \\
\hline & $* \mathrm{SU} 1-7$ & 0.25 & 0.020 & 1800 & Solid & Solid Fuel \\
\hline & SU1-8 & 0.25 & 0.020 & 1900 & Solid & Solid Fuel/High \\
\hline & SU1-9 & 0.25 & 0.025 & 1800 & $15 \%$ void & Thick Emitter \\
\hline & $\star S U 1-10$ & 0.25 & 0.025 & 1900 & $15 \%$ void & Thick Emitter/H \\
\hline & \multicolumn{6}{|c|}{ UFAC BATCH -2} \\
\hline SU2-11 & & 0.5 & 0.040 & 1800 & $15 \%$ void & Batch-1 Replica \\
\hline SU2-12 & & 0.5 & 0.040 & 1800 & $25 \%$ void & High Fuel Void \\
\hline SU2-14 & & 0.5 & 0.040 & 1800 & - & Insulated Fuel \\
\hline \multirow[t]{4}{*}{$\mathrm{SU} 2-15$} & & 0.5 & 0.040 & 1800 & - & Wafered Fuel \\
\hline & SU3-16 & 0.25 & 0.020 & 1800 & $15 \%$ void & Batch-1 Replica \\
\hline & SU3-17 & 0.25 & 0.020 & 1800 & - & Insulated Fuel \\
\hline & SU3-20 & 0.25 & 0.020 & 1800 & - & Wafered Fuel \\
\hline
\end{tabular}

* Removed for examination at end of Run 147. 
PIE of TRIGA test specimens. Capsule 2, fabricated as part of the thermionic technology program in Phase I of the SP-100 program, was disassembled and examined in the GA hot cell.

\subsection{EX-REACTOR TESTING}

Ex-reactor analysis has been primarily focused on the possibility that emitter distortions due to thermal ratcheting and/or bladder phenomena could be important. Early studies in the TFE program showed that both of these mechanisms are not important to the overall fuel emitter distortion. Therefore, the focus of the ex-reactor testing shifted to the investigation of the creep characteristics of the candidate emitter material.

Bars of WHfC advanced emitter material have been successfully extruded and are being evaluated for thermionic applications by Space Power, Inc. Plans to fabricate fueled emitters for testing in EBR-II under this program have been deferred to FY-92.

\subsection{IN-REACTOR TESTING}

Test status and test results from the in-reactor test program, largely in EBR-II, are described in the following sections.

\subsubsection{Reevaluation of Neutron Radiographs}

The effort to evaluate all NR's taken since the program started continues. Table 6.4 summarizes the NR history for all UFAC emitters. The reevaluation will result in a consistent set of data and will include readings at five axial locations: at the bottom and top of fuel, and at the $1 / 4,1 / 2$ and $3 / 4$ points. Readings will also be made at three angular locations: $-60^{\circ}, 0^{\circ},+60^{\circ}$.

\subsubsection{UFAC-1 FE Test Specimens}

Irradiation conditions. Four accelerated FE's are undergoing PIE in the Hanford hot cells. The final irradiation conditions for these emitters 
TABLE 6-4

UFAC NEUTRON RADIOGRAPHY HISTORY

Identification Number

\begin{tabular}{|c|c|c|c|c|c|}
\hline Real Time & Accelerated & $11-87$ & $6-88$ & $6-89$ & $6-90$ \\
\hline SU2-1 & & & $\mathrm{X}$ & $\mathrm{X}$ & \\
\hline SU2-2 & & & $\mathrm{X}$ & $X$ & \\
\hline SU2 $-3^{*}$ & & & $\mathrm{X}$ & & \\
\hline & SU $1-4^{* * *}$ & $\mathrm{X}$ & $\mathrm{X}$ & & $\mathrm{X}$ \\
\hline & SU $1-5^{\star \star}$ & $\mathrm{X}$ & $\mathrm{x}$ & & $\mathrm{x}$ \\
\hline & SU1 $1-6^{*}$ & $\mathrm{X}$ & $\mathrm{X}$ & & \\
\hline & $\operatorname{SU} 1-7^{*}$ & $\mathrm{X}$ & $\mathrm{X}$ & & \\
\hline & SU $1-8^{* *}$ & $\mathrm{X}$ & $\mathrm{X}$ & & $\mathrm{X}$ \\
\hline & SU $1-9^{x *}$ & $X$ & $\mathrm{X}$ & & $\mathrm{x}$ \\
\hline & SU1-10* & $\mathrm{X}$ & $\mathrm{X}$ & & \\
\hline
\end{tabular}

SU2-11

SU2-12

SU2 -14

SU2-15

SU3-16

SU3 -17

SU3-20

$\mathrm{X}$

$\mathrm{X}$

$\mathrm{X}$

\footnotetext{
* Removed for postirradiation examination on 7-88.

${ }^{* *}$ Remove for PIE on 7-90.
}

are summarized in Table 6-5. The burnup ranges from 3.25 to 4.27 atom percent, comparable to the design average burnup of 4.1 atom percent. The fast fluence, however, is about three times the design average fast fluence of $2.7 \times 10^{22} \mathrm{n} / \mathrm{cm}^{2}$.

The very large fluence may excessively degrade the materials in the fueled emitter subassembly. Separate material tests should be conducted to determine the effect on the important material properties such as creep, strength and ductility of the fast neutron fluence. This possibility will be examined in the future.

The actual emitter temperature was less than the design value, as shown on Table 6-6, for reasons outlined in Ref. 6-1 (Section 6.3.5). The actual fission rate was less than originally predicted and the cover gas over the emitter had a lower He/Ar ratio than expected. The net result was a lower emitter temperature. This will be discussed more fully later on. 
TABLE 6-5

FINAL TEST CONDITIONS IN UFAC-1

\begin{tabular}{|c|c|c|c|c|}
\hline Capsule & $\frac{\text { Emitter } T}{\text { Design }}$ & $\frac{\text { rature, } K}{\text { Actual }}$ & $\begin{array}{c}\text { Peak Fuel } \\
\text { Burnup, a/o }\end{array}$ & $\begin{array}{l}\text { Peak Fast } \\
\text { Fluence } \\
\times 10^{22} \mathrm{n} / \mathrm{cm}^{2}\end{array}$ \\
\hline SU1-4 & 1700 & 1640 & 3.78 & 7.13 \\
\hline SU1-5 & 1800 & 1620 & 3.81 & 7.18 \\
\hline SU1-8 & 1900 & 1700 & 3.25 & 6.77 \\
\hline SU1-9 & 1800 & 1580 & 4.27 & 7.57 \\
\hline
\end{tabular}

TABLE 6-6

HELIUM-TO-ARGON RATIOS FROM UFAC BATCH-1 FUELED EMITTERS

\begin{tabular}{ccc} 
Capsule & $\begin{array}{c}\text { Helium-to-Argon Mole Ratio in Gas Gap } \\
\text { Expected } \\
\text { (Design) }\end{array}$ & $\begin{array}{c}\text { Actual } \\
\text { (From PIE) }\end{array}$ \\
\hline SU1-6 & 9.0 & 4.6 \\
$1-7$ & 11 & 5.5 \\
$1-10$ & 6.9 & 3.6 \\
SU1-4 & 11 & 5.9 \\
-5 & 14 & 7.0 \\
-8 & 7.5 & 4.2 \\
-9 & 40 & 17 \\
\hline
\end{tabular}

Results of neutron radiographs. Neutron radiographs were taken prior to shipment to Westinghouse Hanford for the destructive PIE. A brief summary of the information presented in Ref. 2 is given below.

1) SU1-4. The NR showed that the emitter was fractured at the tungsten to tantalum transition joint. This fracture was similar to the previously observed fractures in SU1-6, SU1-7 and SU1-10.

2) SU1-5. The NR showed a localized bulge in the top portion of the fueled region, about 0.25 in. below the upper heat shield. Metallography during PIE should indicate possible causes.

Neutron radiographs taken after 5292 irradiation test hours showed emitter deformation of about .001 inches, very sma11. After 
12,449 test hours, the general deformation was in the range of .010 to .012 inches, a factor of 10 increase. The localized bulge was much greater. Clearly, emitter deformation accelerated prior to the 12,449 hours test point. The reason for this was excessive test specimen temperature, as will be discussed later.

3) SU1-8. The NR showed the emitter to be intact.

4) SU1-9. The NR showed the emitter to be intact.

Fission gas plenums. Fission gas plenums were sampled for quantity and composition of the gas present. Analysis of the gases collected showed the four samples to contain significant amounts of both helium and argon, indicating the emitter-to-collector gap was communicating with the fission gas plenum. This result was expected for Capsules SU1-4 and SU1-5 from the NR analysis. Neutron radiography of SU1-8 and SU1-9 showed the two fueled emitters to be intact. However, the $\mathrm{He}$ and $\mathrm{Ar}$ in the plenums indicates that either the fracture was not visible on the radiograph or they fractured after radiography in-transit to WHC.

The helium-to-argon ratio, design versus actual, is shown on Table 6-6. The excess argon is evident, and the data for $\operatorname{SU} 1-4,-5,-8$ and -9 are consistent with those obtained earlier for SU1-5,-7 and -10 (Ref. 6-1).

The gas volume collected is proportional to the burnup, as shown in Table 6-7. An estimate of the measured volume can be made based on the yields of the fission gases xenon and krypton.

\section{TABLE 6-7}

GAS VOLUME CAPTURED IN PLENUMS FROM UFAC BATCH-1 FUELED EMITTERS

\begin{tabular}{rccc} 
Capsule & Burnup, a/o & Gas Volume Captured, $c c$ & Vol.(cc)/B.U.(a/o) \\
\cline { 1 - 1 } SU1-6 & 1.7 & 1.8 & 1.1 \\
-7 & 1.4 & 1.9 & 1.4 \\
-10 & 1.9 & 1.9 & 1.0 \\
SU1-4 & 3.8 & & \\
-5 & 3.8 & 4.1 & 1.1 \\
-8 & 3.3 & 3.6 & .95 \\
-9 & 4.3 & 4.3 & 1.3 \\
\hline
\end{tabular}




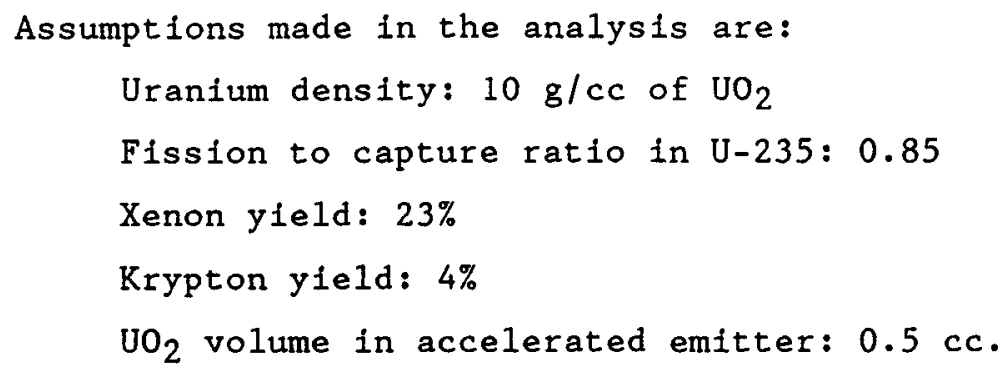

For $3.8 \%$ burnup, the fission gas volumes are:

$$
\begin{array}{ll}
\text { Xenon: } & 3.6 \mathrm{cc} \\
\text { Krypton: } \frac{0.6 \mathrm{cc}}{4.2 \mathrm{cc}}
\end{array}
$$

When the estimated helium and argon volumes are added, the total volume of gas (STP) is $4.8 \mathrm{cc}$. This compares very well with the measured volumes of 3.6 to $4.3 \mathrm{cc}$.

An important conclusion from this analysis is that most of the noble fission product gases are released from the fuel during operation.

The gas content of the gas recovered from the plenums is shown on Table $6-8$.

TABLE 6-8

GAS COMPOSITION IN PLENUM, MOLE \%

$\begin{array}{lcccc}\text { Capsule } & \text { Xe } & \text { Kr } & \text { He } & \text { Ar } \\ & & & & \\ \text { SU1-4 } & 73.7 & 11.7 & 11.3 & 1.87 \\ \text { SU1-5 } & 73.0 & 11.3 & 13.1 & 1.83 \\ \text { SU1-8 } & 72.2 & 11.3 & 11.5 & 2.73 \\ \text { SU1-9 } & 74.0 & 11.7 & 12.9 & 0.71\end{array}$

The $\mathrm{Xe} / \mathrm{Kr}$ ratio is about 6.4 which is roughly consistent with the fission yields mentioned above. The He/Ar ratio is consistent with the data of Table 6-6.

Visual examinations. Detailed visual examinations and photography were completed on the four FE's. The fractures at the top were in the area of the $\mathrm{W}$ to $\mathrm{Ta}$ bond, and were very similar to those at the same location seen in other UFAC-1 emitters that were examined at the second interim at approximately half the burnup. 
Emitter SU1-4 (Fig. 6-3) also has two cracks around the circumference on the outer $W$ surface. The first crack spirals down from the fracture approximately $1 / 4$ inch. The second visible crack is located approximately 1-1/4 1nches down from the fracture.

Emitter SU1-5 is breached in the fuel column in addiiton to the fracture at the bond (Fig. 6-4). The breach is 0.27 inches long and is approximately centered over the top fuel pellet in the column. The breach opening is approximately 0.05 inches wide and the localized distortion at the breach is approximately 0.02 inches. Emitter deformation measured from the photographs in SU1-5, not associated with the breach, is approximately 0.015 to 0.020 inches in diameter.

Emitter SU1-8 was broken into two pieces when it was recovered from the niobium subcapsule (Fig. 6-5). The emitter fractured at the top (in the $W$ to $\mathrm{Ta}$ bond area) and also at approximately $1 / 2$ inch up from the bottom of the emitter in the center of the fuel column. Examinations of emitter SU1-9 showed no additional cracks beyond the fracture at the $\mathrm{W}$ to $\mathrm{Ta}$ bond area (Fig. 6-6).

Analysis of SU1-5 emitter fracture. Emitter fracture has occurred in all of the specimens at or near the tungsten-to-tantalum transition bond. This has allowed the helium/argon gas surrounding the emitter to leak into the fission gas plenum, and the heavy fission gases to leak into the emitter gas gap.

The initial pressure of the helium/argon gas mixture in the gas gap was about $1 / 2$ atmosphere, the volume being about $.86 \mathrm{cc}$. This yields the emitter temperature shown on Table 6-5. The volume of the plenum is about $103 \mathrm{cc}$, or a factor of 120 larger than the gas gap. Hence when the emitter fractured, near the end of the irradiation, the He/Ar concentration decreased by about a factor of 120, and heavy fission product gases entered the gas gap in the ratio shown on Table 6-8. The net result was a significant increase in emitter (and fuel) temperature, the estimated increase being in the range of 500 to $600 \mathrm{~K}$, perhaps more. This temperature increase obviously had a significant (negative) impact on the integrity of the test 


\section{UFAC-1B Fueled Emitters}

SU1-4

Emitter Thickness: 0.020 inch

Fuel Form: Annular

Emitter Surface Temperature: $1640 \mathrm{~K}$ (Revised Calculation)

Fuel Burnup: 3.8 at.\%

Fast Fluence: $7.1 \times 10^{22} \mathrm{n} / \mathrm{cm}^{2}$
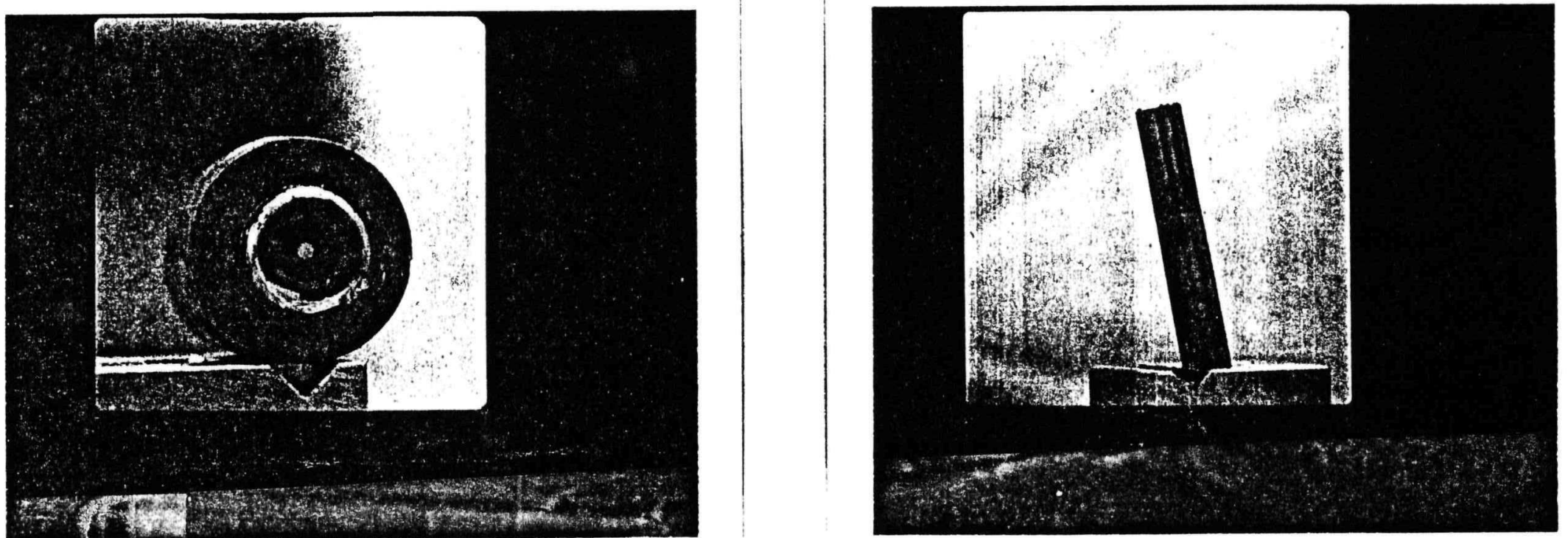

Figure 6-3. UFAC-1B fueled emitter SUl-4 


\section{UFAC-1B Fueled Emitters SU1-5}

Emitter Thickness: 0.020 inch

Fuel Form: Annular

Emitter Surface Temperature: $1620 \mathrm{~K}$ (Revised Calculation)

Fuel Burnup: 3.8 at.\%

Fast Fluence: $7.2 \times 10^{22} \mathrm{n} / \mathrm{cm}^{2}$
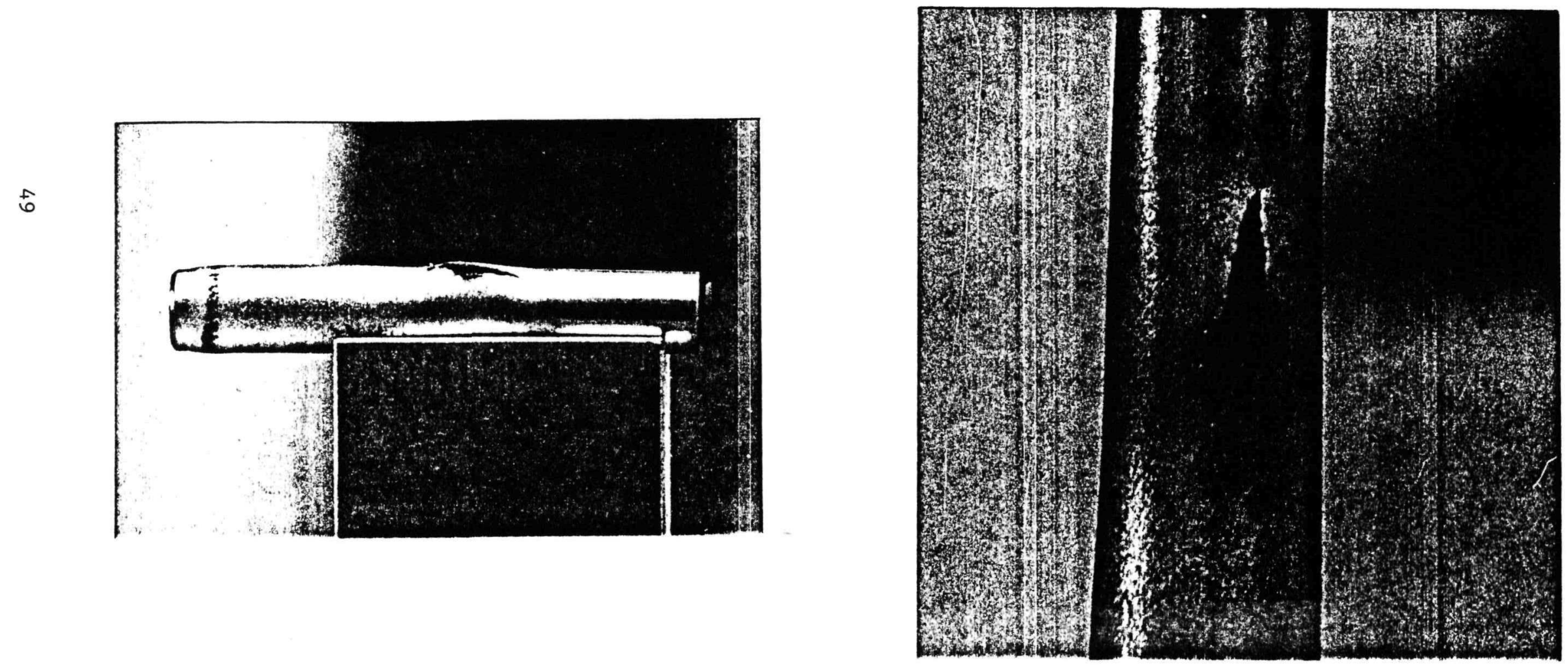

Figure 6-4. UFAC-1B fueled emitter SUl-5 


\section{UFAC-1B Fueled Emitters SU1-8}

Emitter Thickness: 0.020 inch

Fuel Form: Solid

Emitter Surface Temperature: $1700 \mathrm{~K}$ (Revised Calculation)

Fuel Burnup: 3.2 at.\%

Fast Fluence: $6.8 \times 10^{22} \mathrm{n} / \mathrm{cm}^{2}$
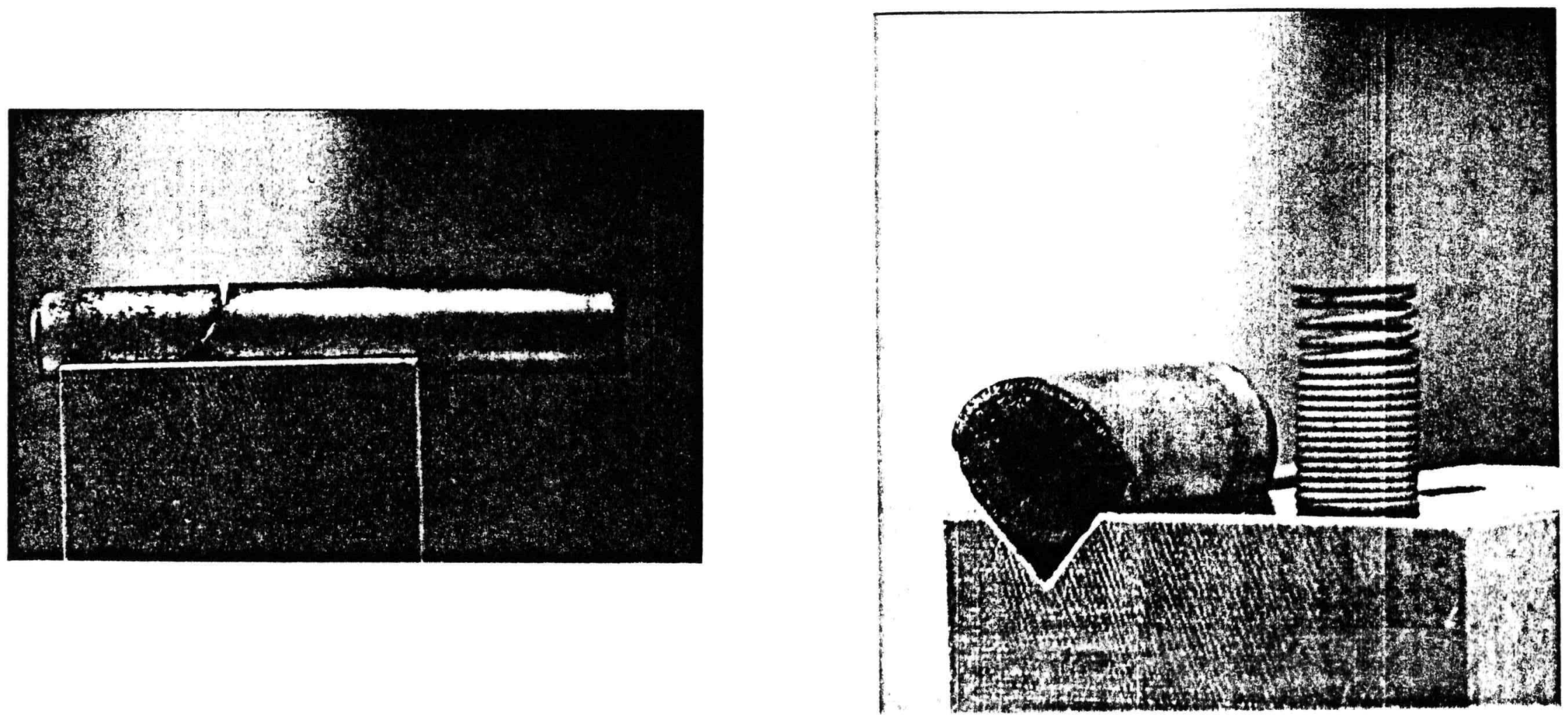

Figure 6-5. UFAC-1B fueled emitter SU1-8. 


\section{UFAC-1B Fueled Emitters SU1-9}

Emitter Thickness: 0.025 inch

Fuel Form: Annular

Emitter Surface Temperature: $1580 \mathrm{~K}$ (Revised Calculation)

Fuel Burnup: 4.3 at.\%

Fast Fluence: $7.6 \times 10^{22} \mathrm{n} / \mathrm{cm}^{2}$
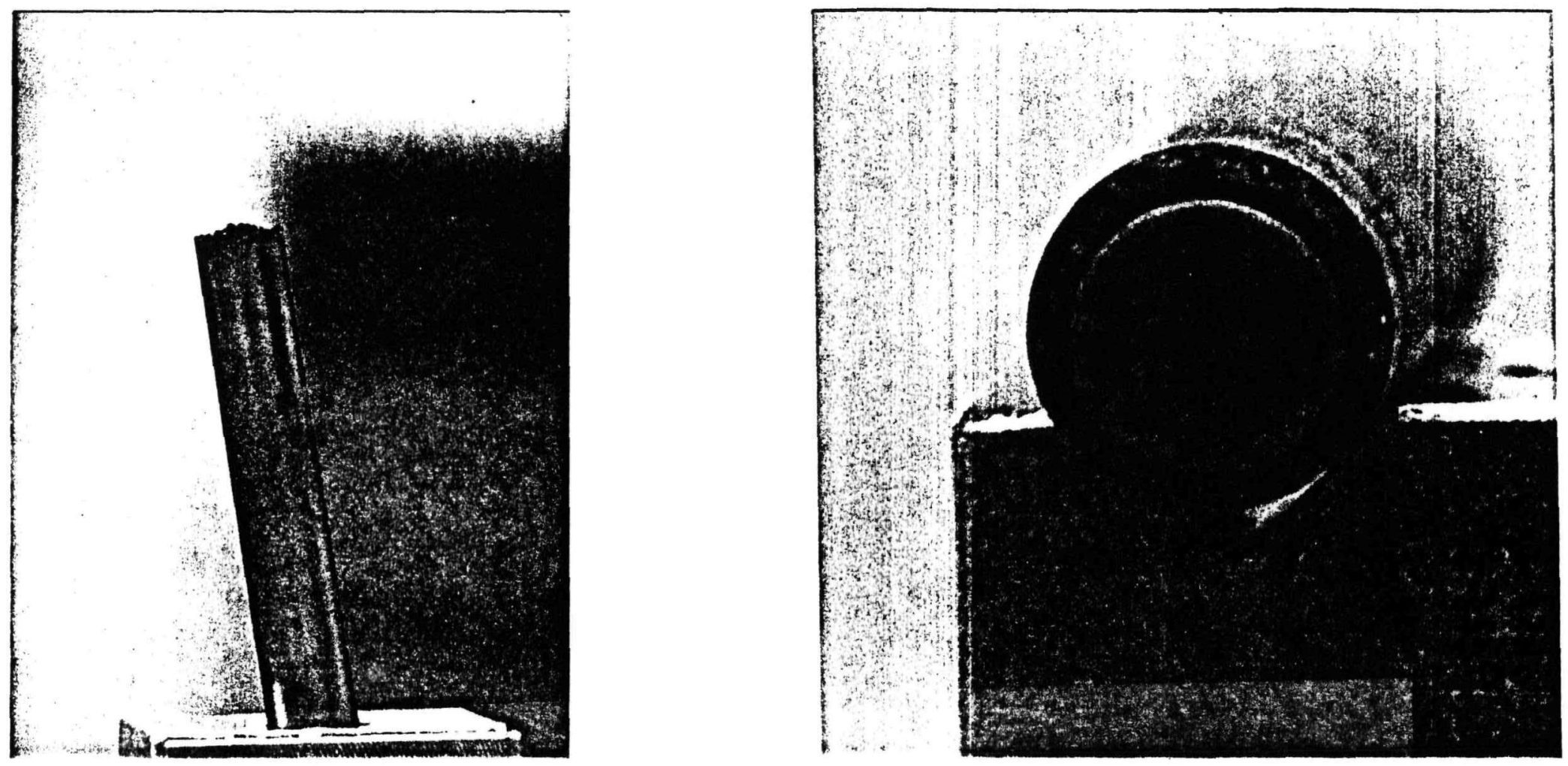

Figure 6-6 - UFAC-1B fueled emitter SUl-9 
specimen. This excessive temperature increase, when combined with the detrimental effect that the fast neutron fluence has on material properties, could well account for the fractures observed in areas other than the W-Ta bond. It is also the explanation for the large emitter deformation discussed earlier which occurred after 5292 test hours but before 12,449 hours.

A LIFE-4 analysis of SU1-5 emitter deformation as a function of possible test specimen temperature is consistent with the observed data. LIFE- 4 is not accurate at the projected high temperatures but inferences are persuasive.

Emitter diameter measurements. The extremely brittle condition of the four emitters dictate that great care be exercised when measuring emitter diameters. Efforts are in progress to adapt the profilometer to measure diameter with the emitters fully supported. The system will be ready for a trial run the first week of January.

\subsubsection{UFAC-2 Status}

UFAC-2 continued on irradiation testing through EBR-II Run 155 and is currently in Run 156. The status of the capsules as of December 31, 1990 is shown in Table 6-2. Neutron radiographs (NR's) will be taken after Run 156, in April 1991, when the burnup will be about 2 a/o.

\subsubsection{UFAC-3 Status}

UFAC-3 was removed from the reactor for the first interim examination April 1, 1990 at the end of Run 153. The three emitters were intact. The plenum springs were partially collapsed suggesting operating temperatures consistent with the design emitter surface temperature of $1800 \mathrm{~K}$.

The capsules were reassembled into UFAC-3A for continued irradiation in Run 154, which was completed September, 1990. The capsules were reconstituted into UFAC-3B with irradiation beginning December 20, 1990 in Run 156. Neutron radiographs are planned at the end of Run 156. 
Neutron radiographs taken after Run 153 yielded the results summarized below.

1) SU3-16. This emitter, which is a Batch-1 replica, was intact with a well formed central fuel cavity. The condition of the test specimen looked good.

2) SU3-17. The NR showed both the central enriched and annular depleted regions to be well formed and without any evident cracks. There appears to be some slight diffusion of the enriched fuel into the region between the depleted annular pellets. Otherwise there appears to be no diffusion of either the enriched or depleted fuel. The condition of the test specimen looked good.

3) SU3-20. The NR showed an equilibrium condition between the fuel and tungsten wafers without any large mass movement. Each fuel wafer appears to have a radially oriented central cavity indicating that the heat generated in the fuel is being transferred axially into the tungsten wafers and then radially out to the emitter for rejection. The condition of the test specimen looked good.

\subsubsection{Postirradiation Examinations - GA Hot Ce11}

The GA hot cell was opened during August 1990 primarily to perform postirradiation examination of Capsule 2 which was originally fabricated as part of the SP-100 Thermionic Technology Program. Components from previously disassembled Capsules 1 and 3 and insulators form Capsule 4 were also examined. Details of this effort were presented in Ref. 6-2.

The examinations consisted of:

1) Gamma scanning of the fission gas plenums, spiral fission gas tubes, and the lower end of the capsule over the emitter region.

2) Visual examination of the components.

3) Measurement of the diameters and lengths of the emitters. 
4) Room temperature electrical resistance measurements on the insulators from Capsule 4 .

Gamma scanning. Gamma scans of the fission product plenums and the fission product lines were taken. The activity of both the plenums and the lines was found to be extremely low; relative count rates are summarized in Table 6-9.

Visual examinations. The visual examination showed that the three emitters had longitudinal cracks in the fuel region not previously detected from the neutron radiographs. The operating conditions for each emitter and possible causes for the failures are discussed below.

TABLE 6-9

GAMMA SCAN RESULTS FROM CAPSULE 2: RELATIVE COUNT RATE

$\underline{\mathrm{K}-85} \underline{\mathrm{C}_{s}-134} \quad \underline{\mathrm{C}_{s}-137} \quad \underline{\mathrm{C}_{0}-58} \quad \underline{\mathrm{C}_{0}-60} \quad \underline{\mathrm{Mn}-54}$

$\begin{array}{lllllll}\text { Fission product plenums } & 320 & 18 & 160 & 1 & 7 & 2\end{array}$

Fission product lines

Emitter 1

Lower spiral

Middle spiral

Upper spiral

Emitter 2

Lower spiral

Middle spiral

Upper spiral

Emitter 3

Lower spiral

Middle spiral

Upper spiral

$\begin{array}{rllll}6 & 650 & 4 & 43 & 7 \\ 4 & 480 & 3 & 33 & 6 \\ 5 & 250 & 3 & 19 & 4 \\ 63 & 860 & 4 & 44 & 8 \\ 57 & 570 & 4 & 36 & 8 \\ 68 & 240 & 2 & 19 & 4 \\ 15 & 670 & 4 & 43 & 7 \\ 34 & 820 & 4 & 36 & 7 \\ 9 & 360 & 2 & 18 & 4\end{array}$

Emitter 2.1, the uppermost in the capsule, had an external short from the very inception of the irradiation testing. The emitter, however, could be partially ignited during about 34,000 hours of irradiation. The operating emitter temperature was very uncertain and could have been significantly higher than design because of the low electron cooling component of the heat balance on the emitter. 
Emitter 2.2 yielded high quality data for 20,255 hours, during which the emitter temperature was estimated to about $1850 \mathrm{~K}$. The I/V curves slowly degraded and gave an indication of a short after about 26,000 hours of irradiation. At that time, with the loss of electron cooling, emfter temperatures could have been excessive.

TABLE 6-10

EMITTER TEMPERATURES

\begin{tabular}{ccccc} 
Ce11 & $\begin{array}{c}\text { Hours of } \\
\text { Useful Data }\end{array}$ & $\begin{array}{c}\text { Emitter } \\
\text { Thickness } \\
\text { mils }\end{array}$ & $\begin{array}{c}\text { Emitter } \\
\text { Temperature } \\
\mathrm{K}\end{array}$ \\
\cline { 2 - 3 } 2.1 & 10,000 & & 100 & 1850 \\
2.3 & 20,255 & 70 & 1850 \\
& 16,000 & 70 & 1750 \\
\hline
\end{tabular}

Emitter 2.3 operated for 16,000 hours in which there was a high degree of confidence in the $1750 \mathrm{~K}$ emitter temperature.

The amount of useful data obtained from each fueled emitter is summarized on Table 6-10. As each emitter deignited and heat transfer was limited to radiation alone, the emitter temperature increased by as much as 300 to $400 \mathrm{~K}$. This is probably the cause of the emitter breaches.

Resistance measurements on Capsule 4 sheath insulators. Resistance measurements were made on the sheath insulators that were recovered from Capsule 4. The samples were separated into two groups, unguarded specimens and guarded specimens. The data presented in Ref. 6-2 are summarized below.

Resistance measurement results for the unguarded specimens are shown in Table 6-11. Results for the guarded specimens are shown on Table 6-12. As can be seen al1 resistances are in the meg-ohm range. 
TABLE $6-11$

UNGUARDED SPECIMEN RESISTANCE MEASUREMENTS

Sample Identification

Serial Number

Resistance, meg-ohms

$5561-103-2$

4966-67-2

$5561-103-4$

4966-65-b

$5561-103-1$

.17 to .30

5 to 43

$>100$

5 to 9

2.7 to 3.5

TABLE $\quad 6-12$

GUARDED SPECIMEN RESISTANCE MEASUREMENTS

\begin{tabular}{|c|c|}
\hline $\begin{array}{c}\text { Sample ID } \\
\text { Serial Number } \\
\end{array}$ & $\begin{array}{c}\text { Resistance } \\
\text { meg-ohms }\end{array}$ \\
\hline $\begin{array}{l}8978-12-D \\
8978-12-a\end{array}$ & $\begin{array}{l}>37 \\
>54\end{array}$ \\
\hline
\end{tabular}

References

6-1 GA-A20119, TFE Verification Program, Semiannual Report for the Period Ending March 31, 1990, issued in July 1990.

6-2 GA-A20335, TFE Verification Program, Semiannual Report for the Period Ending September 30, 1990, issued in March 1991. 


\section{CESIUM RESERVOIR AND INTERCONNECTIVE TFE COMPONENTS}

\subsection{OBJECTIVE}

The overall objective of the ceslum reservoir and interconnective TFE components task is to develop and validate the performance of cesium reservoirs and interconnective TFE components, such as intercell insulation, fission product vents and fission product traps. In particular, the objectives are:

1. Design integral cesium reservoirs and interconnective TFE components.

2. Develop required fabrication processes for integral cesium reservoirs and interconnective TFE components and document the process specifications.

3. Fabricate integral cesium reservoirs and interconnective TFE components for in-reactor and ex-reactor tests.

4. Verify the performance characteristics and lifetimes associated with integral cesium reservoirs and interconnective TFE components by means of in-reactor and ex-reactor testing.

5. Develop an analytical model of the performance and lifetime of the Cs reservoir and interconnective TFE components.

\subsection{TASK DESCRIPTION}

The integral cesium reservoir and interconnective TFE tasks consists of five subtasks:

1. Cesium reservoir and interconnective TFE components design. Design integral cesium reservoir test specimens consistent with the TFE design requirements. Design test specimens of intercell insulation and interconnective TFE components such as TFE end 
restraint and fission product traps, ports and tubes consistent with TFE design requirements.

2. Fabrication development. Determine integral cesium reservoir materials with the capability for storing cesium either as intercalation compounds or as sorption reservoirs. Develop systems for containing the integral reservoir material in a TFE environment. Select insulator materials such as $\mathrm{Al}_{2} \mathrm{O}_{3}, \mathrm{Y}_{2} \mathrm{O}_{3}$ and YAG and develop processes for fabricating TFE end restraints and intercell insulation components. Develop materials for use as fission product traps and develop components for fission product vent and port tubes.

3. Ex-reactor testing. Perform ex-reactor tests to determine the cesium pressure of integral reservoir materials as a function of cesium loading and temperature. Examine the ability of intercell insulation coatings to reduce parasitic discharges. Determine the mechanical stability of TFE end restraints.

4. In-reactor testing. Determine the effect of fast neutron fluence on the stability of the pressure versus temperature characteristics of integral cesium reservoirs at a fixed cesium loading. Also examine the mechanical stability of prototypical TFE end restraints and intercell insulation coatings. Determine fission product release characteristics from the fuel and evaluate the effectiveness of the fission product control components and assemblies.

\subsection{PROGRESS DURING PRESENT REPORTING PERIOD}

\subsubsection{Cs-Graphite Reservoir Mode1 Development}

A functional model describing the operation of a cesium intercalated graphite reservoir was developed. The model describes the structure and thermodynamics of the Cs-graphite compound and provides a qualitative explanation of neutron induced dimensional changes. The reservoir model 
also incudes a description of transient response during reactor startup. Many features of this model have been described in previous semiannual reports, and, in these instances, only a brief mention will be given here. A document giving a full description of the reservoir model has been written and will be released shortly (Ref. 7-1).

Physical description of the model. The classical model of an intercalation compound is one in which the cesium atoms are evenly distributed within the occupied layers. Nearest neighbor occupied layers are separated by a number of carbon layers (or graphite layer planes) determined by the staging of the compound, i.e., in a second stage compound, two carbon layers separate each layer of cesium atoms. The stoichiometry of these compounds is given by $\mathrm{C}_{8} \mathrm{Cs}$ and $\mathrm{C}_{10} \mathrm{Cs}$ for first stage compounds and $\mathrm{C}_{12 \mathrm{n}} \mathrm{Cs}$ for higher stage compounds, where the stage is given by the index $\mathrm{n}$. This classical model presents conceptual difficulties when attempting to describe the kinetics of formation of the intercalation compounds. These difficulties are associated with the order in which the interlaminar layers are filled with Cs. In the classical model, all layers must be filled initially, and then selectively depopulated, leaving only those filled layers that are thermodynamically favored by the existing pressure and temperature. Similarly, an increase in staging (increase in $\mathrm{n}$ ) resulting from a consumption of cesium requires that the graphite expel all the cesium and refill, according to the new equilibrium state. Any other sequence of events requires the cesium to pass through the carbon layers or to anticipate which branch of a complex roadway of reaction paths in phase space leads to a stationary state at the extant pressure and temperature.

A pleated layer, or island model provides a better descripton of the kinetics of formation of the intercalation compounds than does the classical model. Furthermore, there is cosiderable evidence, including experiments conducted in the TFE Verification Program, that this model provides a better explanation of other intercalation phenomena as well. The pleated layer model for second, third and fourth stage intercalation compounds are shown schematically in Fig. 7-1. Note that every interlaminar space contains Cs, but in localized regions (islands) only. In the perpendicular direction, these islands are still separated by the same number of layers as in the 

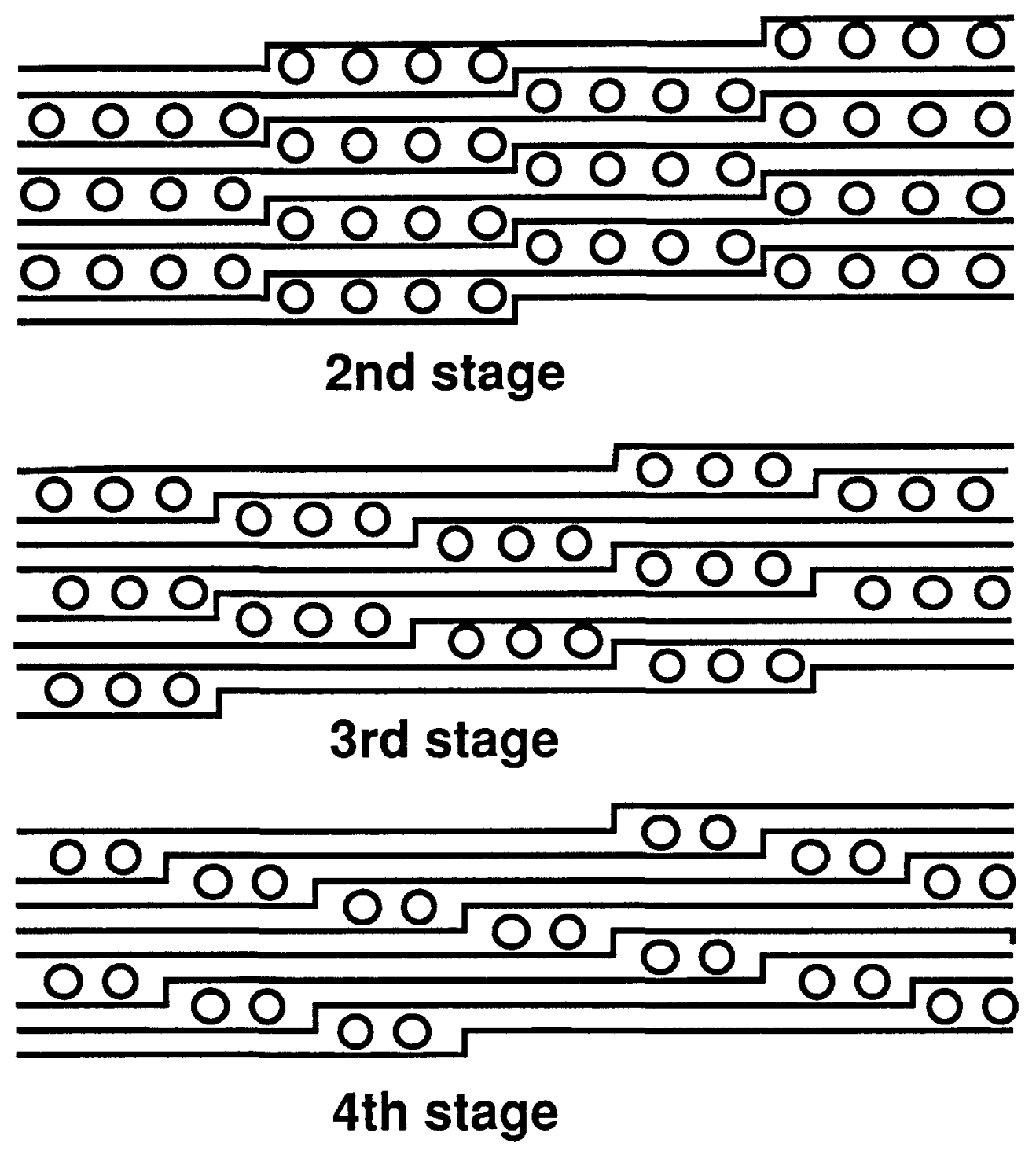

Figure 7-1. Pleated layer model for 2nd, 3rd and 4th stage Cs-graphite intercalation compounds. For $\mathrm{C}_{12 \mathrm{n}} \mathrm{Cs}$ there are $\mathrm{n}$ carbon layers between $C_{s}$ islands, in the vertical direction. Islands of $C_{s}$ in the same interlaminar space are separated by a lateral distance equal to $(n-1)$ islands. The solid lines depict the carbon layers and the open circles depict the cesium atoms. 
classical model and the stoichiometry is still given by $\mathrm{C}_{12 \mathrm{n}} \mathrm{Cs}$. In this island model, transition from, for example, second to third stage is accomplished by a redistribution of Cs atoms within each occupied layer. Initial intercalation, in the context of the island model, allows every layer to accept $C s$ and to retain it. Only the spatial distribution, or island size within the layer is effected by the equilibrium state.

The graphite expands in the direction perpendicular to the layer planes (the c-axis direction) when it is intercalated. This expansion can be calculated from the known graphite spacing and $C s$ ionic radius, and the result has been verified experimentally by numerous investigators. The result is given in Table $7-1$ as the ratio of c-axis dimension after intercalation, $t_{n}$, to initial dimension, $t_{0}$.

An examination of Fig. 7-1 leads to the conclusion that intercalation is accompanied by an a-axis shrinking as well as the c-axis swelling of Table 7-1. This would result from the "pleating" of the carbon layer planes around the cesium islands. This effect has not been reported in the literature as yet.

TABLE 7-1

C-AXIS SWELLING OF ORIENTED GRAPHITE DUE TO CS INTERCALATION

Stage Compounds Loading, mgCs per gC $t_{n} / t_{0}$

\begin{tabular}{llrl}
\hline 1st & $\mathrm{C}_{8} \mathrm{Cs}$ & 1384 & 1.79 \\
1 st & $\mathrm{C}_{10} \mathrm{Cs}$ & 1108 & 1.79 \\
2nd & $\mathrm{C}_{24} \mathrm{Cs}$ & 461 & 1.40 \\
$3 \mathrm{rd}$ & $\mathrm{C}_{36} \mathrm{Cs}$ & 308 & 1.26 \\
$4 \mathrm{th}$ & $\mathrm{C}_{48} \mathrm{Cs}$ & 231 & 1.20 \\
$5 \mathrm{th}$ & $\mathrm{C}_{60} \mathrm{Cs}$ & 185 & 1.16 \\
\hline
\end{tabular}

Thermodynamics of the model. The vapor pressure of Cs-graphite is given as a function of temperature as:

$$
\ln \mathrm{P}(\mathrm{atm})-\Delta \mathrm{H}^{\circ} / \mathrm{RT}-\Delta \mathrm{S}^{\circ} / \mathrm{R}
$$


where $\Delta H^{\circ}$ and $\Delta S^{\circ}$ are the heat of formation and entropy of reaction, respectively. Experimental values of the $\mathrm{Cs}$ pressure as a function of temperature are shown in Fig. 7-2 which shows the isosteres for the UCA-3 reservoirs obtained in the laboratory at General Atomics.

The values of the thermodynamic quantities of equation 1 are listed in Table 7-2, along with the values given in the earlier work of Salzano and Aronson (Ref, 7-2). For intermediate values of loading, the Cs pressure is best described by utilizing the $\Delta H^{\circ}$ value from the nearest isostere of Fig. 7-2 and adjusting the value of $\Delta S^{\circ}$ to force the new isostere to pass through the loading point of the reservoir in question.

TABLE 7-2

COMPARISON OF THERMODYNAMIC VALUES

Salzano and Aronson Present Work

\begin{tabular}{ccccc}
\hline $\begin{array}{l}\text { Loading } \\
\mathrm{mgCs} / \mathrm{gC}\end{array}$ & $\begin{array}{c}\Delta \mathrm{H}^{\circ} \\
\mathrm{cal} / \mathrm{mol} \mathrm{Cs}\end{array}$ & $\begin{array}{c}\Delta \mathrm{S}^{\circ} \\
\mathrm{cal} / \mathrm{mol} \mathrm{Cs}-\mathrm{K}\end{array}$ & $\begin{array}{c}\Delta \mathrm{H}^{\circ} \\
\mathrm{cal} / \mathrm{mol} \mathrm{Cs}\end{array}$ & $\begin{array}{c}\Delta \mathrm{S}^{\circ} \\
\mathrm{cal} / \mathrm{mol} \mathrm{Cs}-\mathrm{K}\end{array}$ \\
\hline & & & & -8.3 \\
378 & $-31,000$ & -16.9 & $-22,500$ & -10.3 \\
396 & $-29,400$ & -19.4 & $-23,782$ & -10.0 \\
586 & $-29,400$ & -19.4 & $-23,428$ & -13.2 \\
\hline
\end{tabular}

Dimensional changes. Dimensional changes in anisotropic graphite due to Cs interaction were discussed above. The values of $t_{n} / t_{0}$ shown in Table 7-1 can be extended to the case of an isotropic graphite by considering the latter to be an isotropically distributed collection of oriented crystallites, with each crystallite behaving according to Table 7-1. The result can be determined with reference to Fig. 7-3. In this figure, $\Delta L$ is the expansion (contraction) of a crystallite in the direction d $\theta$ about $\theta$. In the case of graphite, the dimensional change would be in the direction of either the a-axis or the c-axis, $\Delta \mathrm{L}_{\mathrm{a}}$ or $\Delta \mathrm{L}_{\mathrm{c}}$ respectively. We wish to compute the dimensional change in the $Y(X$, or $Z)$ axis direction, i.e., the quantity $\Delta \mathrm{L}_{\mathrm{y}}$ averaged over all orientations, for an isotropic distribution of $\Delta \mathrm{L}$. The result is given in equation (2): 


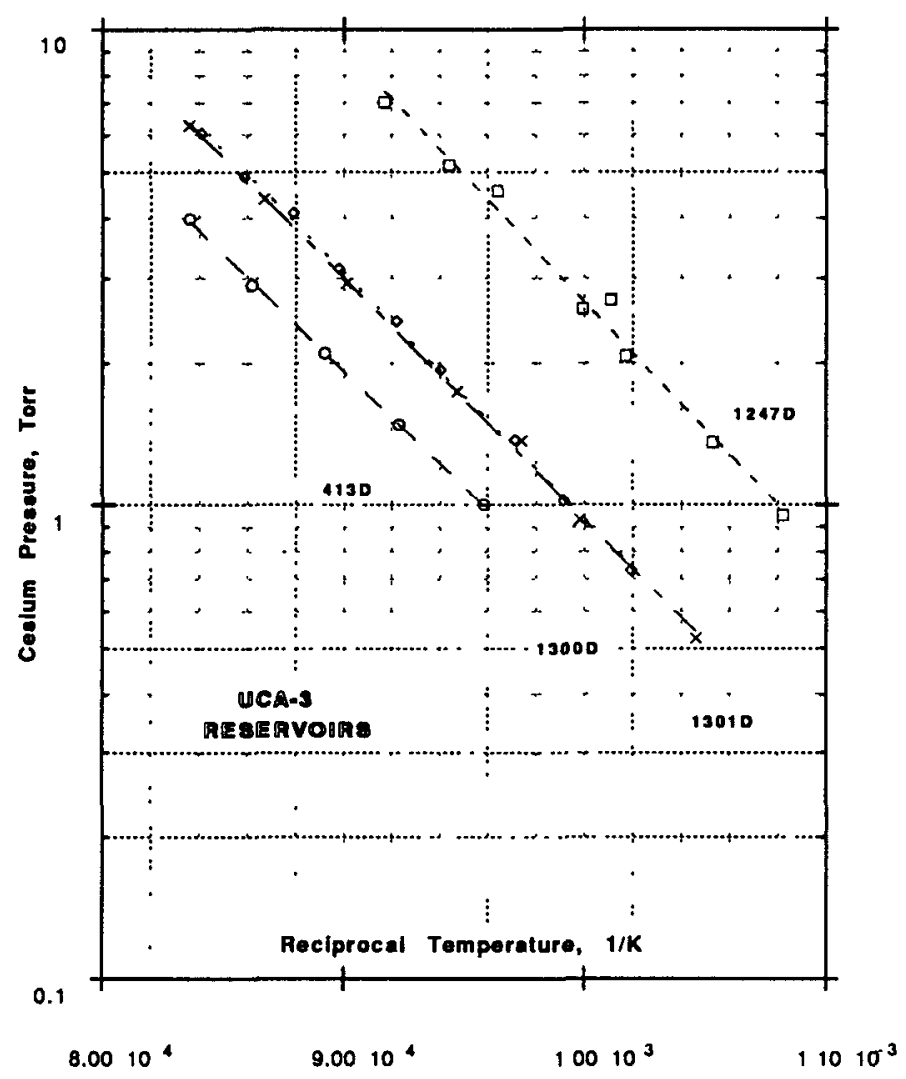

Figure 7-2. Experimental Cs pressure vs graphite temperature.

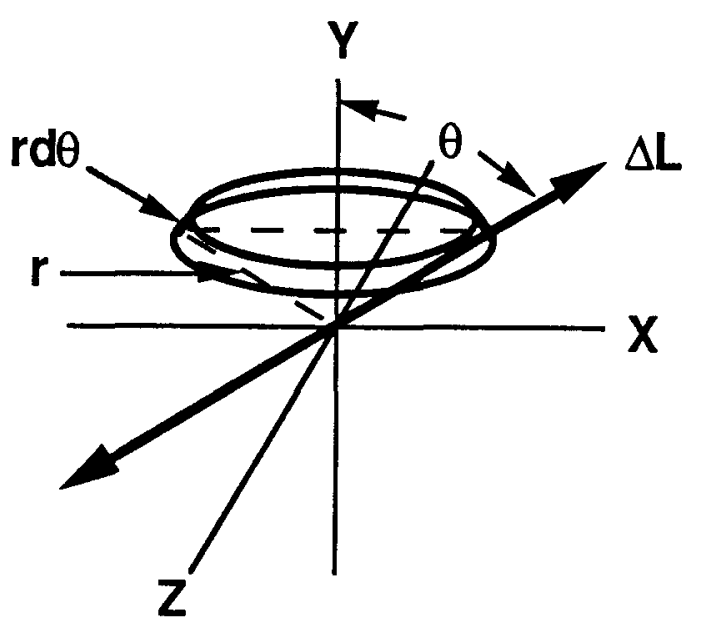

Fig. 7-3. Coordinate system for calculating dimensional changes in an isotropic material composed of a collection of anisotropic crystallites. 


$$
\begin{aligned}
\Delta \mathrm{L}_{\mathrm{y}} & =\int_{0}^{\frac{\pi}{2}}\left(\Delta \mathrm{L}_{\mathrm{c}} \cos \theta\right)\left(\frac{2 \pi \mathrm{r} \sin \theta \mathrm{rd} \theta}{4 \pi \mathrm{r}^{2}}\right) \\
& =\frac{\Delta \mathrm{L}_{\mathrm{c}}}{4} \int_{0}^{\frac{\pi}{2}} \sin 2 \theta \mathrm{d} \theta=\frac{\Delta \mathrm{L}_{\mathrm{c}}}{4}
\end{aligned}
$$

In this equation, c-axis expansion is explicitly considered. The first term in parentheses is the projection of $\Delta L_{c}$ on the $Y$-axis and the second parenthetical term is the isotropic distribution function.

To demonstrate the utilization of this result, consider that POCO graphite is an isotropic assemblage of HOPG crystallites. The c-axis expansion resulting from $C s$ intercalation, in an oriented graphite such as HOPG, is well documented and given in Table 7-1 above. Table 7-3 gives this linear expansion as $t_{n} / t_{0}$ and the corresponding value for POCO as $1_{n} / 1_{0}$. For POCO, the volume expansion, $\mathrm{V}_{\mathrm{n}} / \mathrm{V}_{\mathrm{O}}$, is also given.

TABLE 7-3

EXPANSION OF GRAPHITE UPON CS INTERCALATION

\begin{tabular}{lccccc} 
Stage & Compound & Loading & $\begin{array}{c}\text { Anisotropic } \\
\mathrm{t}_{\mathrm{n}} / \mathrm{t}_{\mathrm{o}}\end{array}$ & \multicolumn{2}{c}{ Isotropic } \\
$1_{\mathrm{n}} / 1_{\mathrm{o}}$ & $\mathrm{V}_{\mathrm{n}} / \mathrm{v}_{\mathrm{o}}$ \\
\hline 1st & $\mathrm{C}_{10} \mathrm{Cs}$ & 1108 & 1.79 & 1.2 & 1.73 \\
$2 \mathrm{nd}$ & $\mathrm{C}_{24} \mathrm{Cs}$ & 461 & 1.40 & 1.1 & 1.33 \\
$3 \mathrm{rd}$ & $\mathrm{C}_{36} \mathrm{Cs}$ & 308 & 1.26 & 1.06 & 1.19 \\
$4 \mathrm{th}$ & $\mathrm{C}_{48} \mathrm{Cs}$ & 231 & 1.20 & 1.05 & 1.16 \\
\hline
\end{tabular}

In the anisotropic case, $C s$ intercalation does not introduce any stress into the graphite lattice. There is, however, a considerable force associated with the expansion; it can be sufficient to distort the metal containers in which the intercalation is performed. In an isotropic graphite, however, the expansion of the individual crystallites is constrained by their nearest neighbors, as a result of the random orientation. This constraint introduces 
considerable stress into the specimen, making it friable. However, like the oriented material, the isotropic material can exert a considerable force on its surroundings before its yield point is reached. Thus the values of $1_{n} / 1_{o}$ In Table 7-3 must be taken into account when designing a reservoir containment volume for an isotropic Cs-graphite reservoir. Also, means must be provided to prevent broken fragments of cesiated graphite from migrating into regions of the converter where they could present a problem. This could be accomplished by installing screen or increasing the tortuosity of the channels connecting the reservoir and the interelectrode space. It must be emphasized that the pressure vs temperature characteristics of the Csgraphite are uneffected by fragmentation.

Operational considerations. In an integral reservoir design, the (graphite) reservoir is located in the converter envelope and its temperature is determined passively by the electrode temperatures. Specifically, the reservoir temperature can be closely related to the collector temperature.

When the reservoir is located in the collector, a high emitter temperature excursion could occur during start unless the startup is handled carefully. This results from the fact that a major portion of the heat transport to the collector is due to the electron current. However the electron current is low until the $C s$ pressure becomes appreciable. The Cs pressure is low until the collector temperature is elevated. Lacking the electron cooling current, the emitter temperature could overshoot until the cesium pressure increases.

For a highly simplified case, Gietzen (Ref. 7-3) has quantified this seqence of events. He considers a converter in which the reservoir is thermally coupled to both the emitter and the collector by parametrically variable radiation and conduction terms. For the special case where the reservoir is at the collector temperature, the $\mathrm{J}-\mathrm{V}$ characteristics are shown in Fig. 7-4. At low $C s$ pressures and emitter temperatures below about $2200 \mathrm{~K}$, the converter does not operate in the power-producing quadrant. The startup trajectory for a fixed load resistance can be followed in Fig. 7-4 by adding a load line through the design operating point as shown. At zero heat input the output of the converter is zero as shown by point $A$ on the 
load line. As the heat input is increased, the operating point moves along the load line toward point $B$. The low collector temperature, and therefore low $C s$ pressure, forces the operating point to fall on the low current branch of the J-V curve, between points $A$ and $B$, rather than on the high temperature branch between $B$ and $C$. At point $B$, the $C s$ pressure is sufficiently high that electron cooling becomes appreciable, which also causes the graphite to heat up. Above $B$, the $C s$ pressure increases and the emitter temperature decreases until $C$ is reached. At point $C$, the heat conduction to the collector by the electron current has dropped, due to the lowering emitter work function, to a point such that the Cs pressure is too low. At this point, the emitter heats back up in the usual fashion until the operating point $D$ is reached. This same sequence of events is depicted in Fig. 7-5.

Gietzen also calculated the J-V characteristics for other reservoir locations. In one, it was coupled to the emitter by radiation and to the collector by both radiation and conduction. This is shown in Fig. 7-6. In this case the emitter temperature doesn't rise above the design temperature during startup.

Although the thermal coupling model will prevent high temperature excursions during startup, the concomitant mechanical design in a compact converter is very difficult. Qualitatively the same effect can be achieved by raising the collector temperature slightly during startup. An additional consideration is suggested by Figs. 7-4, 7-5 and 7-6. Up to this point, a constant load resistance has been assumed, If the load resistance changes during startup, the situation will be altered. In particular, if the load resistance increases during startup, a higher temperature excursion can occur. On the other hand, a lower resistance during startup will reduce the magnitude of the temperature excursion. It may be advisable to consider programming a power conditioner appropriately during reactor startup.

\subsubsection{UCA-3 Irradiations}

The preirradiation $x$-radiographs of the four Cs-graphite reservoir samples prepared for the UCA-3 tests show that all four POCO graphite discs were broken into smaller pieces, as seen in Fig. 7-7. The tantalum inner 

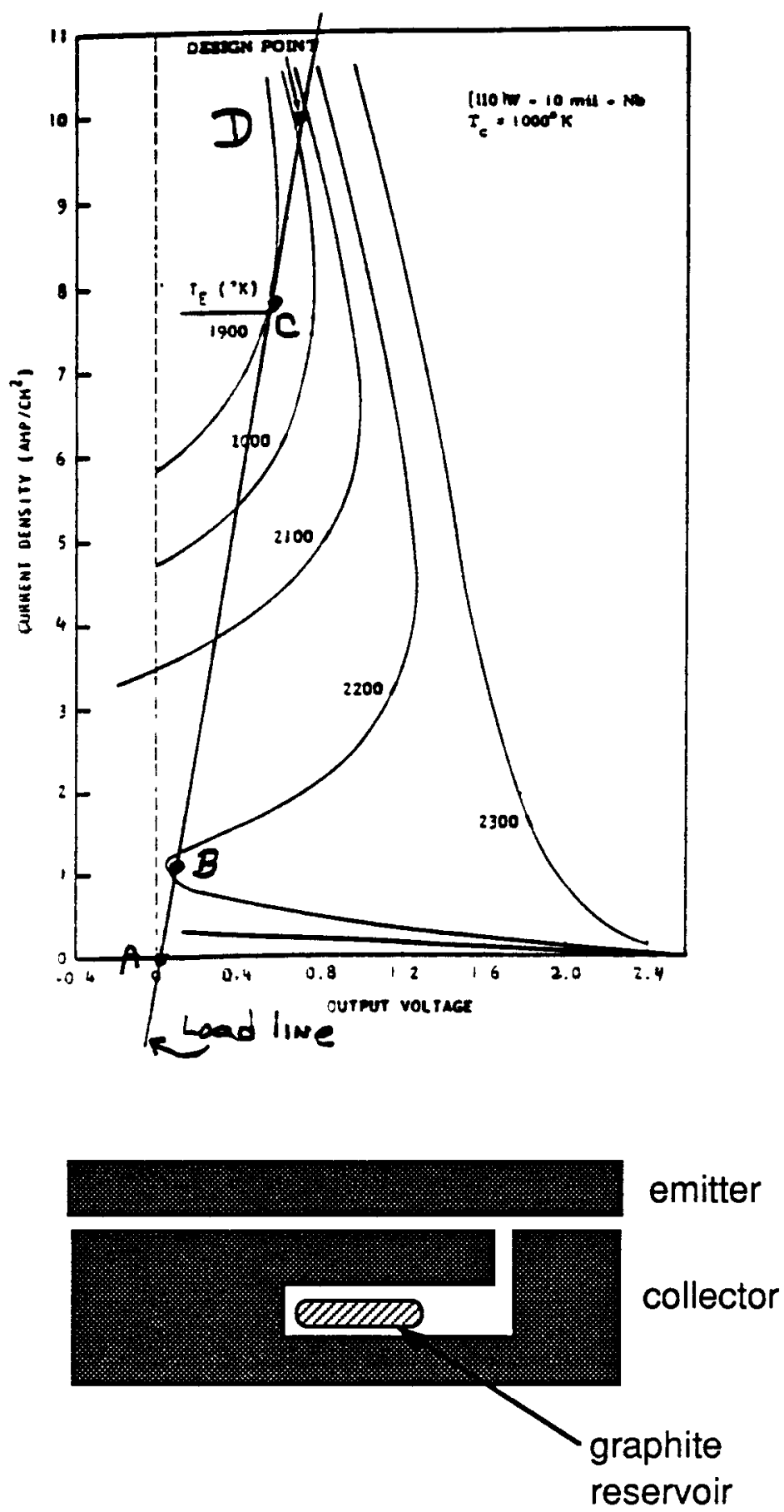

Fig. 7-4 - Converter performance for reference case, with reservoir at the collector temperature. A load line for a constant resistive load is shown. Computational results from Gietzen, 1969. 


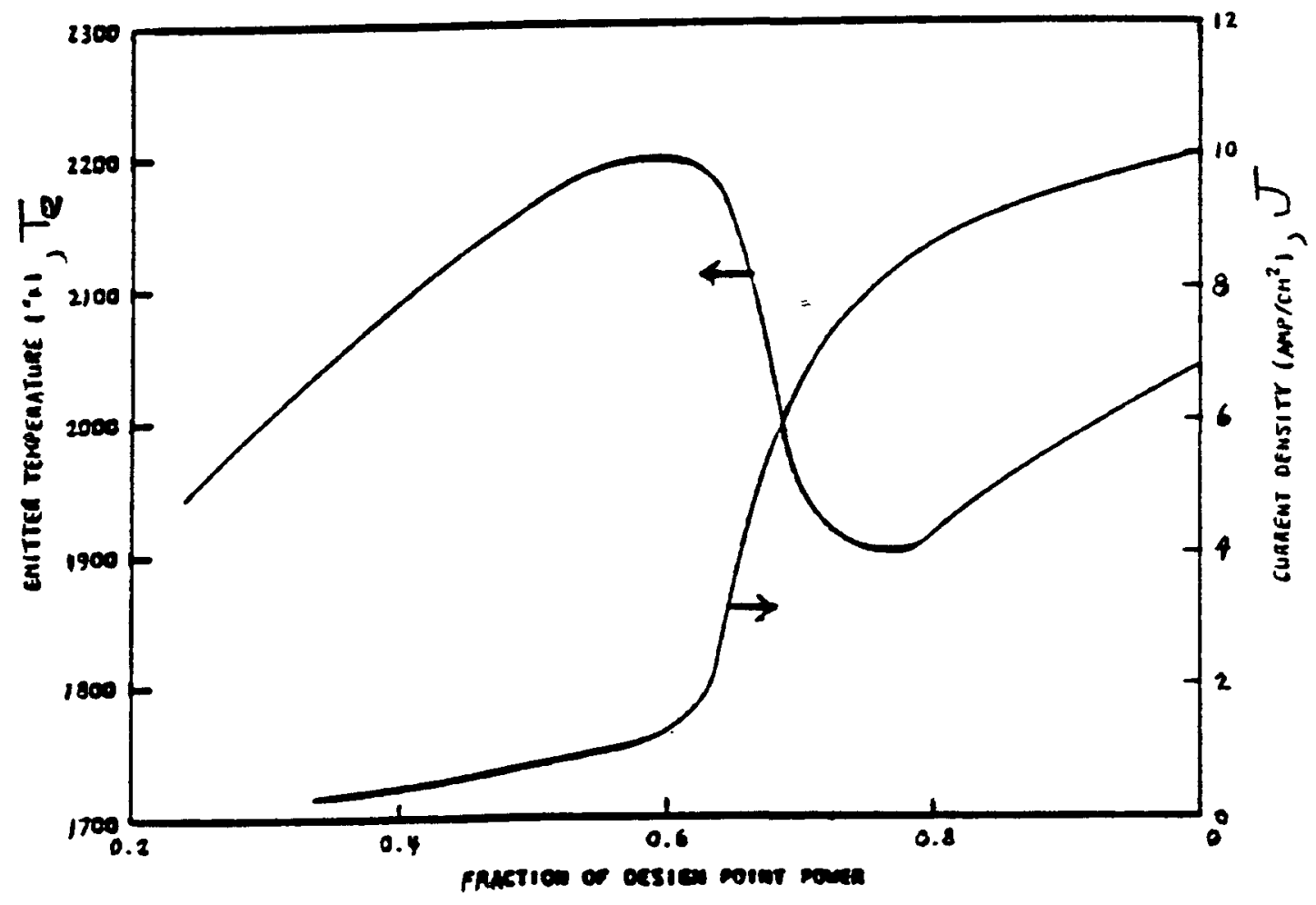

Fig. 7-5 - Emitter temperature and current density dependence on input power at constant load resistance. From Gietzen, 1969. 

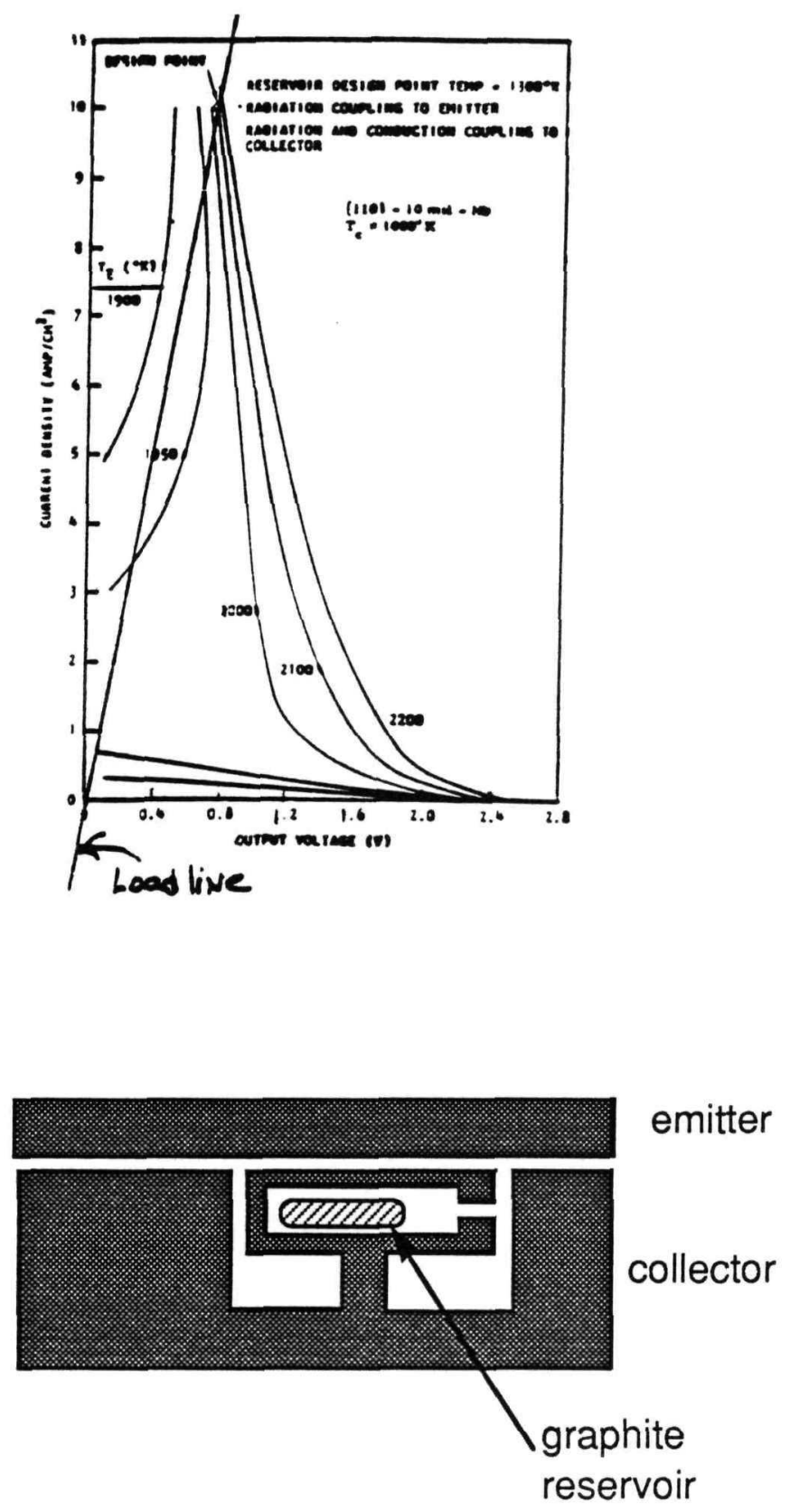

Fig. 7-6 - Converter performance for reference case with reservoir temperature determined by radiative coupling to both emitter and collector and also conductive coupling to the collector. Constant resistance load line. Computation from Gietzen, 1969. 

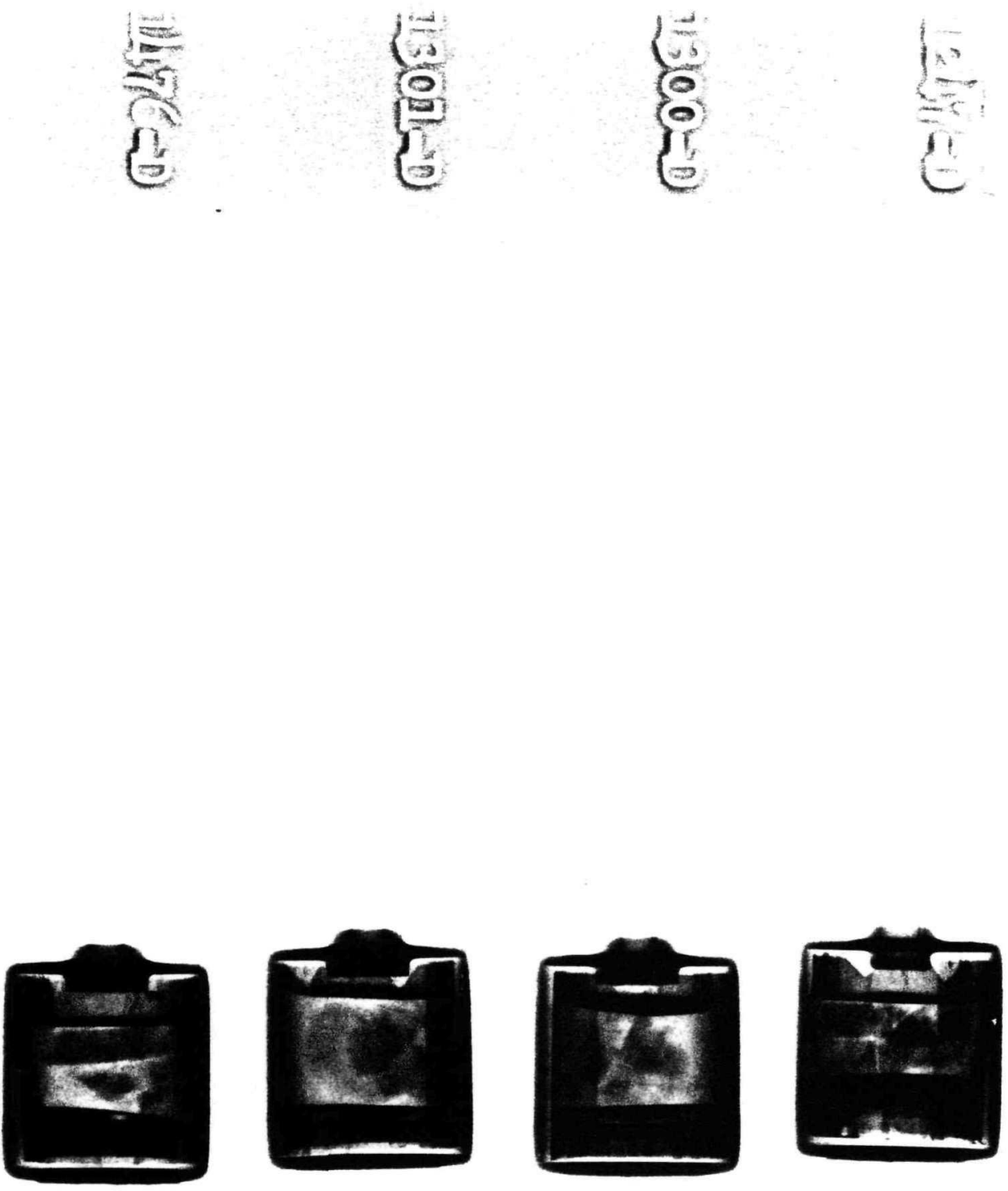

Figure 7-7. X-ray radiographs of the four UCA-3 POCO reservoir samples 
liner for two the specimens showed a localized hoop distortion at the original location of the graphite discs, resulting from a diametral expansion of the discs.

Since the breakup of the discs will not prejudice the intent of the UCA-3 test, the specimens were encapsulated and are being irradiated in EBR-II, as originally scheduled.

A reexamination of the documented history of the four UCA-3 reservoir samples indicates that there were two occurrences that led to the breakup of the graphite discs. Two of the graphite samples were loaded to a high level during processing, then loaded to their final, lower value before pinchoff.

This higher loading was sufficient to cause the hoop distortion and to stress the discs sufficiently to cause breakage. The other two discs were never loaded to a level higher than their final level, which was insufficient to cause breakage by itself. However when the encapsulated parts were being removed from the electron beam welder, they were dropped. Breakage occurred at that time, due to the internal stress in the isotropic graphite resulting from intercalation.

For mixed stage compounds, like the UCA-3 samples shown in Table 7-4, the oriented expansion was calculated assuming that it was due to a proportionate mixture of the adjacent compounds. Thus sample $\# 1247$, with a loading of $950 \mathrm{mg} \mathrm{Cs} / \mathrm{gC}$, would behave as a mixture of $75.6 \% \mathrm{C}_{10} \mathrm{Cs}$ and $24.4 \% \mathrm{C}_{24} \mathrm{Cs}$, with a resultant oriented expansion of 1.69 , or an isotropic expansion of 1.17 , giving a maximum diameter of .496 inches.

In Table 7-4, the maximum diameter and thickness calculation is based on the maximum process Cs loading ( $8 \mathrm{th}$ column). Loading values are given in $\mathrm{mg}$ Cs/gC. All graphite specimens are POCO CZR-2. The inside diameter of the tantalum cans was .470", as built. No hoop distortion was observed in the tantalum cans for samples $\# 1300$ and $\# 1301$, and the hoop distortion measurement for \#1476 subject to appreciable error. 
TABLE $7-4$

DIMENSIONAL CHANGES

Serial Original Original Maximum Maximum Hoop Hoop Maximum Final

\# Diameter Thickness Diameter Thickness Diameter Thickness Load Load

\begin{tabular}{rllllllll}
\hline 1247 & $.424^{\prime \prime}$ & $.082 "$ & $.496 "$ & $.096^{\prime \prime}$ & $.515^{\prime \prime}$ & $.105 "$ & 950 & 586 \\
1300 & $.425^{\prime \prime}$ & $.083^{\prime \prime}$ & $.459^{\prime \prime}$ & $.090^{\prime \prime}$ & N/A & N/A & 348 & 348 \\
1301 & $.424^{\prime \prime}$ & $.082^{\prime \prime}$ & $.462^{\prime \prime}$ & $.089^{\prime \prime}$ & N/A & N/A & 396 & 396 \\
1476 & $.424^{\prime \prime}$ & $.081^{\prime \prime}$ & $.509^{\prime \prime}$ & $.097^{\prime \prime}$ & $.50^{\prime \prime}$ & $.10^{\prime \prime}$ & 1130 & 287 \\
\hline
\end{tabular}

As seen from Table 7-4, the processing of samples \#1247 and \#1476 included loading the sample to a value that exceeded the final (test) loading value. These values of maximum loading resulted in a maximum disc diameter during processing, as given in the fourth column of the table, that was calculated from the known dimensional changes in highly oriented graphite, corrected for the isotropic distribution of individual crystallites. These calculated values exceed the original tantalum can diameter, and are very close to the value of the hoop diameter. The logical inference is that the discs expanded during processing and, in the act of stretching the $\mathrm{Ta}$ cans, became sufficiently stressed themselves to fracture. When the final loading of these two samples was performed, they were already in the form of chips.

Samples \#1300 and \#1301 were never loaded with Cs sufficiently to cause a hoop distortion. From the table, their maximum diameter was about .010" less than the inner diameter of the $\mathrm{Ta}$ can. However these two samples, along with sample \#1247, were mounted in a common chill-block when they were installed in the electron beam welder, to be welded into the stainless steel secondary containment. The chill-block was accidently dropped when it was being removed from the vacuum chamber of the welder. Although careful visual examination and He leak detection failed to show any damage, it is now presumed that the breakage of samples \#1300 and \#1301 occurred in this accident. Sample \#1247 was already broken, due to high loading during processing, but additional breakage may have occurred in the accident.

Cesium intercalation does not introduce large stresses in highly oriented graphites, such as HOPG. However in a fine-grained, isotropic 
graphite, such as POCO, large localized strains can be expected at the grain boundaries. Each grain in the POCO experiences a $c$-axis expansion upon intercalation, just as does a monolithic piece of HOPG. However there is a mismatch in the strain of adjacent grains, at the grain boundaries, which gives rise to the internal stress in the material and causes it to fracture easily.

\section{$\underline{\text { References }}$}

7-1 "Functional Model of the Cesium Reservoir for a Thermionic Fuel Element", J. N. Smith, Jr., GA Document 910271, March 1991.

7-2 Salzano, F. J. and S. Aronson, "Thermodynamic Properties of the CesiumGraphite Lamellar Compounds", J. Chem. Phys. 43, 149 (1965).

7-3 "Performance Evaluation of a Thermionic Converter Using a Graphite Integral Reservoir", A. J. Gietzen, IEEE Specialists Conference, Carmel, CA, October 1969. 


\section{THERMIONIC FUEL ELEMENT}

\subsection{OBJECTIVE}

The overall goal of the thermionic fuel element task is to demonstrate that TFEs prototypic of a $2 \mathrm{MW}(e)$ thermionic space nuclear power system of seven year life can be fabricated from well modeled components, and that their performance is as predicted when operated in a prototypic thermionic reactor environment. Derivative goals include:

1) Produce a TFE engineering design and specifications.

2) Develop required TFE assembly processes, process specifications, and demonstrate manufacturing capability.

3) Fabricate TFEs and test them to demonstrate the processes and the integrated performance of the components.

4) Develop and verify a TFE model that can predict TFE performance and lifetime.

Components with demonstrated performance and which are projected to meet lifetime requirements will be used in these TFEs. The performance of one prototypic TFE will be demonstrated in EBR II. Thermionic fuel elements leading up to the prototype will undergo irradiation in the General Atomics Mark F TRIGA reactor.

\subsection{TASK DESCRIPTION}

\subsubsection{Testing Logic}

A11 converters tested in the TFEs will be of the baseline configuration. The balance of the test article will be as close to the baseline TFE design in geometry and performance as practicable. Test and design requirements are compared in Table 8-1. 
TABLE 8-1

COMPARISON OF TFE TEST REQUIREMENTS WITH SYSTEM

BASELINE DESIGN REQUIREMENTS

TFE
Test Requirements Baseline Design (BOL) Requirements (BOL)

\begin{tabular}{|c|c|c|}
\hline Converter power density average $(\mathrm{W} / \mathrm{c}$ & $\mathrm{cm}^{2}$ ) & 3.4 \\
\hline Current density average $\left(\mathrm{A} / \mathrm{cm}^{2}\right)$ & 7 & 7 \\
\hline Emitter temperature average $(\mathrm{K})$ & 1800 & 1800 \\
\hline Collector temperature average $(\mathrm{K})$ & 1070 & 1070 \\
\hline Sheath-collector voltage maximum (V) & \pm 7.5 & \pm 7.5 \\
\hline Converter configuration & Baseline & Baseline \\
\hline TFE materials & $\begin{array}{l}\text { Baseline or variants } \\
\text { for performancel } \\
\text { structural improvements }\end{array}$ & Section 2 \\
\hline Fue1 enrichment (\% U-235) & Variable enrichment & $\begin{array}{l}93 \text {; variable } \\
\text { fuel volume } \\
\text { fraction }\end{array}$ \\
\hline Fast fluence: nominal (E>0.1 Mev) & Real time & $2.7 \times 10^{22} / 7$ years \\
\hline Fuel burnup: nominal (a/o) & 4.1 & 4.1 \\
\hline Cesium reservoir type & Variable with test & Integral graphite \\
\hline TFE environment/heat sink & $\begin{array}{l}\text { Helium/test reactor } \\
\text { coolant }\end{array}$ & Liquid metal ( $L i$ ) \\
\hline Reflector above/below within TFE & No & Yes \\
\hline $\begin{array}{l}\text { Reactor vessel penetration integral } \\
\text { with TFE }\end{array}$ & No & Yes \\
\hline
\end{tabular}


The separate in-reactor tests and the distinctions between them are outlined in Table 8-2. Note that tests $3 \mathrm{H} 2$ thru $3 \mathrm{H} 4$, which were originally proposed, have been deleted.

TABLE 8-2

TFE IN-REACTOR TEST SUMMARY MATRIX

\begin{tabular}{|c|c|c|c|c|}
\hline TFE & Fuel/Emitter & Cs & Purnose & Reactor \\
\hline $1 \mathrm{H} 1$ & $\mathrm{UO}_{2} / \mathrm{W} / \mathrm{Nb}$ & Pool & $\begin{array}{l}\text { Verification of reference cell design } \\
\text { performance and fabrication processes. } \\
\text { Sheath integration. }\end{array}$ & TRIGA \\
\hline $1 \mathrm{H} 2$ & $\mathrm{UO}_{2} / \mathrm{W} / \mathrm{Nb}$ & Graphite & $\begin{array}{l}\text { Verification of integral cesium } \\
\text { reservoir design, performance. }\end{array}$ & TRIGA \\
\hline $1 \mathrm{H} 3$ & $\mathrm{UO}_{2} / \mathrm{W} / \mathrm{Nb}$ & Pool & $\begin{array}{l}\text { Study effect of fission products } \\
\text { mixing with cesium. }\end{array}$ & TRIGA \\
\hline $3 \mathrm{H} 1$ & $\mathrm{UO}_{2} / \mathrm{W} / \mathrm{Nb}$ & Graphite & $\begin{array}{l}\text { Intercell process development. } \\
\text { Fission product control. }\end{array}$ & TRIGA \\
\hline $3 \mathrm{H} 5$ & $\mathrm{UO}_{2} / \mathrm{W} / \mathrm{Nb}$ & Graphite & $\begin{array}{l}\text { Backup to } 3 \mathrm{H} 1 \text {. Introduction of } \\
\text { prototypic components outside cell. }\end{array}$ & TRIGA \\
\hline $6 \mathrm{H} 1$ & $\mathrm{UO}_{2} / \mathrm{W} / \mathrm{Nb}$ & Graphite & $\begin{array}{l}\text { Verification of long-TFE fabricability. } \\
\text { Consider evolutionary improvements. } \\
\text { Verification of fission gas ventings. } \\
\text { Increased voltages. }\end{array}$ & TRIGA \\
\hline $6 \mathrm{H} 2$ & $\mathrm{UO}_{2} / \mathrm{W} / \mathrm{Nb}$ & $\begin{array}{l}\text { Integral } \\
\text { Graphite }\end{array}$ & Backup to $6 \mathrm{H} 1$. & TRIGA \\
\hline $6 \mathrm{H} 3$ & $\mathrm{UO}_{2} / \mathrm{W} / \mathrm{Nb}$ & $\begin{array}{l}\text { Integral } \\
\text { Graphite }\end{array}$ & $\begin{array}{l}\text { Verification of TFE performance in } \\
\text { fast reactor environment. }\end{array}$ & TBD \\
\hline
\end{tabular}

The logic behind this test series is a step-by-step development of the fabrication processes, culminating in the fast reactor prototype. The first step is the development of the processes for a single cell, and the integration of the single cell into a TFE sheath tube with appropriate end fittings. These end fittings involve the cesium reservoir, fission gas venting and the conduction of electrical current produced. This single-cell TFE is designated " $1 \mathrm{H}$ ", where the $\mathrm{H}$ refers to the latest generation of thermionic cell in a megawatt class TFE, and the " 1 " refers to the number of cells in the TFE. 
The second step is the development of the intercell region of the TFE. The test vehicle will be the 3 H-series TFE which w1ll contain three of the $\mathrm{H}$-series cells welded end-to-end in an electrical series circuit. The center cell in the series is isolated from TFE end-fittings and is thereby typical of cells within the interior of a thermionic reactor. The testing of the three cell TFE also allows the study of fission gas venting in a representative multicell environment at a minimum expense.

As the last step in the testing before the fast reactor prototype test, 6H-series TFEs will be built to demonstrate the fabricability of a long TFE where axial alignment is critical. Testing of these TFEs will provide additional demonstration of fission product venting and the capability to maintain unobstructed fission gas passages.

Success in the process development will be evidenced by the observed in-reactor performance and stability.

The following materials and/or components are used in all TFEs:

- Insulator crystal state: polycrystalline

- Emitter body material: W from $\mathrm{WF}_{6}$

- Emitter surface material: W from $\mathrm{WCl}_{6}$

- Emitter stem material: W from $\mathrm{WF}_{6}$

- Length: $.43 \mathrm{in.}$

- Thickness: .020 in.

- Collector material: Nb

- Emitter transition material: tantalum

Other TFE features that vary are shown on Table 8-3.

\subsubsection{TFE Design}

The TFE design has been described in previous semiannual reports (Refs. 8-2 through 8-6). The H-series thermionic converter design is as illustrated in Fig. 8-1, and the representative TFEs for TRIGA test are pictured in Fig. 8-2. 
Table 8-3

TFE TEST MATRIX

$\underline{1 \mathrm{H} 1} \quad \underline{\mathrm{H} 2} \quad \underline{1 \mathrm{H}} 3 \quad \underline{3 \mathrm{H}} 1 \quad \underline{3 \mathrm{H}} 5 \quad \underline{6 \mathrm{H} 1} \underline{6 \mathrm{H} 2} \underline{6 \mathrm{H} 3}$

Emitter cap material

$\mathrm{Ta}$

$\mathrm{Nb}$

Flight fuel holddown

No, use spring

TBD

Volatile fission product trap Location

Material

Optimized design

$\begin{array}{cl}\text { Vac. } & \mathrm{Ce} 11 \\ - & \mathrm{Al}_{2} \mathrm{O}_{3} \\ - & \mathrm{Mo}\end{array}$

TBD

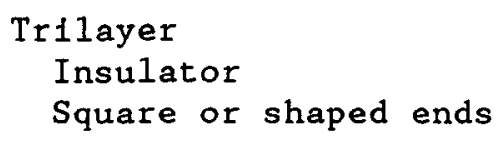

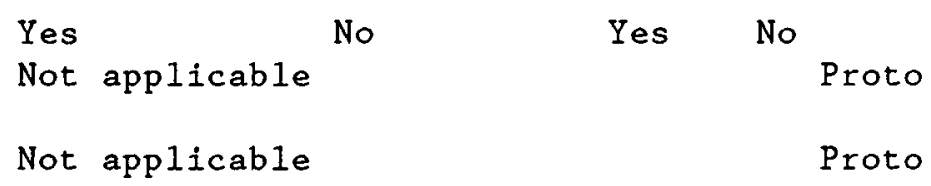


FISSION GAS VENT TUBE INTERCELL INSULATION

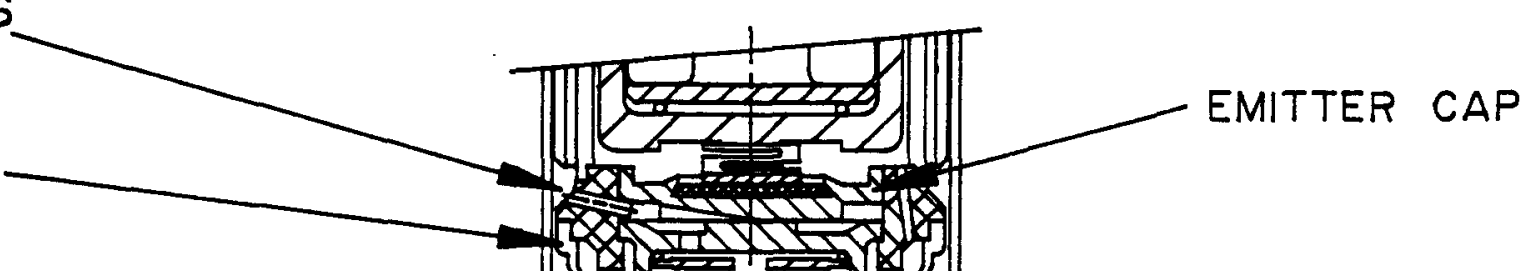

SOLID FISSION PRODUCT TRAP

CERAMIC TO METAL SEAL FUEL HOLD DOWN SPRING EMITTER TRILAYER
SHEATH $\left\{\begin{array}{l}\text { SHEATH INSULATOR- } \\ \text { INNER SHEATH } \\ \text { COLLECTOR }\end{array}\right.$

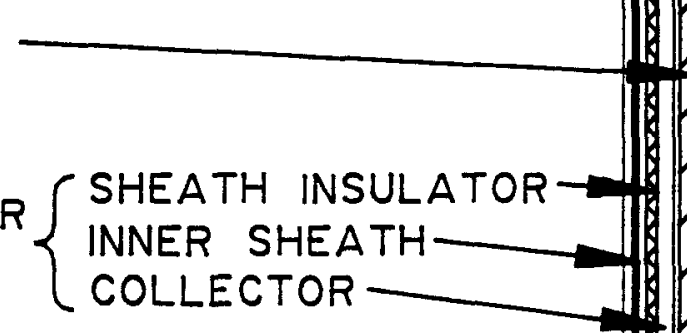

NUCLEAR FUEL

OUTER SHEATH TUBE

FISSION GAS

PASSAGE SLOT

FUEL PEDESTAL

EMITTER ALIGNMENT SPRING
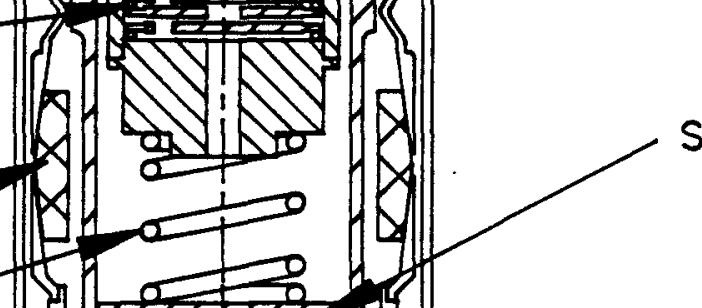
SPACER WIRE

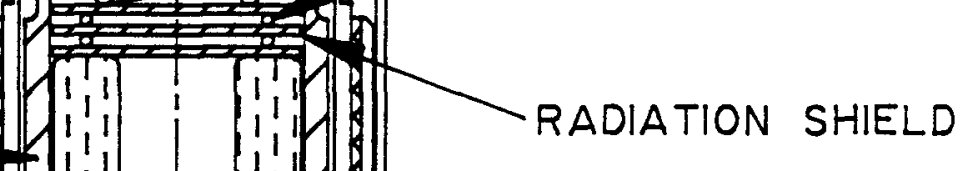

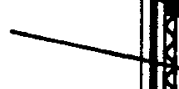
CONVERTER TO
CENVERTER

Figure 8-1. H-series thermionic converter (typical of $3 \mathrm{Hl}$ ) 

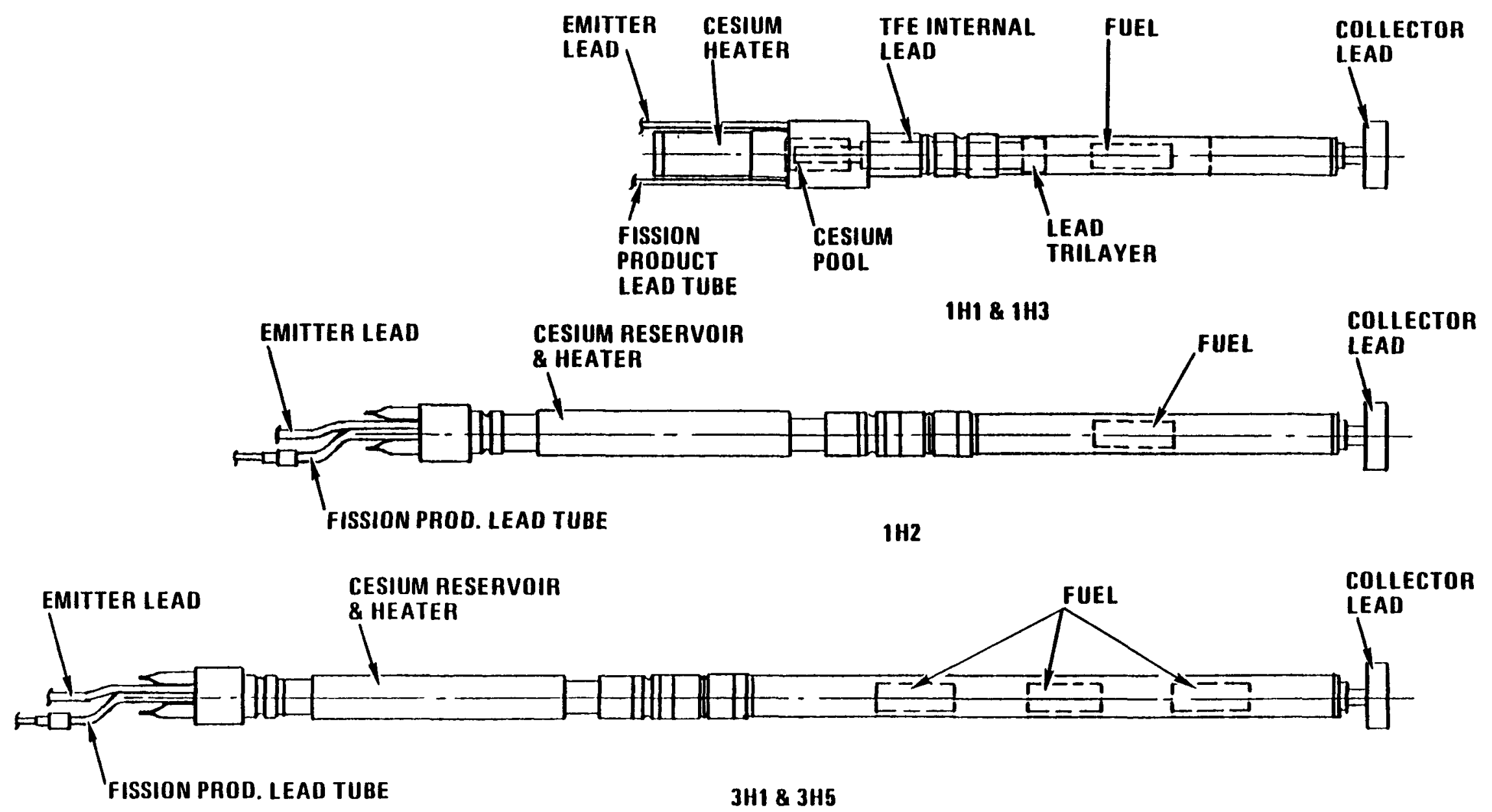

Figure 8-2. TFEs for TRIGA test 


\subsubsection{TRIGA Facility}

The Mark F TRIGA reactor at General Atomics will be used for most TFE testing. TRIGA is a water-moderated pool-type research reactor. The Mark F includes a neutron radiography facility located within the reactor pool for periodic nondestructive diagnostic examinations of the TFE internals. A hot cell at the site provides capability for postirradiation examination.

The TRIGA typically operates at about $1.4 \mathrm{MW}(t)$. At this power level, the fast fluence is about $1 \times 10^{21}$ nvt (E>.1 Mev) per year.

\subsection{ENGINEERING AND HARDWARE DESIGN}

A significant step towards a more accurate data base and faster incorporation of drawing revisions was made by introduction of the computer aided design concept. The CAD system installed is Autocad, Version 11 . New drawings will be computer generated and old drawings will be converted to the CAD system as the schedule permits.

\subsubsection{Test Article Design for TFE-3H1 and $3 \mathrm{H} 5$}

The design of the test articles remained unchanged during the reporting period.

\subsubsection{Test Article Design for TFE-6H1/6H2}

The drawing tree for $6 \mathrm{H} 1$ has been converted to $\mathrm{CAD}$ and is being updated.

A significant portion of the design effort is being devoted to incorporating the additional length of the $6 \mathrm{H} \mathrm{TFE}$, in comparison with $1 \mathrm{H}$ and $3 \mathrm{H}$ devices, into the existing fabrication and processing facilities. Modifications to the TFE lead and exhaust tubulation structures are required. Critical path items have been released first. The locations for thermocouples, voltage probes and current probes have been identified. 


\subsubsection{Test Vehicle Design}

Changes required during the encapsulation of TFE 3 H 1 were immediately incorporated into the design of later capsules. For example, during the installation of the collector bus tube assembly into the primary containment housing assembly, it was found that the fillet weld joining the inner containment adaptor assembly and the primary containment housing assembly had caused enough weld shrinkage and distortion in the inner containment adaptor to prevent assembly. The minimum clearance of .003 between the two subassemblies was insufficient as shown in Fig. 8-3.

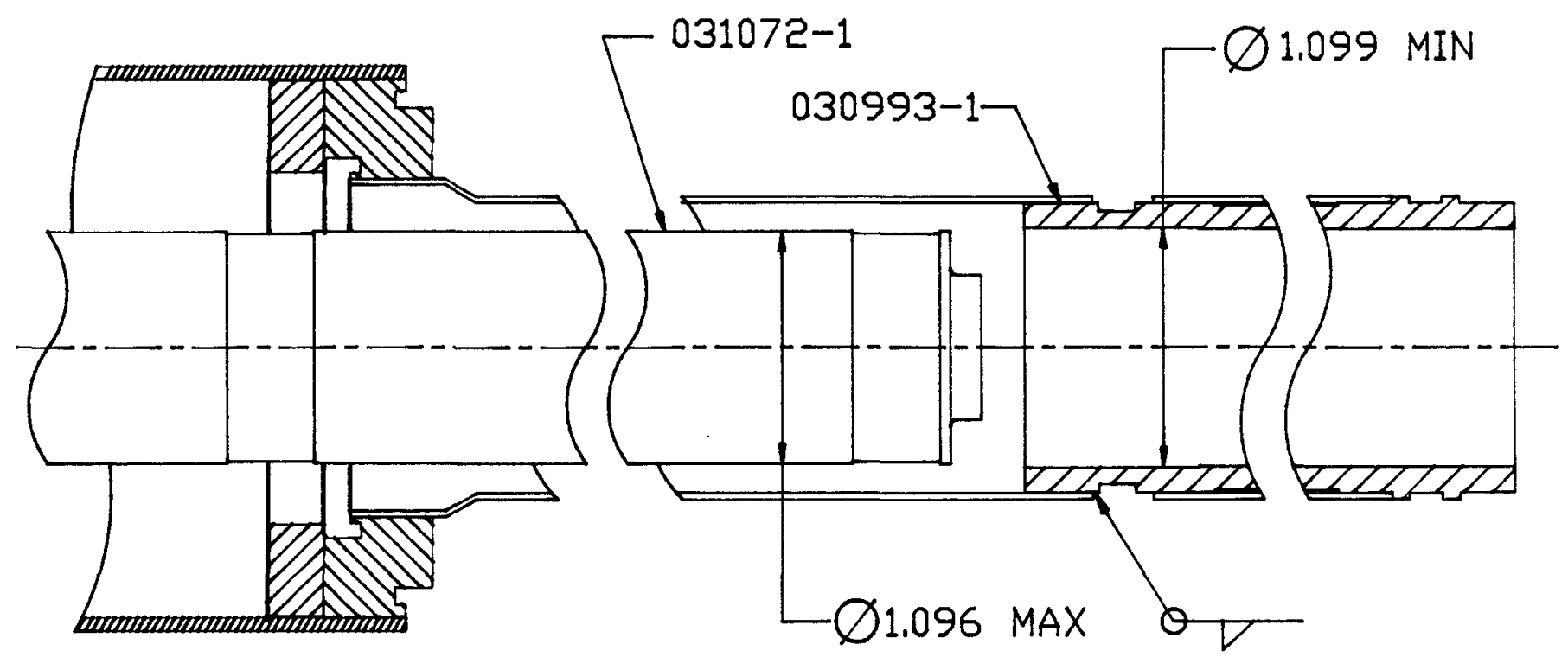

Figure 8-3. Interference due to weld distortion

It was necessary to grind off the weld and to machine a relief counterbore into the inner containment adapter. This counterbore was also immediately incorporated into the $3 \mathrm{H} 5$ and $6 \mathrm{H} 1$ design. The gap between the two subassemblies has to be held to a minimum, for it controls the waste heat transfer to the outside. 
The final assembly TFE model 3H TRIGA test has been released. This drawing defines the secondary containment with feedthroughs and vent lines and shows the routing of gas exchange lines, fission gas monitoring tubes and the location of the pressure gauges.

The capsule installation and plumbing diagram for $3 \mathrm{H}$ has been released. This drawing shows the installation in the TRIGA facility, the location of all pressure gauges, valves and tubing routing from the capsule to the console. In support of the installation effort a capsule piping schematic has been produced. See Fig. 8-4. This schematic shows the capsule, the fission gas monitoring system, the fission gas over pressure containment system, the heat transfer gas exchange system and the secondary containment pressure monitoring system.

\subsection{TFE FABRICATION}

TFE fabrication is based on an all welded TFE assembly to improve reliability and fabrication economy. Assembly of converters and TFEs in a clean room atmosphere is necessary to ensure that contamination of electrodes is minimized, and the effect of particulate contamination on subsequent fue 1 element degassing operations is eliminated. In order to provide for stable long term converter operation, bulk degassing is performed for machined components and subassemblies to remove sources of gas that could degrade TFE performance. Accurate rotary weld fixturing and electron beam welding techniques are specified for converter and TFE assembly operation to help control and minimize welding distortion from weld shrinkage. The electron beam welder chamber is installed as part of the clean room so that the benefits of clean room assembly extend to the assembly welding operations.

Final degassing and cesium loading of TFEs must be performed within an ultra high vacuum chamber utilizing all metal-to-metal seals and ion pumping to provide sensitive leak checking methods and vacuum safety should a power failure occur with the TFE at degassing temperature $\left(\sim 1250^{\circ} \mathrm{C}\right)$. 


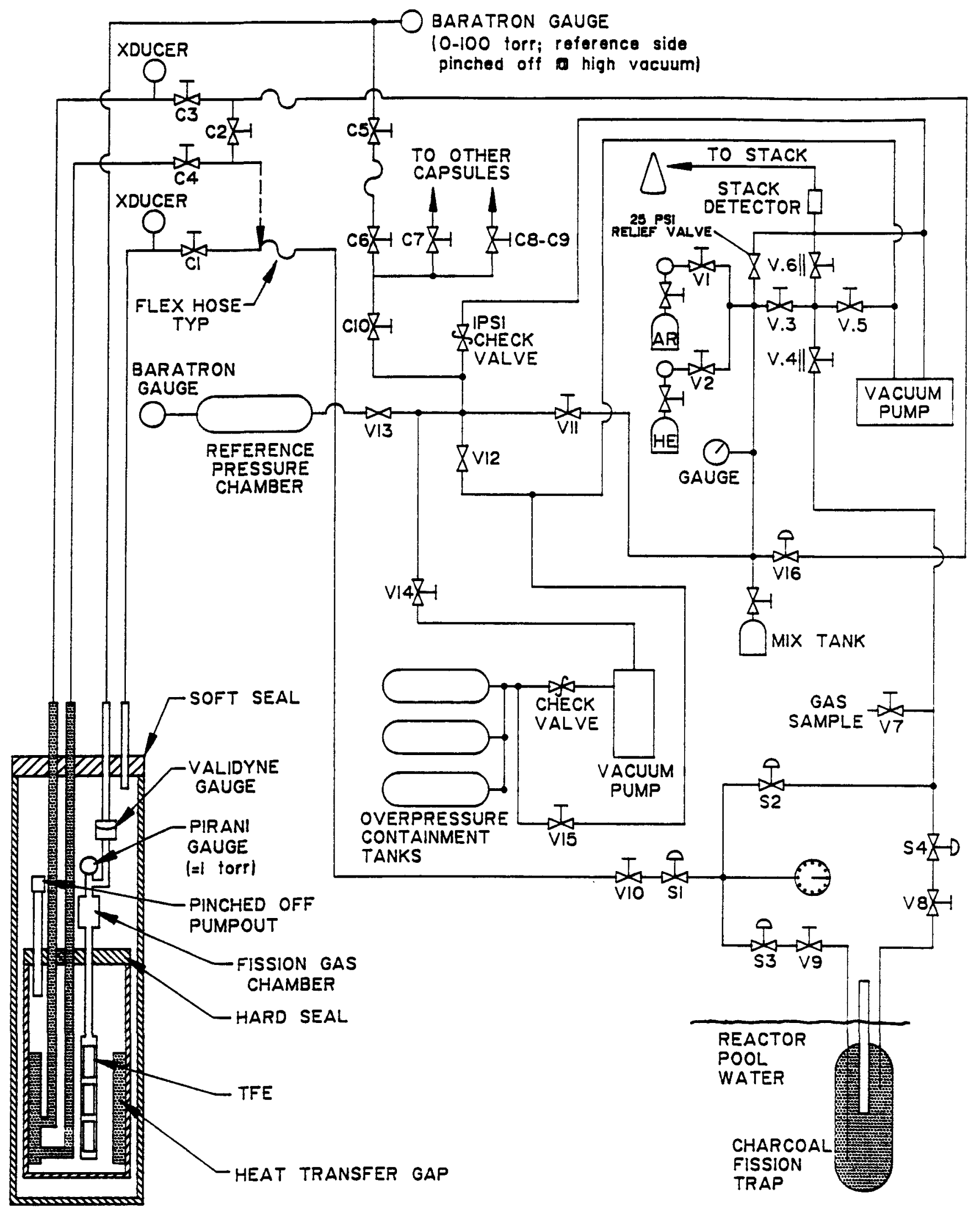

CAPSULE 3HI

Figure 8-4. Capsule piping schematic 
Impurities in test environments have contributed to rapid embrittlement and failure of TFE envelopes. An appropriate test environment for TFEs is within a static envelope filled with high purity inert gas. The test containment must be sealed by welding, and with ceramic-to-metal seals for power and instrumentation lead feedthroughs. It must be vacuum degassed to remove residual impurities before inert gas backfilling to provide the test environment.

A system of manufacturing controls incorporating detailed machine shop and assembly processing travelers is used. Materials, component and assembly procurement and processing specifications, and detailed scheduling methods are necessary to guide the fabrication effort. These systems were designed to comply with the Quality Assurance program applied to the overall program activity.

\subsubsection{Summary of Past Work}

TFE fabrication and fabrication development facilities were set up and fabrication process parameters and assembly sequences were established for planned TFEs. Work on process improvement and weld parameter qualification has continued as needs became apparent. These activities are described in detail in Refs. 8-1, 8-2, 8-3, 8-4, 8-5 and 8-6. Fabrication of an H-series mockup TFE was used to verify the selected processing methods.

Fabrication of H-series TFE components and subassemblies during earlier reporting periods included preparation of sintered, degassed and machined $\mathrm{UO}_{2}$ fuel forms for TFE's $1 \mathrm{H} 1,1 \mathrm{H} 2,1 \mathrm{H} 3,3 \mathrm{H} 1$ and $3 \mathrm{H} 5$. Isostatically processed graded trilayers, ceramic-to-metal seals, and tungsten tantalum emitter assemblies were prepared along with backup components and finish machined for these TFEs. Assembly of TFE's $1 \mathrm{H} 1,1 \mathrm{H} 2$ and $1 \mathrm{H} 3$ was accomplished, and the TFEs were installed into the primary and secondary containments and testing was initiated. For $3 \mathrm{H} 1$, containment detail work was completed for a majority of components, the notable exception being details associated with collector heat rejection and fission gas pressure measurement. 
Fabrication of TFE $3 \mathrm{H} 1$ proceeded to completion of the TFE through sheath tube bonding, final processing and electrical testing. Installation of the TFE into its primary containment was initiated. Component fabrication for TFEs $3 \mathrm{H} 5$ and $6 \mathrm{H} 1$ was initiated, however, an emitter machining problem caused delays until it could be resolved.

\subsubsection{H-Series Fabrication}

Fabrication efforts were directed towards TFEs $3 \mathrm{H} 1,3 \mathrm{H} 5$ and $6 \mathrm{H} 1$ this reporting period. Component status is shown on Table 8-4.

TFE 3H1. Primary encapsulation of this TFE was completed and installation into the secondary containment was initiated with the objective of completing preparation for testing by early May 1991.

Prior to installation on the TFE, the collector bus tube required rework at both TTC and GA for the rigors of shipping ( $>50 \mathrm{~g}$ loads were transmitted into the foam lined shipping container) caused distortion of the bus. Once the lead was successfully straightened, it was installed over the TFE and welded into position, and all heater wire leads were brazed at locations where they passed through the primary penetration assembly. Positioning of the primary containment gas gap fill tubulation through the lead caused considerable difficulty because of tight fits and a slight misalignment of the holes in the lead with the primary penetration assembly insulator positions.

A trial fitup of the primary containment showed the need for rework of weld shrinkage not allowed for in the original design. With rework accomplished, the containment was used to finally position the gas fill tubulation for brazing into the primary penetration assembly. Lead degassing and tube brazing was accomplished and the primary containment gas gap assembly and .060 inch diameter gas fill tubulation details once the tubulation fittings of the containment were welded to the fittings of the tubes installed through the collector lead. Figure 8-5 also shows the weld preparation where the pumpout tubulation was attached. Degassing of the containment was accomplished using ion pumping, and the assembly was leak 
TABLE $8-5$

CELL AND TFE FABRICATION STATUS SUMMARY THROUGH MARCH 31, 1991

$\begin{array}{lllllllllllllllllllllllllllllllll}\text { CELLS }: & 1 & 2 & 3 & 4 & 5 & 6 & 7 & 8 & 9 & 10 & 11 & 12 & 13 & 14 & 15 & 16 & 17 & 18 & 19 & 20 & 21 & 22 & 23 & 24 & 25 & 26 & 27\end{array}$

Major Cel1 Components

Fluoride deposited emitter

Chloride deposited emitter

Emitter transition

Fuel

Trilayer

Ceramic-to-metal seals

$\begin{array}{lll}\mathrm{C} & \mathrm{C} & \mathrm{C} \\ \mathrm{C} & \mathrm{C} & \mathrm{C} \\ \mathrm{C} & \mathrm{C} & \mathrm{C} \\ \mathrm{C} & \mathrm{C} & \mathrm{C} \\ \mathrm{C} & \mathrm{C} & \mathrm{C} \\ \mathrm{C} & \mathrm{C} & \mathrm{C}\end{array}$

$\mathrm{C} C \mathrm{C} \quad \mathrm{C} C \mathrm{C}$

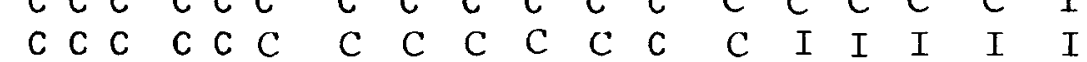

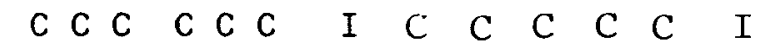

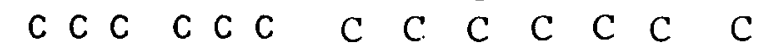

Subassemblies

Fueled emitter

Cell assembly

Emitter lead assembly

Cesium reservoir assembly

\begin{tabular}{|c|c|c|c|c|c|c|c|c|c|}
\hline \multirow{5}{*}{ TFE : } & C & C & C & $C \mathrm{C} C$ & $\mathrm{C} C \mathrm{C}$ & $\mathrm{C}$ & C & $\mathrm{C}$ & $\mathrm{C}$ \\
\hline & C & C & C & $\mathrm{C} C \mathrm{C}$ & $\mathrm{C} C \mathrm{C}$ & $I$ & $I$ & $I$ & $I$ \\
\hline & $1 \mathrm{H} 1$ & $1 \mathrm{H} 2$ & $1 \mathrm{H} 3$ & $3 \mathrm{H} 1$ & $3 \mathrm{H} 5$ & & & & \\
\hline & C & $\mathrm{C}$ & C & C & $\mathrm{C}$ & & & & \\
\hline & C & C & C & C & C & & & & \\
\hline
\end{tabular}

$6 \mathrm{H} 2$

TFE Assembly

Cells welded

Sheath tube welded

$\begin{array}{lllll}C & C & C & C & I \\ C & C & C & C & \end{array}$

TFE Final Processing

Instrumentation

Bonding complete

$\begin{array}{llll}C & C & C & C \\ C & C & C & C\end{array}$

Test Containment

\section{Primary penetration}

Containment housings

Primary encapsulation complete

Secondary encapsulation complete $C$

$\begin{array}{llll}C & C & C & C \\ C & C & C & C \\ C & C & C & C \\ C & C & C & I\end{array}$

Begin Testing

$\begin{array}{lllll}9 / 88 & 3 / 90 & 8 / 89 & 1 / 91 & 9 / 91\end{array}$

$2 / 92$

TBD

TBD

Legend: C - Complete 


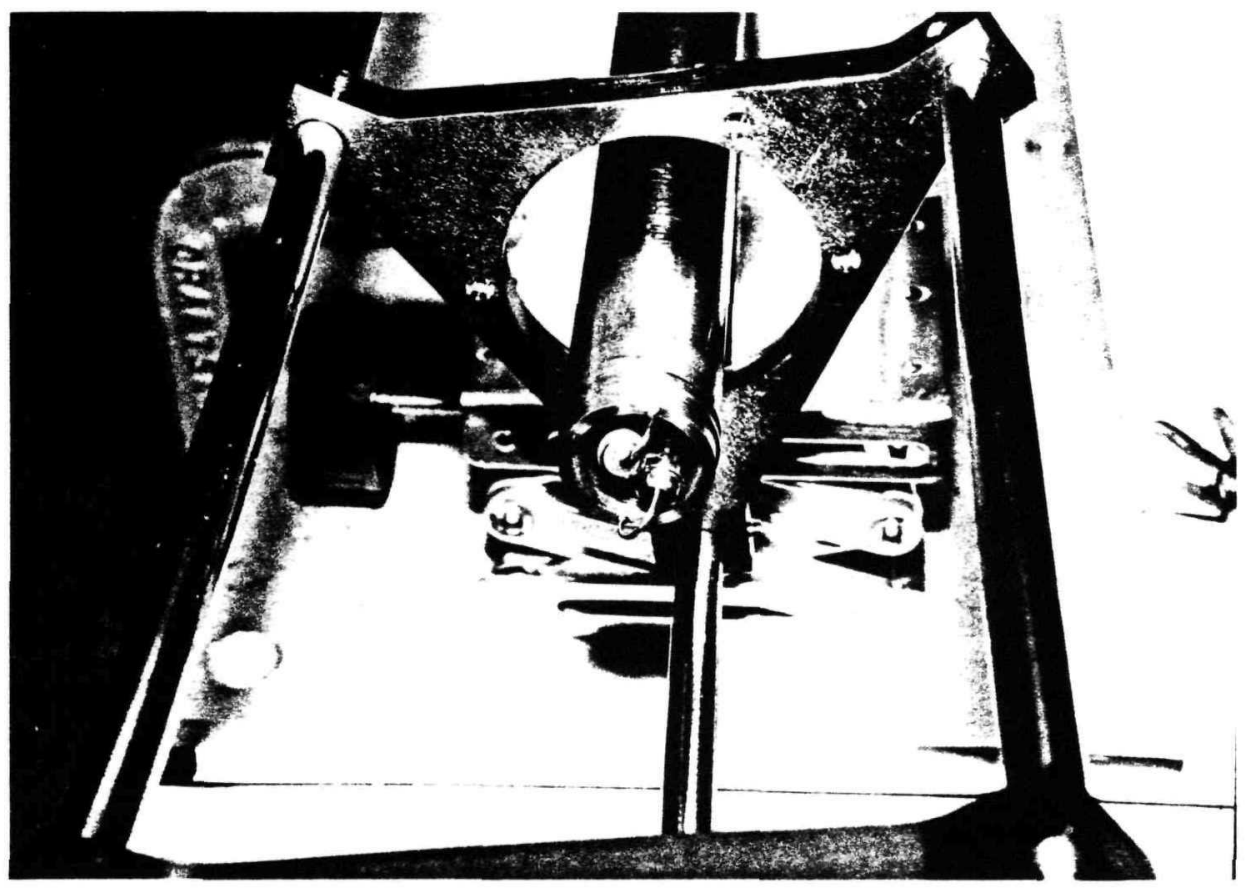

Figure 8-5. View of lower end of 3H1 primary containment assembly. Gas gap fill tubulation and fittings are visible.

checked, backfilled with $200 \mathrm{~mm}$ Hg of ultra high purity helium and pinched off to complete the primary containment process.

A11 required subassemblies for the secondary containment and fission gas pressure monitoring gauging and tubulation were completed by TTC and delivered to GA for use.

Initiation of the secondary containment process included extension of the heater wire leads. The upper end of the primary containment assembly showing the primary penetration assembly insulators and leads can be seen in Fig. 8-6 supported by the secondary containment fixturing.

TFE-3H5. Electropolishing of all emitters for the converters of this TFE was completed and fuel loading and emitter cap machining was accomplished. Figure 8-7 illustrates the emitter internal components and the associated emitter for one of the converters. Cell assembly welding was followed by repair welding to correct small amounts of misalignment using techniques worked out during the fabrication of TFE $3 \mathrm{H} 1$. The three converters and the dummy cell can be seen in Fig. 8-8a. Figure 8-8b provides a closeup view of the one of the converters shown in Fig. 8-8a. Figure 8-8c of the dummy cell, 


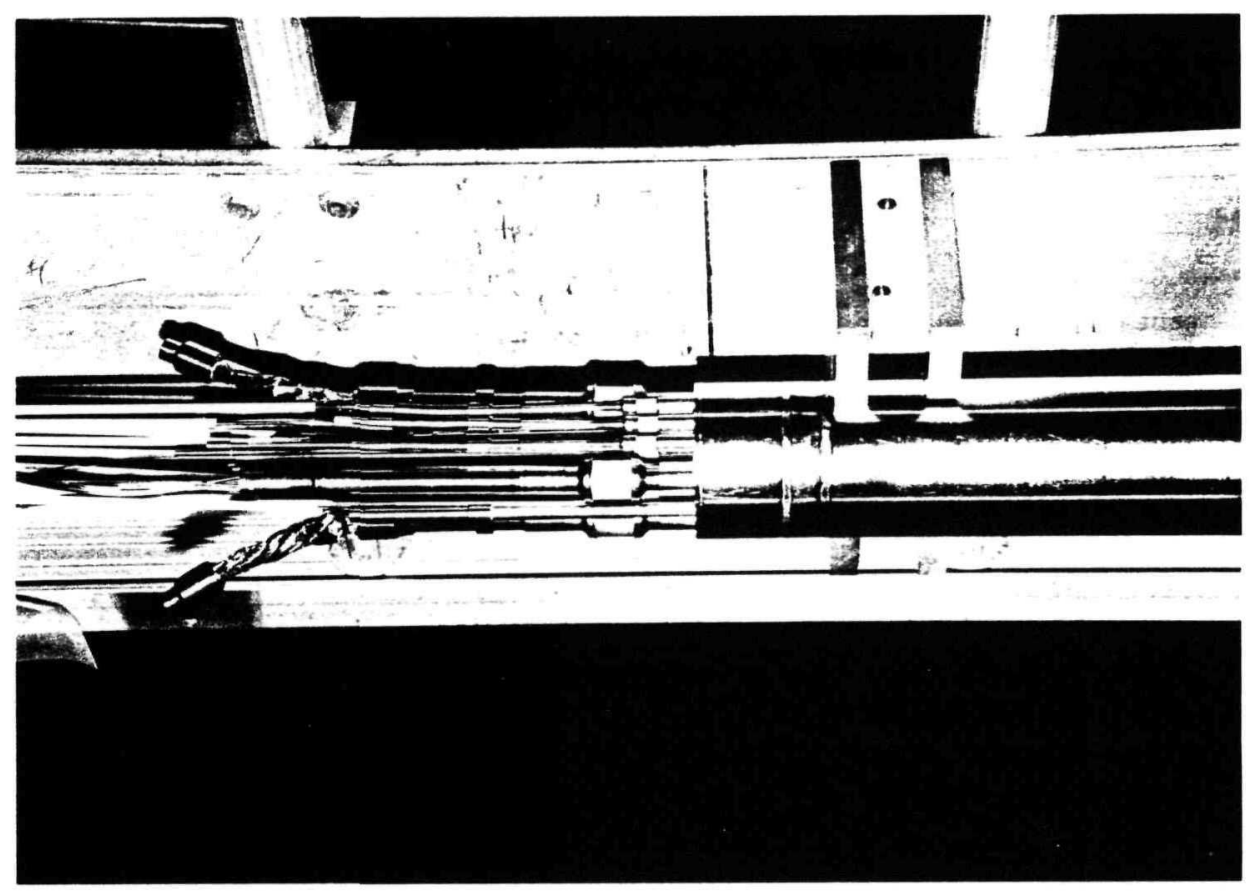

Figure 8-6. Upper end of $3 \mathrm{H} 1$ primary containment assembly. The primary penetration assembly insulators are visible.

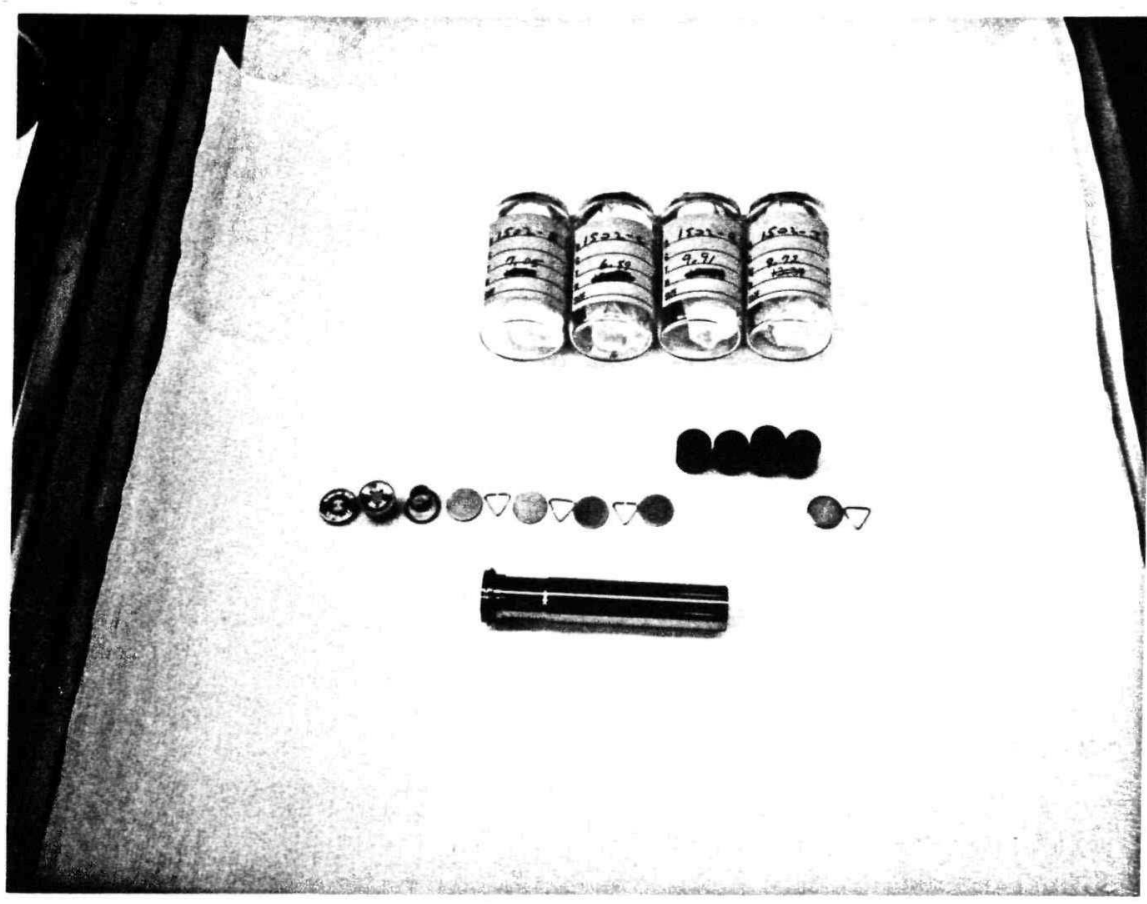

Figure 8-7. Components for emitter fuel loading. The emitter cap is on the far left with fission product trap, fuel holddown spring, heat shields, fuel pellets and fuel support plate arranged to its right. 

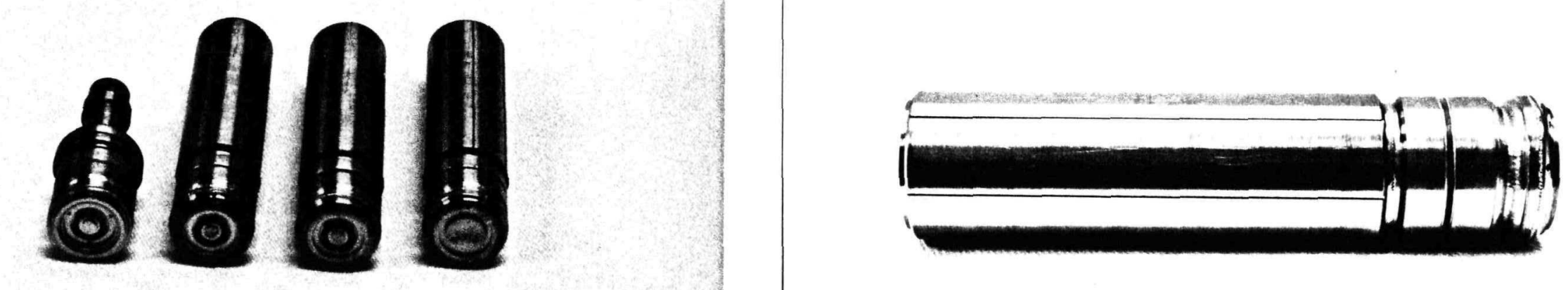

$\because$

Figure 8-8. Converters and Dummy

$8-8 a$

Cell for TFE-3H5

A. Three converters and dummy cell

B. Closeup of converter

Note: OD of collector is .651 in.

c. Dummy cell showing emitter alignment insulator

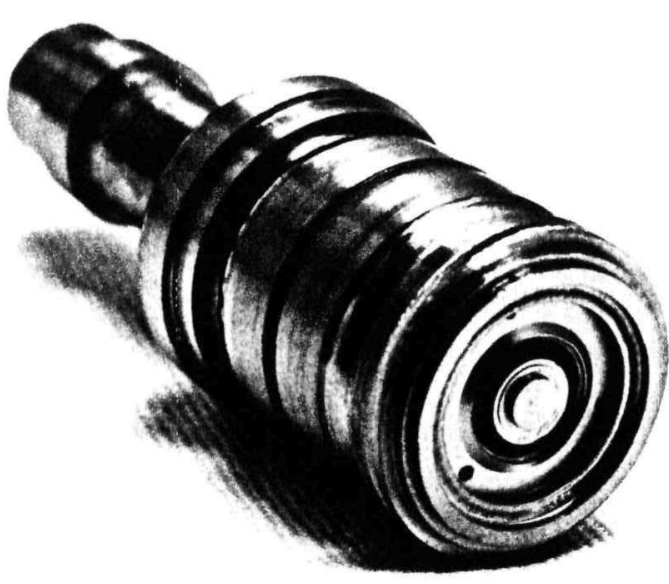


shows the emitter alignment insulator structure used in all emitter caps except for the cell adjacent the emitter lead where an insulated cap would serve no purpose. Emitter alignment device machining was performed to fit the devices into the spaces between emitters for cell-to-cell assembly welding.

Cell-to-cell and dummy cell, and TFE-to-electric lead welding was accomplished. Some misalignment was experienced that will be corrected next reporting period to prepare the assembly for installation into the sheath tube.

Components for the primary containment for this TFE are in work and reflect the experience of assembly in TFE $3 \mathrm{H} 1$. This includes completion of the primary penetration assembly and initiation of machining and assembly work for the collector bus assembly at TTC. Other TFE components were assembled at TTC and degassed at GA, including the cesium reservoir heater assembly and the lead and lead cap assemblies.

Work planned for the next period includes completion of TFE assembly and final processing, and the initiation of the primary encapsulation process.

TFE 6H1. All of the emitters for this TFE were deposited, preliminarily machined, and diffusion bonded to tantalum transition pieces at GA and finish machined at TTC. Degassing and electropolishing was performed at GA, and fuel loading was accomplished for five of the six emitters.

Fuel to correct enrichment and oxygen-to-uranium ratio for this TFE was produced using a die set with a central pin to create a hole through the center of the pellets. The die set was tested with good success using depleted uranium oxide to produce test pellets that showed that machining of the central hole would no longer be necessary. Pellets of one enrichment were flawed so that only one fuel loading could be produced, rather than the two needed. An additional batch of fuel was prepared, with appropriate modification to the pressing cycle to prevent cracking, in order to satisfy the requirement for the remaining emitter. A large enough batch of pellets were produced so that the requirement for TFE $6 \mathrm{H} 2$ could be met in addition to that for TFE $6 \mathrm{H} 1$. 
Four of the five fuel loaded emitters were machined to permit cell assembly and assembly welding of the four cells was accomplished. Figure 8-9 shows the appearance of these converters. Inspections of the four completed cells showed that some electrode misalignment requires correction. This work is scheduled for April 1991.

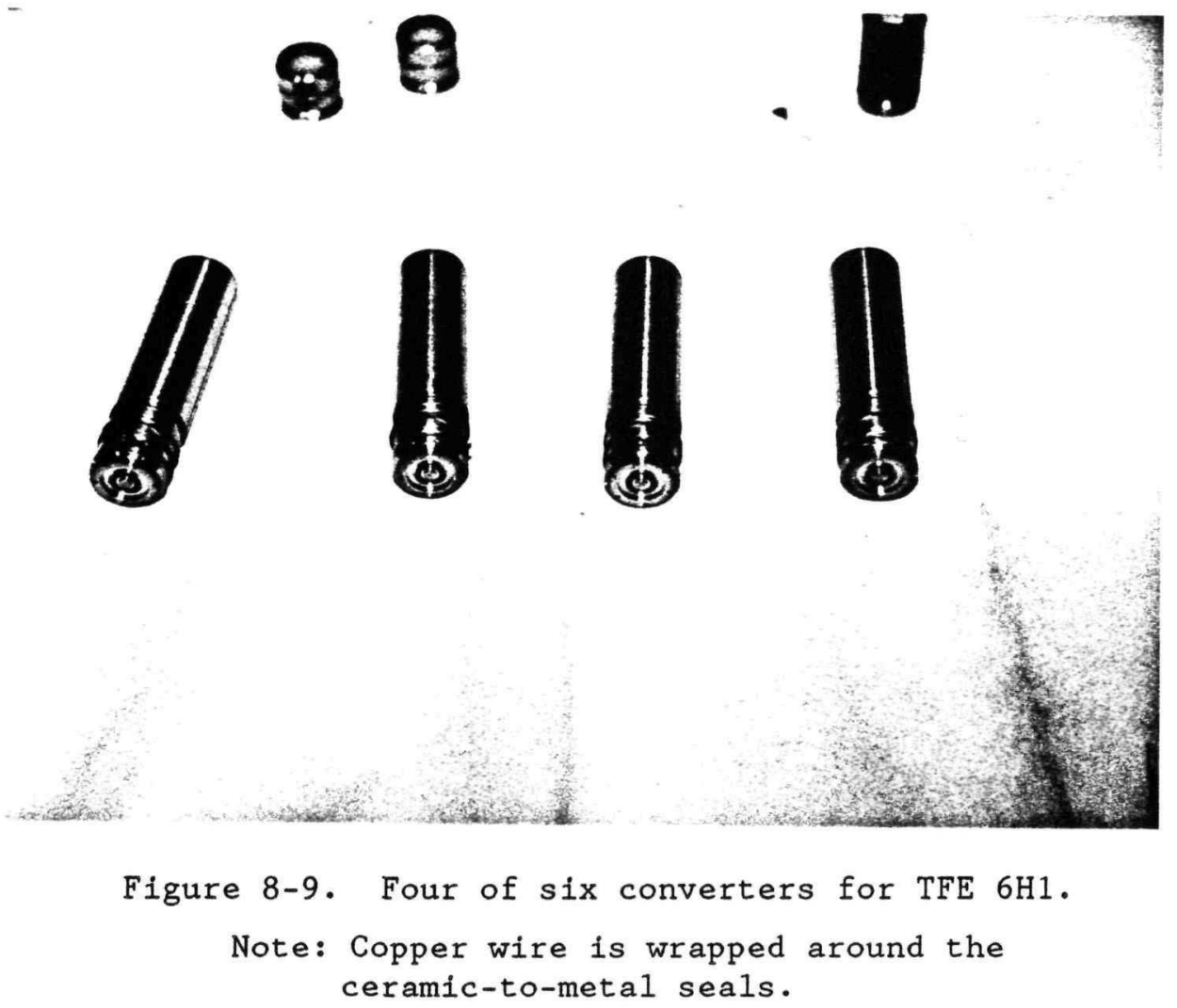

Components for parts of the TFE other than the converters were in work at TTC. These include the cesium reservoir heater, emitter lead assembly, lead sheath components and the sheath tube and holder.

TFE 6H2. Cell components for this TFE are in work in various stages of completion. Components for the ceramic-to-metal seals are in the assembly process, and emitters have been deposited-machining and bonding are in work. Fuel of the three enrichments required was pressed and sintered and has been characterized for enrichment and chemical analysis. Fabrication of other components awaits further design definition. 


\subsection{TFE OPERATING EXPERIENCE}

Irradiation testing of $1 \mathrm{H} 1,1 \mathrm{H} 2$ and $1 \mathrm{H} 3$ continued during this reporting period. Table 8-5 summarizes the events that occurred. The operating characteristics of the three TFEs are summarized in Table 8-6. The last row of the table shows the converter electrode voltage calculated using TECMDL for the cell parameters listed earlier in the table. For $1 \mathrm{H} 1$ and $1 \mathrm{H} 3$, the operating point is sufficiently far from the knee in the $I-V$ curve that TECMDL calculates a voltage about $10 \%$ high. In addition, neither of the estimates in the last row of Table 8-6 account for the presence of resistive elements in the TFE, and for this reason the cell voltages in the last row should be compared with those in the row immediately above, and not with the uncorrected TFE voltage.

TABLE $8-5$

IRRADIATION TESTING EVENTS - OCTOBER 1990 THROUGH MARCH 1991

10-30- Varfed reactor power slightly to perform diagnostics tests on $1 \mathrm{H} 1$ $11-7-90$

12-10-90 Scram due to radiation monitor shorting during calibration. Changed $1 \mathrm{H} 1$ and $1 \mathrm{H} 2$ driving power supplies while down.

12-12-90 Lowered reactor power down to $200 \mathrm{~kW}$ to change $1 \mathrm{H} 1$ and $1 \mathrm{H} 2$ driving power supplies back

12-21-90 Holiday shutdown

1-4-91 1 H 1 removed from core

1-13-91 Reactor backup delayed by UPS (Uninterruptible Power Supply) problems

1-14-91 Scram due to UPS malfunction

1-16-91 Back to full power

1-17-91 Scram due to UPS testing

1-23-91 Back to full power - UPS removed from circuit

2-5-91 5 cram @ 0040 hours due to SDG\&E grid power fluctuation. Back at ful1 power @ 0919 hours.

2-18-91 Scram a 0025 hours due to SDG\&E grid power fluctuation. Back at full power a 0916 hours.

2-22-91 Short shutdown to put new UPS into system.

2-23-91 Scram @ 0200 hours due to grid power fluctuation caused by lightening storms. Returned to full power a 1344 hours. 
TABLE $8-6$

IRRADIATION STATUS OF H-SERIES TFES AS OF 3-1-91

$\begin{array}{lrrr} & \underline{\mathrm{H} 1} & \underline{\mathrm{H} 2} & \underline{1 \mathrm{H} 3} \\ \text { Irradiation time, hours } & 17166 & 6900 & 11289 \\ \text { Emitter temperature, K } & 1720 & 1800 & 1780 \\ \text { Collector temperature, K } & 1166 & 1065 & 1038 \\ \text { Current density, amps } / \mathrm{cm}^{2} & 3.9 & 6.4 & 3.3 \\ \text { Cesium pressure, tor } & 3.2 & 3.8 & 4.1 \\ \text { Measured TFE voltage corrected } & & & \\ \quad \text { for appropriate series of } & & & .56 \\ \quad \text { resistance, volts } & -.78 & .47 & 0.58 \\ \text { Cell voltage from TECMDL, } & 0.27 & 0.51 & \\ \quad \text { volts } & & & \\ \end{array}$

\subsection{1 $\underline{\mathrm{TFE}-1 \mathrm{H} 1}$}

Background. The abnormal output of TFE-1H1 was described in detail in Ref. 8-1. TFE circuit analysis showed a voltage offset was necessary to explain diagnostic measurements. Possible causes of a voltage offset were discussed: collector work function changes, fission product gases in the interelectrode space, emitter swelling and cesium reservoir effects. Instrumentation problems could also contribute to the observed data. It was concluded in Ref. 8-1 that while the behavior of $1 \mathrm{Hl}$ remained thermionic, its continued testing was prejudiced by the uncertainty in emitter temperature that results from possible ambiguities in the accessible diagnostics.

Recent evaluations. An extensive review of the data from TFE-1HI was held in November, 1990, and the conclusion given in Ref. 8-1 was reaffirmed. While $1 \mathrm{H} 1$ remained a functional thermionic converter in the power quadrant, the uncertainty in the output data reduced its value and warranted removing the capsule from the reactor core. 
TFE-1H1 irradiation was stopped on 12-21-90 and was removed from the reactor in early January, 1991 during the Christmas shutdown. Total irradiation time at removal was 17,166 hours.

Early history of TFE-1H1. The diagnostic uncertainty noted above is believed to be linked to incidents which occurred early in the life of $1 \mathrm{H} 1$. One of the sheath insulators was damaged during weIding of the secondary containment. It was a redundant insulator, however, and since the thermionic fuel element electrodes remained isolated, the containment was finished with the damaged insulator in place.

During the initial startup in TRIGA, cesium pressure was lost on two occasions due to an inadvertent drop in reservoir temperature. With the loss of electron cooling the emitter temperature increased. During one of these events, the driving power supply increased its output in an attempt to maintain a constant current density from the emitter. As a result, the emitter temperature rose to as high as $2300 \mathrm{~K}$ before the incident was recognized and corrected. Concurrently, the driving power supply produced a $600 \mathrm{~W}$ arc which was sustained for several tens of seconds. The power supply which caused this arc is a diagnostic tool used in test converters to produce IV curves and would not be used in production TI power systems. Fabrication and testing procedures were changed to preclude further incidents of this type.

In the second event, the emitter temperature increased significantly, again for tens of seconds, but there was no arc.

After these incidents, data obtained through instrumentation leads indicated the creation of an additional parallel resistance path across the diode. After accounting for this parallel resistance, good IV curves were obtained and good data continued to be produced through the year 1989 and most of 1990 .

Neutron radiographs. Neutron radiographs of TFE-1H1 were taken at about 14,000 hours with results shown in Fig. 8-10. Peak radial deformation is less than .002 inches, or less than $0.8 \%$. These data are being analyzed with the LIFE-4 code. 


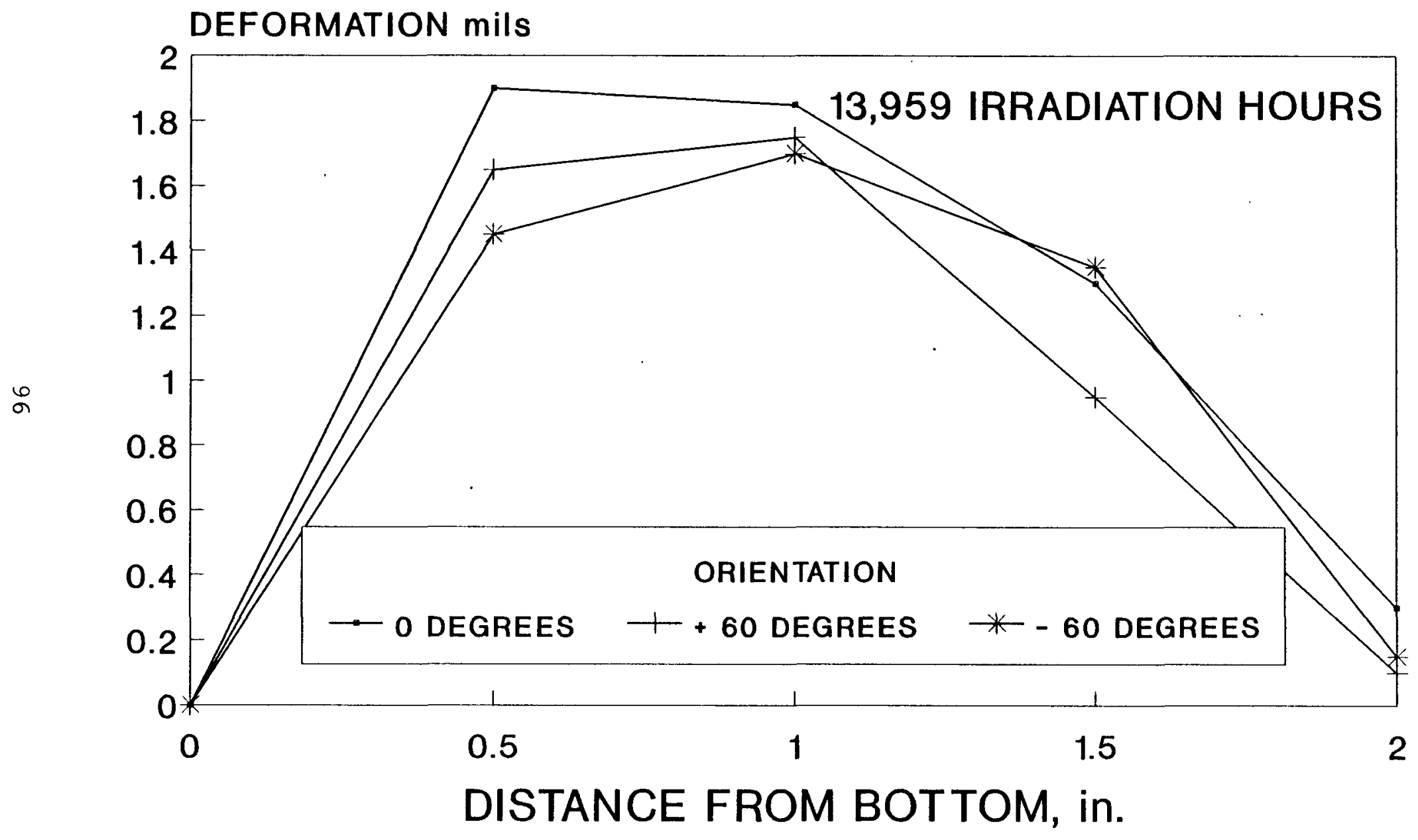

Figure 8-10. $1 \mathrm{Hl}$ Radial Deformation 
Future plans. A PIE plan is being prepared, and it is anticipated that early in FY-92 the TFE-1H1 will be disassembled in the GA hot cell for visual and physical measurements and gamma scans. The cell will then be shipped to WHC for metallography and microprobe analyses.

\subsubsection{TFE-1H2 and TFE-1H3}

Testing of TFE's $1 \mathrm{H} 2$ and $1 \mathrm{H} 3$ continued with stable performance and without significant events through the reporting period.

An analysis of the most recent neutron radiographs showed that emitter distortion was sma11:

- TFE-1H2: <0.001" radia1 distortion @ 2829 hours

- TFE-1H3: <0.0015" radial distortion @ 7217 hours.

The axial deformation for TFE-1H3 is shown on Fig. 8-11. No correlations have been attempted with IIFE- 4 code at this early stage. 


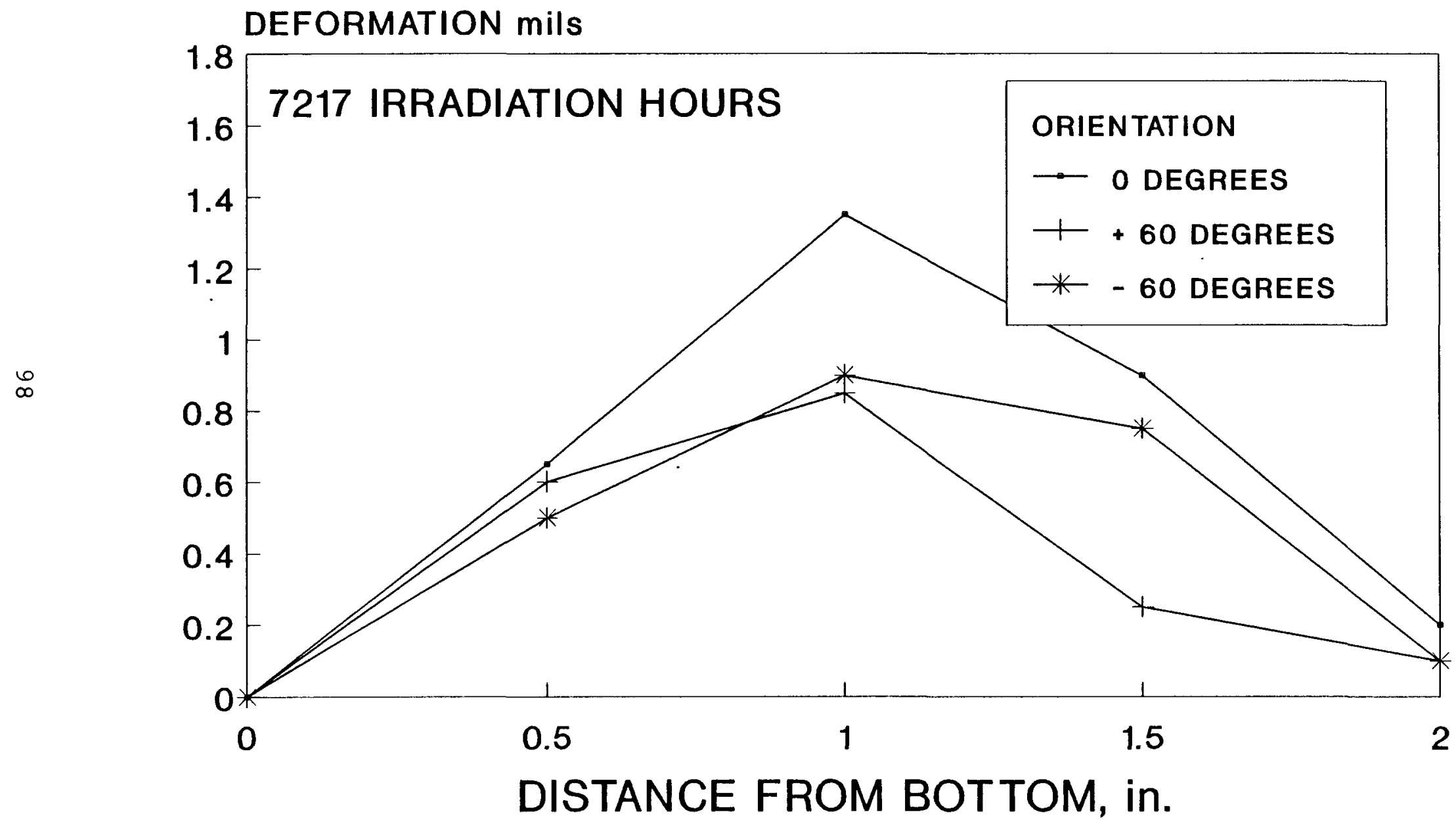

Figure 8-11. 1H3 Radial Deformation 


\section{References}

8-1 TFE Verification Program Semiannual Report for the Period Ending September 30, 1990, GA-A20335, January 1991.

8-2 TFE Verification Program Semiannual Report for the Period Ending March 31, 1990, GA-A20119, July 1990.

8-3 TFE Verification Program Semiannual Report for the Period Ending October 31, 1988, GA-A19412, January 1989.

8-4 TFE Verification Program Semiannual Report for the Period Ending September 30, 1989, GA-A19876, March 1990.

8-5 TFE Verification Program Semiannual Report for the Period Ending September 30, 1987, GA-A19115, March 1988.

8-6 TFE Verification Program Semiannual Report for the Period Ending April 30, 1988, GA-A19269, June 1988.

8-7 1H1 Electrical Lead Voltages and Errors in Electrical Output, J. W. Holland, TFE Verification Program Document 909794, December 1988.

8-8 Makenas, B. J., L. A. Lawrence and L. M. McWethy, Interim Examinations of UFAC-1 and UFAC-2 Fueled Emitters, Westinghouse Hanford Company, WHC-SP-0519, Apr11 1990.

8-9 Shimada, K., Out-of-Core Evaluations of a Nonfueled and a $\mathrm{UO}_{2}$ Fueled Cylindrical Thermionic Converter, Thermionic Conversion Specialists Conference, October 1971, San Diego, CA.

8-10 Baksht, F. G., et al., Thermionic Converters and Low-Temperature Plasma, English Translation by L. K. Hansen, USDOE, 1978.

8-11 Rasor, N. S. and C. Warner, J. Appl. Phys., 2589, 35 (1964). 
References

8-12 Thermionic Technology Program Final Report B: Thermionic Converter Performance, Rasor Associates, Inc. Report NSW-25-25, E-533-003-B053188, Apri1 30, 1988.

8-13 Rufeh, F. and s. S. Kitrilakis, Thermionic Converter Performance in the Presence of Inert Gases, Thermionic Conversion Specialists Conference, 1966.

8-14 SP-100 Thermionic Technology Program Annual Report,GA-A18182, November 1985. 